ORNL/TM-2014/553

\title{
Definition of Capabilities Needed for a Single Event Effects Test Facility
}

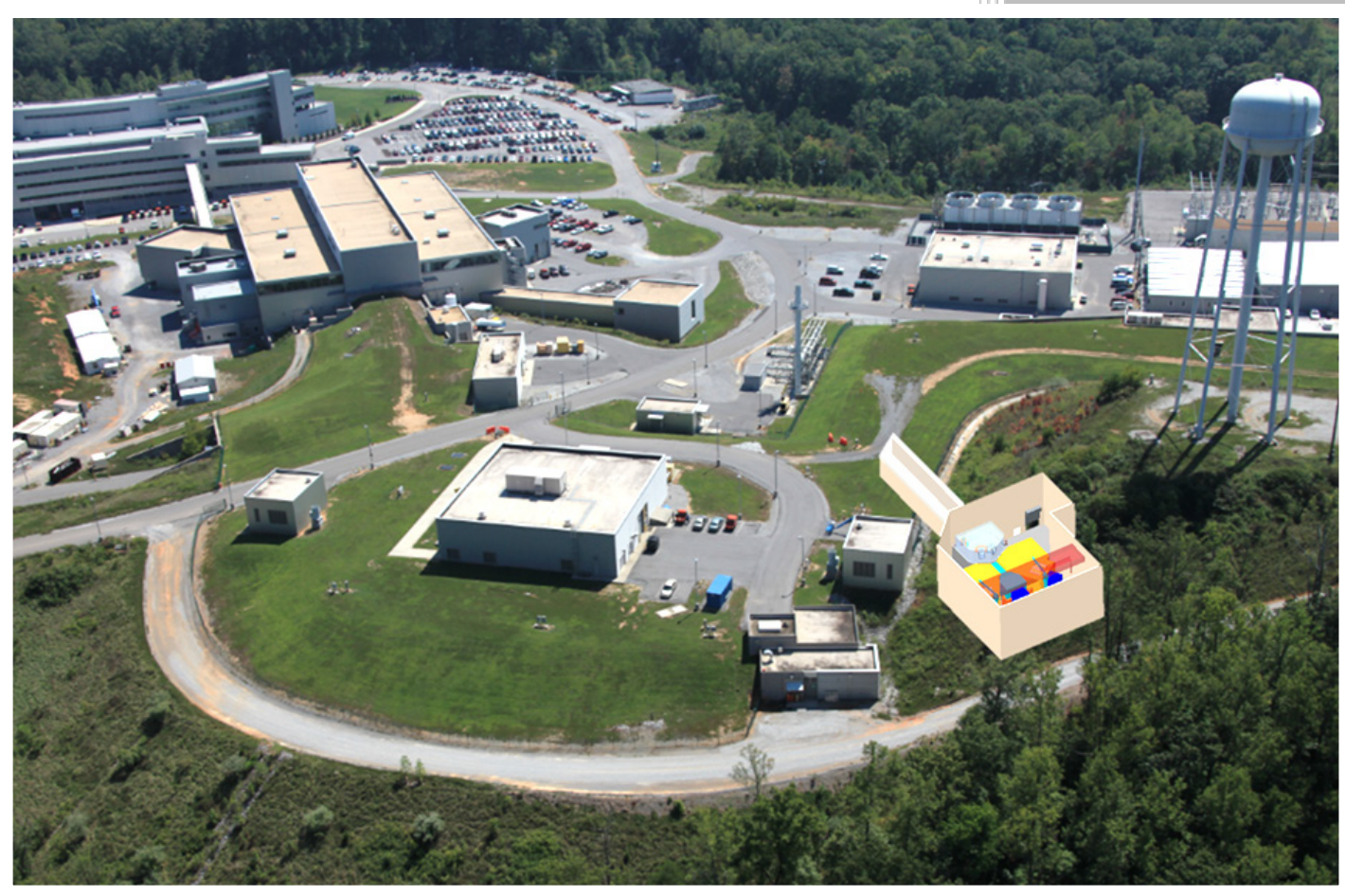

Approved for public release. Distribution is unlimited.
B. W. Riemer

F. X. Gallmeier

December 5, 2014 


\section{DOCUMENT AVAILABILITY}

Reports produced after January 1, 1996, are generallyavailable free via US Department of Energy (DOE) SciTech Connect.

Website http://www.osti.gov/scitech/

Reports produced before January 1, 1996, may be purchased by members of the public from the following source:

National Technical Information Service

5285 Port Royal Road

Springfield, VA 22161

Telephone 703-605-6000 (1-800-553-6847)

TDD 703-487-4639

Fax 703-605-6900

E-mailinfo@ntis.gov

Website http://www.ntis.gov/help/ordermethods.aspx

Reports are available to DOE employees, DOE contractors, Energy Technology Data Exchange representatives, and International Nuclear Information System representatives from the following source:

Office of Scientific and Technical Information

PO Box 62

Oak Ridge, TN 37831

Telephone 865-576-8401

Fax 865-576-5728

E-mail reports@osti.gov

Website http://www.osti.gov/contact.html

This report was prepared as an account of work sponsored by an agency of the United States Government. Neither the United States Government nor any agency thereof, nor any of their employees, makes any warranty, express or implied, or assumes any legal liability or responsibility for the accuracy, completeness, or usefulness of any information, apparatus, product, or process disclosed, or represents that its use would not infringe privately owned rights. Reference herein to any specific commercial product, process, or service by trade name, trademark, manufacturer, or otherwise, does not necessarily constitute or imply its endorsement, recommendation, or favoring by the United States Government or any agency thereof. The views and opinions of authors expressed herein do not necessarily state or reflect those of the United States Government or any agency thereof. 
ORNL/TM-2014/553

Neutron Sciences Directorate

Instrument and Source Division

\title{
DEFINITION OF CAPABILITIES NEEDED FOR A SINGLE EVENT EFFECTS TEST FACILITY
}

\author{
Bernard W. Riemer \\ Franz X. Gallmeier
}

Date Published: December 5, 2014

Prepared by

OAK RIDGE NATIONAL LABORATORY

Oak Ridge, Tennessee 37831-6283

managed by

UT-BATTELLE, LLC

for the

US DEPARTMENT OF ENERGY

under contract DE-AC05-00OR22725 



\section{CONTENTS}

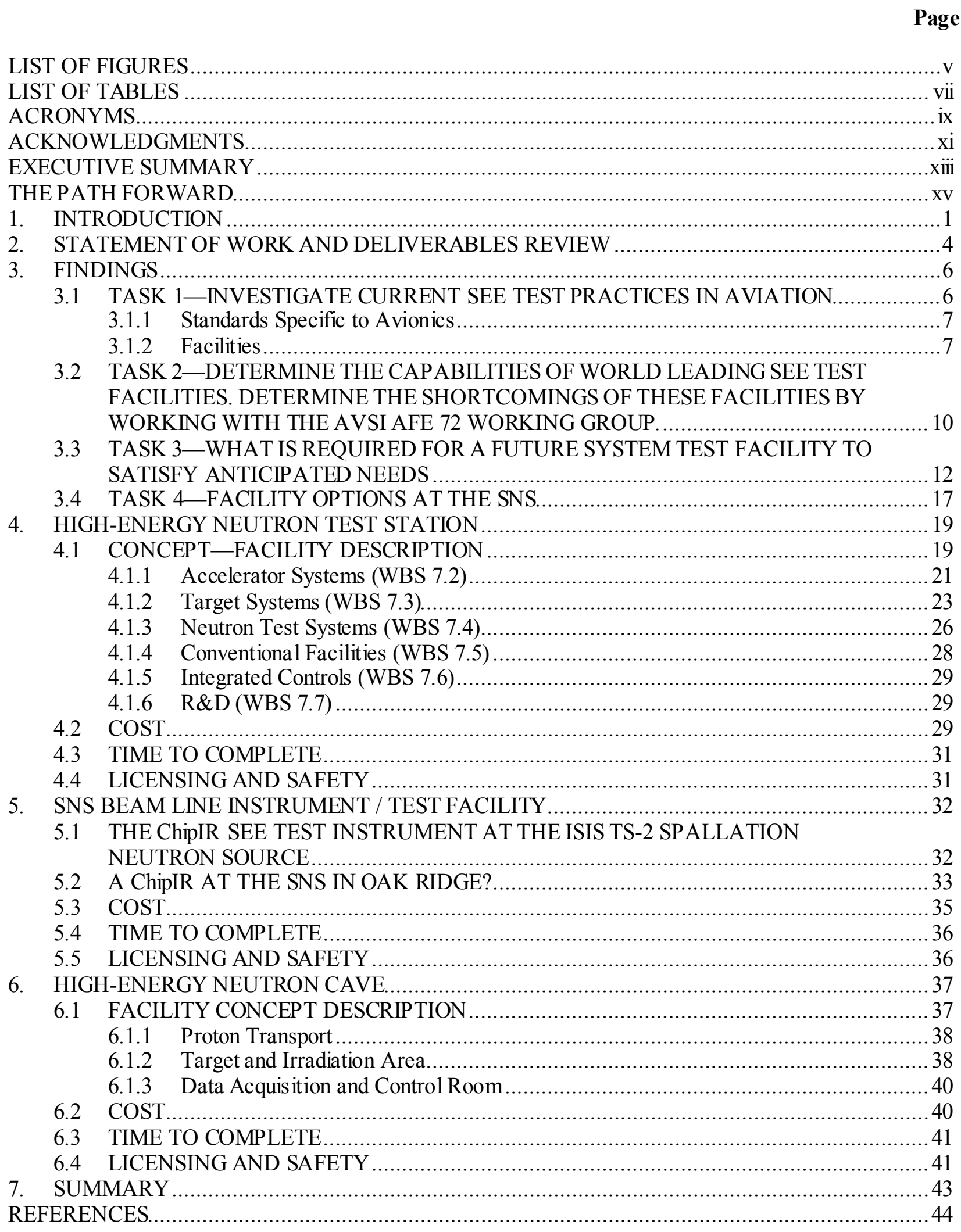


APPENDIX A. NOTES FROM REVIEW MEETING AT FAA WILLIAM J. HUGHES

TECHNICAL CENTER, ATLANTIC CITY, NJ, NOVEMBER 7, 2013 (B. RIEMER)............... 7-1 APPENDIX B. PRESENTATION "NEUTRON TEST FACILITY - INDUSTRY AND FAA

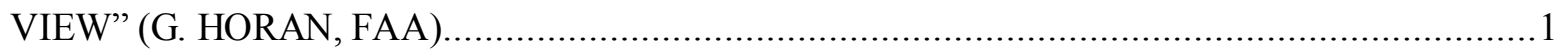




\section{LIST OF FIGURES}

Figure

Fig. 3-1. Energy spectrum of atmospheric neutrons at 40,000 ft (12,160 m), latitude $45^{\circ}$. Source: IEC Standard 62396-1.....

Fig. 3-2. Comparison of Los Alamos and TRIUMF neutron beam spectra with terrestrial spectrum. Source: JEDEC Standard No. 89A, Measurement and Reporting of Alpha Particle and Terrestrial Cosmic Ray-Induced Soft Errors in Semiconductor Devices, Arlington, Va., 2006.

Fig. 3-3. Circuit boards with components aligned for neutron irradiation at the ICE House. Source: L. Dominik, "Atmospheric Radiation Testing," Presentation at 2012 National User Facility Organization meeting, Los Alamos, N.M., June 2012.

Fig. 3-4. Comparison of neutron flux spectra for regular cosmic-ray and solar-flare enhanced conditions of January 7, 1997, and February 23, 1956. Sources: F. Lei et al., "Improvement to and Validations of the QinetiQ Atmospheric Radiation Model (QARM)," IEEE Transactions on Nuclear Science 53, No. 4, 1851, August 2006, and C. Dyer et al., "The QinetiQ Atmospheric Radiation Model and Solar Particle Events," presentation at the Third European Space Weather Week, Brussels, November 13-17, 2006.

Fig. 3-5. Angular neutron and proton emissions due to a proton beam of $1.0 \mathrm{GeV}$ energy and $1 \mathrm{~kW}$ power incident on a $5 \mathrm{~cm}$ diameter tungsten target compared with the Boeing model atmospheric neutron spectrum.

Fig. 3-6. Left: Angular neutron and particle emissions due to a proton beam of $1.0 \mathrm{GeV}$ energy and $1 \mathrm{~kW}$ power incident on a $5 \mathrm{~cm}$ diameter tungsten target. Right: Atmospheric particle spectra [reported by J. F. Ziegler and W. A. Lanford, "Effect of Cosmic Rays on Computer Memories," Science 206, No. 4420, 776 (November 16, 1979)]

Fig. 3-7. Neutron spectrum at $30^{\circ}$ from a $1 \mathrm{~kW} 1 \mathrm{GeV}$ proton beam incident on a bare tungsten target, from a $2.5 \mathrm{~cm}$ water slab at the tungsten target, and from a $2.5 \mathrm{~cm}$ water slab at a reflector surrounded by beryllium, to a $30 \mathrm{~cm}$ radius, at a tungsten target.

Fig. 3-8. High-energy neutron flux spectra at SNS beam line 8 at $9 \mathrm{~m}$ distance from the moderator compared to the Boeing model and a high-energy test station (HETS).....

Fig. 3-9. Beam transport to the RID, which is off to the right. The stripping foil equipment is behind the stairs; this is the highest dose rate region of the accelerator.

Fig. 4-1. CAD model of the High Energy neutron Test Station superimposed on an aerial photo of the Oak Ridge Spallation Neutron Source site........................................................ 19

Fig. 4-2. HETS target station layout. ................................................................................ 20

Fig. 4-3. HETS neutron spectra at the component and system test positions. ............................... 20

Fig. 4-4. HETS project work breakdown structure.............................................................. 21

Fig. 4-5. Location of beam extraction from main SNS H beam for HETS. .................................. 22

Fig. 4-6. Laser stripping and beam separation of the kilowatt-level beam sent to HETS...................... 22

Fig. 4-7. Tungsten target with annular flow gap.......................................................... 24

Fig. 4-8. Target axial heat distribution (left) and resulting tungsten centerline and outer surface temperatures (right), assuming $2.3 \mathrm{~kW}$ proton beam power incident on the tungsten

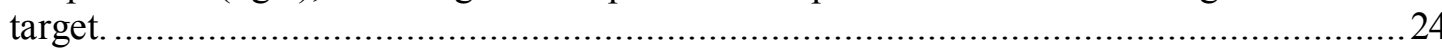

Fig. 4-9. Sectional views of HETS target monolith and test enclosures..................................... 27

Fig. 5-1. ChipIR at ISIS. Source: Drawing of ChipIR provided by Dr. Christopher Frost, Rutherford

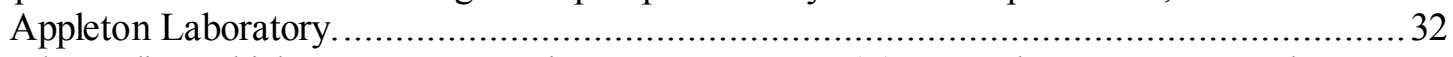

Fig. 5-2. SNS beam line 8 high energy neutron instrument concept (L); space between BL-7 and BL-9 as of July 2014 (R). 


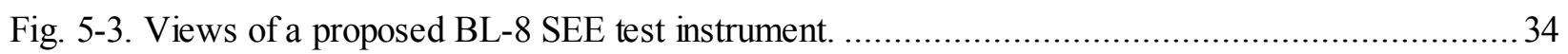

Fig. 6-1. HENC location on SNS site (L) and concept configuration (R).................................... 37

Fig. 6-2. Angular variation of neutron and proton emission spectra from a tungsten target powered

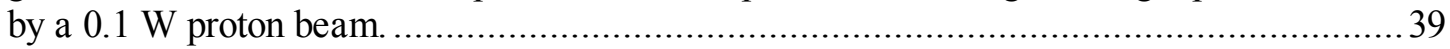

Fig. 6-3. HENC tunnel-cave facility plan (L) and isometric (R) sections....................................... 40 


\section{LIST OF TABLES}

\section{Table}

Page

Table 4-1. Beam-shaping components integrated into the high-energy beam line ..............................25

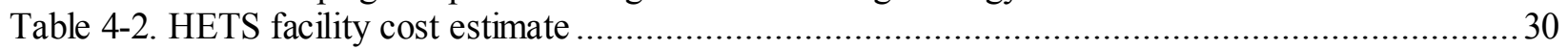

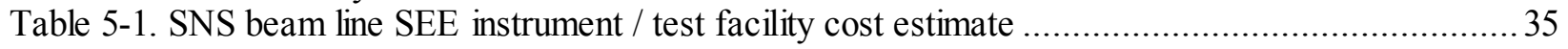

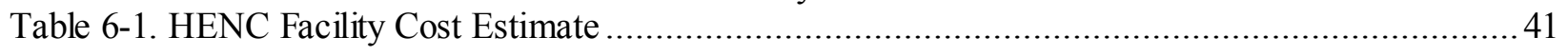





\section{ACRONYMS}

$\begin{array}{ll}\text { AFE } & \text { Authority for Expenditure } \\ \text { ALARA } & \text { as low as reasonably achievable } \\ \text { ALD } & \text { Associate Laboratory Director } \\ \text { ANITA } & \text { Atmospheric-like Neutrons from thIck TArget } \\ \text { AVSI } & \text { Aerospace Vehicle Systems Institute } \\ \text { BES } & \text { Basic Energy Sciences } \\ \text { BL-8 } & \text { beam line } 8 \\ \text { CAD } & \text { computer aided design } \\ \text { DAQ } & \text { data acquisition } \\ \text { DOE } & \text { US Department of Energy } \\ \text { DOE BES } & \text { Department of Energy Office of Basic Energy Sciences } \\ \text { EASA } & \text { European Aviation Safety Agency } \\ \text { EPICS } & \text { Experimental Physics and Industrial Control System } \\ \text { FAA } & \text { Federal Aviation Administration } \\ \text { FADEC } & \text { Full Authority Digital Engine Control } \\ \text { FSAD } & \text { Final Safety Assessment Document } \\ \text { FY } & \text { fiscal year } \\ \text { HE } & \text { high-energy } \\ \text { HEBT } & \text { High Energy Beam Transport } \\ \text { HENC } & \text { High-energy Neutron Cave } \\ \text { HETS } & \text { High Energy neutron Test Station } \\ \text { IC } & \text { integrated circuit } \\ \text { IEC } & \text { International Electrotechnical Commission } \\ \text { LANSCE } & \text { Los Alamos Neutron Science Center } \\ \text { MCNPX } & \text { Monte Carlo N-Particle Transport Code } \\ \text { NNSA } & \text { National Nuclear Security Administration } \\ \text { NScD } & \text { Neutron Sciences Directorate } \\ \text { NUFO } & \text { National User Facility Organization } \\ \text { ORNL } & \text { Oak Ridge National Laboratory } \\ \text { PE } & \text { polyethylene } \\ \text { PI } & \text { principal investigator } \\ \text { PPS } & \text { personnel protection system } \\ \text { QARM } & \text { QinetiQ Atmospheric Radiation Model } \\ \text { RCNP } & \text { Research Center for Nuclear Physics } \\ \text { RID } & \text { Ring Injection Dump } \\ \text { SEE } & \text { single event effects } \\ \text { SNS } & \text { Spallation Neutron Source } \\ \text { SOW } & \text { statement of work } \\ \text { WBS } & \text { work breakdown structure } \\ \text { WNR } & \text { Weapons Neutron Research } \\ & \end{array}$





\section{ACKNOWLEDGMENTS}

This report is the product and final deliverable of a Work for Others project (project number 2108-V67813) funded by Federal Aviation Administration and conducted by Oak Ridge National Laboratory staff in the Source Development and Engineering Analysis Group of the Instrument Source Division, Neutron Sciences Directorate. In addition to the authors, significant contributions came from Erik B. Iverson, Larry C. Jones, Wei Lu, Thomas J. McManamy, Mark E. Phillips, Michael A. Plum and Irina Popova.

The efforts of Phillip D. Ferguson to cultivate communication with the FAA and Aerospace Vehicle Systems Institute and to initiate this study are gratefully acknowledged. 



\section{EXECUTIVE SUMMARY}

The Federal Aviation Administration (FAA) is contemplating new regulations mandating testing of the vulnerability of flight-critical avionics to single event effects (SEE). A limited number of high-energy neutron test facilities currently serve the SEE industrial and institutional research community. The FAA recognizes that existing facilities have insufficient test capacity to meet new demand from such mandates; it desires more flexible irradiation capabilities to test complete, large systems and would like capabilities to address greater concerns for thermal neutrons. For this reason, the FAA funded this study by Spallation Neutron Source (SNS) staff with the ultimate aim of developing options for SEE test facilities using highenergy neutrons at the SNS complex.

After an investigation of current SEE test practices and assessment of future testing requirements, three concepts were identified covering a range of test functionality, neutron flux levels, and fidelity to the atmospheric neutron spectrum. The costs and times required to complete each facility were also estimated. SEE testing is generally performed by accelerating the event rate to a point where the effects are still dominated by single events and double event causes of failures are negligible. In practice, acceleration factors of as high as $10^{6}$ are applicable for component testing, whereas for systems testing acceleration factors of $10^{4}$ seem to be the upper limit. It is strongly desirable that the irradiation facility be tunable over a large range of high-energy neutron fluxes of $10^{2}-10^{4} \mathrm{n} / \mathrm{cm}^{2} / \mathrm{s}$ for systems testing and from $10^{4}-10^{7} \mathrm{n} / \mathrm{cm}^{2} / \mathrm{s}$ for components testing.

The most capable, most flexible, and highest-test-capacity option is a new stand-alone target station named the High-Energy neutron Test Station (HETS). It is also the most expensive option, with a cost to complete of approximately $\$ 100$ million. Dual test enclosures would allow for simultaneous testing activity effectively doubling overall test capacity per HETS operating hour. Using about 1 kilowatt $(\mathrm{kW})$ of proton power extracted from the accelerator before injection in the accumulator ring, its operation would be unnoticeable by neutron scattering users at the SNS target station. The $\mathrm{H}^{-}$beam laser stripping technique would allow for control of beam power on the HETS target independent from power delivered to the SNS. Large systems with frontal areas of up to $1 \times 2 \mathrm{~m}^{2}$ could be accommodated with integral highenergy flux values (above 10 megaelectron-volt, or MeV) to at most $10^{4} \mathrm{n} / \mathrm{cm}^{2} / \mathrm{s}$; components could also be tested with flux levels to at most $10^{7} \mathrm{n} / \mathrm{cm}^{2} / \mathrm{s}$ on beam sizes of up to $0.2 \times 0.2 \mathrm{~m}^{2}$. Selectable moderating material and neutron filters would allow tailoring of the neutron spectrum to user demands; charged particle deflectors could be switched to allow or deflect protons, pions, and muons. It is estimated that HETS would take 5 years to complete after award of contract, including engineering design and construction. Commissioning would take at least another 6 months. Interference with SNS principal operations was not considered in the construction time estimate; connection of the proton transport line and tunnel from the accelerator high energy beam transport (HEBT) and construction around existing site utilities would require careful planning and coordination with beam operations at the SNS.

A high-energy (HE) neutron test facility using an available beam line on the SNS target station is a technically and financially attractive option. Inspired by the new ChipIR instrument on the ISIS TS-2 spallation source in the UK, a similar facility could be placed on an unused beam line in the SNS instrument hall [e.g., on beam line 8 (both A and B channels would be needed) or on beam line 10]. The performance would approach that of an HETS $(\sim 80 \%)$, but it would be operationally more limited, with only a single user at a time. Space is more limited, so the maximum system size would be about half of that in an HETS. Flexibility to tailor the spectrum would be somewhat more limited. While this concept was not as fully developed and characterized, preliminary work indicates very high HE flux levels should be possible, with ample thermal neutrons as well. Flux control would be more difficult than at HETS because proton power on target be whatever the SNS was operating at for neutron scattering. Neutron attenuation devices would have to be employed with as-yet undetermined control resolution. However, no 
new buildings would be needed, and the necessary utilities are already present in the SNS Experiment Hall. The estimated cost for a beam line option is around $\$ 15$ million; the time to complete would be 3 years after award of contract, plus at least 6 months for commissioning. Interference of construction activities with SNS operations should be negligible. This option would require negotiation with the Department of Energy Basic Energy Sciences (BES) office - the primary stakeholder of SNS - for an application outside the usual scope of neutron scattering sciences. Furthermore, these presently open beam lines are highly desirable locations for proposed neutron scattering instruments and obtaining one of them for an SEE test facility will come only with persuasive and timely arguments to SNS leadership and the DOE BES.

The third option is a tunnel extension/target cave facility providing the most basic system-level irradiation capability with minimal flexibility. Again not as well developed a concept as HETS, it would use a laserstripping technique like an HETS, redirecting protons to a tunnel similar to the initial HETS proton transport tunnel. Indeed, this concept is intended to be upgradable to a full HETS facility. Only a small fraction of a watt of proton power would be used in this basic configuration, though. An uncooled target and primitive shielding arrangement would provide beam on modestly sized systems that must be placed in close proximity to the target. The neutron fluence would be less uniform over the system than with the HETS or the beam line option. A data acquisition room and support area would be located on the ground level; access to the target cave would be via elevator and/or stairway. As a result of the required excavation, new tunnel construction, shielding, data acquisition building, utilities, and other items, the estimated cost is $\$ 30$ million. The time to complete is expected be more than 3 years; here again construction interference with SNS operations has not been accounted for, but it could have a significant impact.

Promotion of a SEE test facility based at the SNS site requires strategy, planning, and effort beyond the scope of this study. However, a few points are offered for consideration. Acceptance and welcome from the BES office for an SNS facility is essential. Achieving that will require communication and persuasion regarding the importance of the national need for such a facility and the unique capability that an $\mathrm{HE}$ spallation source offers. BES has primary ownership of the SNS, and any SEE footprint would require negotiation with BES for an agreeable construction and operation model. Dedicated funding to construct and provide full and sustained operation of any facility option must be found and must augment the budget that BES provides for operating the SNS via its Scientific User Facilities program. Finally, further optimization of any preferred option is needed to develop a true conceptual level, a necessary requirement before proceeding to full engineering design. 


\section{THE PATH FORWARD}

The authors wish that with the conclusion of this study pursuit of a SEE test facility at the SNS is undertaken. Opportunities to provide outstandingly representative radiation conditions for testing avionics and ground-based computing systems and for fundamental SEE research are rare. High-energy accelerators suitable for spallation neutron sources that can mimic the atmospheric radiation conditions are uncommon national assets. The SNS offers particularly good options for such facilities, and because it operates as a user facility for scientific research, it is well suited to hosting and supporting many visitors from industry and research institutes.

The three facility options described here cover ranges of capability, flexibility, cost and testing throughput - and different sets of challenges. The preferred choice depends in part on the SEE user community's assessment of what is needed now and in the future, and what funding can be provided. The HETS is clearly the best performing but also the most expensive option with the longest time to complete. It will have the most throughput capacity and have the greatest irradiation condition flexibility. Coordination of construction with SNS operations will present some challenges. A beam line facility will perform very well for much less cost, with minimal construction coordination concerns, but it lacks the same abilities for spectrum adjustment and flux intensity that HETS provides, and has half test throughput potential. Competition for a suitable available beam line on the SNS is intense. If a beam line cannot be assigned and funding is a limitation, the HENC option can perform as a system test facility, with minimal irradiation flexibility, and poor component test functionality.

The SNS is a scientific user facility funded by the U.S. Department of Energy Office of Basic Energy Sciences (DOE, BES, http:/science.energy.gov/bes/ ) and operated and managed by the Neutron Sciences Directorate (NScD) of ORNL. NScD's primary mission is neutron scattering research. A high-energy neutron test facility for SEE applications differs from the standard scattering instrument normally supported by BES.

There are broad challenges in two critical areas for advancing a SEE test facility at SNS. First, communication with the sponsors and custodians of the SNS must be enhanced to make the case that this kind of test and research capability is urgently needed in the United States and that the SNS has excellent long-term potential to serve this national need. The SNS would be expanding its science mission beyond neutron scattering sciences. There is precedent for this vis-à-vis a Fundamental Neutron Physics Beam instrument funded by the DOE Nuclear Physics program. Strong communication with DOE BES will be needed along the way. Second, funding for construction and sustained operation of the facility must be secured (in addition to the BES current budgeting).

A strategy to address these challenges and advance a facility needs to be formed and executed. The stakeholder parties must all be involved, the FAA, avionics industries, the DOE, ORNL and the SNS. The close-out meeting for this Work for Others (WFO) study project - set for November 2014 - will also serve as an opportunity to form such a strategy. 


\section{INTRODUCTION}

The Federal Aviation Administration (FAA) funded this study to investigate capabilities for single event effects (SEE) avionics system testing at the Spallation Neutron Source (SNS) ${ }^{1}$ because there is a recognized need to increase the available testing capacity and improve on existing test facility capabilities, particularly in North America. ${ }^{2}$ Industry trends such as greater use of complex flight-critical avionic systems, smaller integrated circuit (IC) feature sizes, and lower IC voltage, in aggregate, point to increasing susceptibility to adverse effects of atmospheric radiation. The dominant radiation form leading to SEE phenomena in aircraft avionics is high-energy (HE) neutrons (above $1 \mathrm{MeV}$ ) which have their origins from cosmic radiation and its interactions with the upper atmosphere. ${ }^{3}$

Cosmic radiation in outer space is primarily (92\%) high energy protons with smaller contributions from alpha particles and other heavier ions, with energies up $10^{19}$ electron-volt $(\mathrm{eV}) .^{4}$ Through interaction with the atmosphere, radiation from space is transformed to predominantly neutrons $(96 \%)$ with a spectrum of energies up to about $10^{11} \mathrm{eV}$. SEE occur when atmospheric radiation, comprised of high energy neutrons and other particles, collide with specific locations on semiconductor devices contained in aircraft systems. Interaction with IC materials can lead to elastic or inelastic collisions resulting in ionization and / or displacement of circuit material. Memory devices, microprocessors and field-programmable gate arrays (FPGAs) are most sensitive to SEE. Low energy or thermal neutrons (25-200 millielectron-volt) can also lead to SEE; these are produced within aircraft through moderation of HE neutrons with fuel, personnel or carbon-based materials which are now more widely used in airframe construction. Thermal neutron interaction with Boron-10 - a dopant sometimes used in IC manufacturing and intimately located within the devices - leads to a reaction producing energetic Lithium ions or alpha particles with similar adverse effects on IC function.

New regulations for industry are being contemplated to mandate assessment of avionic system SEE vulnerability with $\mathrm{HE}$ and thermal neutrons and for qualification testing of mitigation techniques against SEE phenomena. Example avionic systems include:

- aircraft control systems that use fly-by-wire technology;

- autopilot;

- flight warning;

- communication (high frequency, very high frequency, satellite voice);

- navigation;

- displays;

- FADEC (Full Authority Digital Engine Control);

- engines (including auxiliary power units) or propeller control systems; and

- any other systems containing digital and/or electrical devices.

Suitably designed spallation neutron sources - using an incident proton beam of about 1 gigaelectron-volt $(\mathrm{GeV})$ - can provide a close match to the atmospheric HE neutron spectrum at substantially accelerated rates. As envisioned by the FAA, the anticipated scale of required testing exceeds the current capacity of US facilities. Furthermore, improvements over existing capabilities are sought, for example, in the size of avionic systems that can be tested and in flexibility to additionally test with lower-energy neutrons (thermal, epi-thermal) and protons. Assessment regulations are also being proposed by the European Aviation Safety Agency, EASA.

The initial concept for an SNS-based SEE test facility proposed using an existing waste proton beam directed to the SNS Ring Injection Dump (RID), to which some $100 \mathrm{~kW}$ of beam power can be sent. At an early point in the study, this option was decided to be impractical and to pose potential risks to neutron 
scattering operations. Reconfiguration of the RID itself would be an endeavor entailing radiation and contamination hazards; the RID was not designed for reconfiguration. The region of the accelerator facility leading into the RID is congested with components for charge stripping, beam steering, and control, as well as for diagnostics. Radiation levels are high relative to most of the accelerator complex. There is very little space to add new steering magnets or other components that might be used to direct a beam to a nearby new spallation target and SEE test area. Neutronics studies confirmed that $100 \mathrm{~kW}$ was much more power than is needed to provide necessary neutron flux levels at a purpose-built test station, so significant collimation / attenuating devices would be needed.

A technique using a laser to strip electrons off the $\mathrm{H}^{-}$beam after the end of the High Energy Beam Transport (HEBT) bend could be used to send a modest and useful amount of proton power (a few kilowatts) to a new target and test facility. The laser stripping technology exists and has been demonstrated at this power level. ${ }^{5}$ It allows for fine adjustment of power to target, a feature that could be exploited depending on user demands for neutron intensity. Although other areas of the SNS complex besides the RID were examined for test facility potential, the laser stripping approach has the best prospects for providing either a full-featured test facility or a low-cost option with upgrade potential.

Emphasis has been placed on accommodating testing avionic systems, as opposed to individual components (e.g., IC chips on boards). Systems were clearly identified in the study's statement of work (SOW) negotiated with the FAA. The required dimensions are a driver for test enclosure size and therefore for the volume of neutron shielding, which is a significant facility cost driver. However, the definition of "large" was not clear. Informally, at a meeting among SNS staff, FAA staff, and an Aerospace Vehicle Systems Institute (AVSI) representative, the minimum size was agreed to be approximately that of a household microwave oven, and the maximum size that of a jet engine. In the course of reviewing worldwide facility capabilities, it was noted that the ChipIR SEE test instrument (now under commissioning) at the ISIS TS-2 spallation source was designed for neutron irradiation of systems of up to $1 \times 1 \mathrm{~m}^{2}$ in frontal area. ${ }^{6-8}$ Consideration has been given to including ground-based computer systems that are also adversely impacted by SEE phenomena, albeit at a slower rate. Although this study focused on needs for the aviation industry, the ground-based electronics community would also be a large base of potential users of a future SNS facility. For design purposes in this study, a maximum beam size for system irradiations of $1 \times 2 \mathrm{~m}^{2}$ in frontal area was considered — big enough for a $42 \mathrm{U}$ computer rack cabinet.

Component testing was not explicitly defined in the study's SOW. However, the SNS study team expects sustained demand for component testing by the avionics industry and institutional researchers and considers component test capability a priority. This was confirmed with at a meeting with the FAA and an AVSI member in November 2013. Key differences between component and system testing are the required neutron flux and beam spot size. Goals for both types of testing have been defined. The beam spot size for components could be as small as a few square millimeters but as large as approximately 0.2 $\times 0.2 \mathrm{~m}^{2}$. The high flux levels anticipated for component testing - even with the relatively small spot size compared with the system requirement - are a driver for enclosure shielding thickness and facility cost. Flux levels will be discussed in detail.

Study of the ChipIR instrument at ISIS indicates that it will provide world-leading capabilities superior to those of the ICE (Irradiation of Chips and Electronics) House at the Los Alamos Neutron Science Center (LANSCE) $^{9}$ in terms of system irradiation capabilities, component flux levels, spectrum modification, data acquisition (DAQ) infrastructure, available operating hours, and ease of access (for European Union users). A full-featured and world-class option for North America at the SNS would have features partially based on ChipIR. Technically, this could be achieved with either of two options at SNS: an HE neutron SEE test instrument using one of the SNS target station's unused instrument beam lines, or a new HE Neutron Test Station (HETS) optimized for SEE testing. Although the former would be substantially less 
expensive to construct, the reality is that the Department of Energy Office of Basic Energy Sciences (BES) has made a very large investment in the SNS for the purpose of neutron scattering science. The beam lines on the SNS target station are highly valued.

This study has therefore focused on the HETS option. Regardless of competition for an available SNS beam line, capabilities and cost estimates for an SNS beam line instrument are also included in less detail as it is possible this option could ultimately be approved. A third low-cost, low-capability option is also included that could provide some system testing functionality in a shorter time frame with less flexibility and performance than an HETS, but that is consistent with upgrading to the full-featured facility should resources later become available. 


\section{STATEMENT OF WORK AND DELIVERABLES REVIEW}

Four tasks and related deliverables were identified in the SOW for the study.

\section{Task 1- Investigate curre nt SEE test practices in aviation}

Testing for SEE is currently taking place at a number of facilities both inside and outside the United States. The purpose of Task 1 is to gain an understanding of current test practices through literature searches and interviews with active researchers in the field. Understanding the tests that researchers desire, and how they go about trying to complete the tests, is the first step in understanding if a gap in current testing exists.

Deliverable for Task 1-Briefing via teleconference or web presentation. In addition, a summary report in the form of PowerPoint slides or short text shall be delivered. This deliverable shall ultimately be incorporated in the final report.

Task 2-Determine the capabilities of world-le ading SEE test facilities. Determine the shortcomings of the se facilities by working with the AVSI AFE 72 working group

In Task 2, we will understand the current best practices in the field, such as beam size, spectral modifications, and so on. In conjunction with the AVSI working group, it will be determined where the current testing ability is inadequate or could be improved for system-level testing (development of design criteria). Recommendations for improvements shall be documented and ranked according to how important these changes are for a new facility.

Deliverable for Task 2-Briefing via teleconference, web presentation, or on site at the FAA Technical Center. In addition, a summary report in the form of PowerPoint slides or short text shall be delivered. This deliverable shall ultimately be incorporated in the final report.

Task 3-Study and de te rmine what capabilities are required to generate the atmospheric conditions that are described in Task 2 for sys tem level testing

In Task 3, Monte Carlo models will be developed of a possible facility at SNS. Calculations will be completed to determine if, or to what extent, the design criteria developed in Task 2 can be met. Anticipated studies will be completed to answer questions such as these:

1. What is the maximum energy achievable?

2. What are the tradeoffs between flux and maximum energy?

3. Can solar flare testing be accommodated?

4. What is the impact of apertures and filters? How much phase space can be accommodated?

5. What beam size can or should be accommodated, knowing beam size is related to cost?

6. How does target view impact spectrum and performance?

7. What is the impact of extracted beam size on incident flux?

8. To what extent can the thermal beam component be enhanced through the introduction of a neutron moderator? 
Deliverable for Task 3-Briefing via teleconference, web presentation, or on site at FAA Technical Center. In addition, a summary report in the form of a short document shall be delivered. This deliverable shall ultimately be incorporated in the final report.

Task 4-Based on the current shortcomings (of current SEE test facilities) and the capabilities at ORNL, de termine if a new facility could close these gaps, and at what es timated cost and schedule

This task will focus on modifications to existing facilities at SNS that could be made to address the needs identified in Task 2 and the design options studied in Task 3. A schedule for the resulting concept will be developed and a cost estimate completed. Areas to be addressed include the location or possible locations for such a facility, the proton beam optics required to transport the proton beam, the possibility of using existing utilities for the facility, and the location or locations of the experiment room(s).

Deliverable for Task 4 -Briefing at the FAA Technical Center. A final report will be delivered after the briefing, providing the opportunity to address questions raised during the briefing in the final report. 


\section{FINDINGS}

The study effort began in May 2013. The team focused on investigating current SEE test practices (Task 1) and determining the capabilities and limitations of world-leading SEE test facilities (Task 2) for several months. Publications were researched, standards compiled, and web sites explored. More than 100 papers, standards, and related documents were collected and more than two dozen relevant web sites were identified. The team communicated with AVSI member and Honeywell employee Laura Dominik, an acknowledged expert in SEE phenomena and testing.

In addition, unrelated trips by SNS staff provided the opportunity for the principal investigator (PI) to visit and tour perhaps the two most important SEE test facilities:

1. the ICE House at LANSCE Weapons Neutron Research (WNR) facility in Los Alamos, New Mexico, ${ }^{9,10}$ and

2. the ChipIR instrument at the ISIS TS-2 spallation neutron source at Rutherford Appleton Laboratory in Didcot, Oxfordshire, UK. ${ }^{6,7}$

In November 2013, a status meeting was held at the FAA William J. Hughes Technical Center, ${ }^{11}$ where findings for Tasks 1 and 2 were presented. (Those deliverables had been provided previously.) In attendance at the November meeting were

SNS: $\quad$ Bernie Riemer, Franz Gallmeier

FAA: John Zvanya, Charles Kilgore II

AVSI / Honeywell: Laura Dominik

By telecom: $\quad$ Gary Horan and Srini Mandalapu (FAA)

The meeting was characterized by productive discussion that was very useful to the SNS team. The requirements/needs/wish-list features for a new SEE test facility were better understood; that clarity was necessary to progress on concepts for a facility sited at SNS. However, some design goal parameters remain ambiguously defined. The industry and regulators are in a state of continuing evolution regarding the testing capability required to meet future standards. For example, the need for protons/pions/ muons vs pure neutron irradiation could not be established at the time of the meeting. Participants in the meeting expressed a desire for test facility flexibility. The PI's meeting notes are included in Appendix A.

\subsection{TASK 1-INVESTIGATE CURRENT SEE TEST PRACTICES IN AVIATION}

A broad range of industries with interest in SEE testing was identified. In the case of aviation, HE neutrons (10 MeV and up) and protons (100 MeV and up) have been most responsible for SEE in electronics at commercial flight altitudes. Devices with dimensions of $150 \mathrm{~nm}$ and below also have a significant SEE sensitivity to neutrons in the range of 1-10 MeV. Devices containing boron as a dopant or in a glassivation layer become very sensitive to thermal neutrons (reaction: $\mathrm{B}^{10}+\mathrm{n} \rightarrow \mathrm{Li}^{7}+\alpha$ ).

Atmospheric neutron flux depends on altitude and latitude. Integral flux for neutrons at $10 \mathrm{MeV}$ and above at 40,000 ft and $45^{\circ}$ latitude is reported as $6000 \mathrm{n} / \mathrm{cm}^{2} / \mathrm{h}$ (ref. 3). HE neutrons are moderated and thermalize with hydrogenous materials (e.g., cargo, fuel, passengers, and plastics) and are absorbed by neutron poisons like boron if they are present. 


\subsubsection{Standards Specific to Avionics}

Two International Electrotechnical Commission (IEC) standards specific to avionics were noted as particularly useful for SEE avionic testing and our study: IEC International Standards 62396-1 (ref. 12) and 62396-2 (ref. 13). Figure 3-1 shows the atmospheric neutron spectrum at 40,000 ft, based on measurements and models, over the range from 1 kiloelectron-volt to $3 \mathrm{GeV}$. IEC standard 62396-1 states that neutrons with energies greater than $10 \mathrm{MeV}$ are the dominant cause of SEE for sensitive devices with geometric features larger than $150 \mathrm{~nm}$; however, for devices with feature sizes $\leq 150 \mathrm{~nm}$, the contribution of neutrons with energies between 1 and $10 \mathrm{MeV}$ may be significant. What was learned from current practice is that integral flux values are typically reported for energies above $10 \mathrm{MeV}$, but the importance of lower-energy neutrons is recognized particularly since the industry trend is toward feature sizes much smaller than $150 \mathrm{~nm}$. Lower-energy neutrons in aircraft are addressed in IEC Technical Specification 62396-5 (ref. 14).

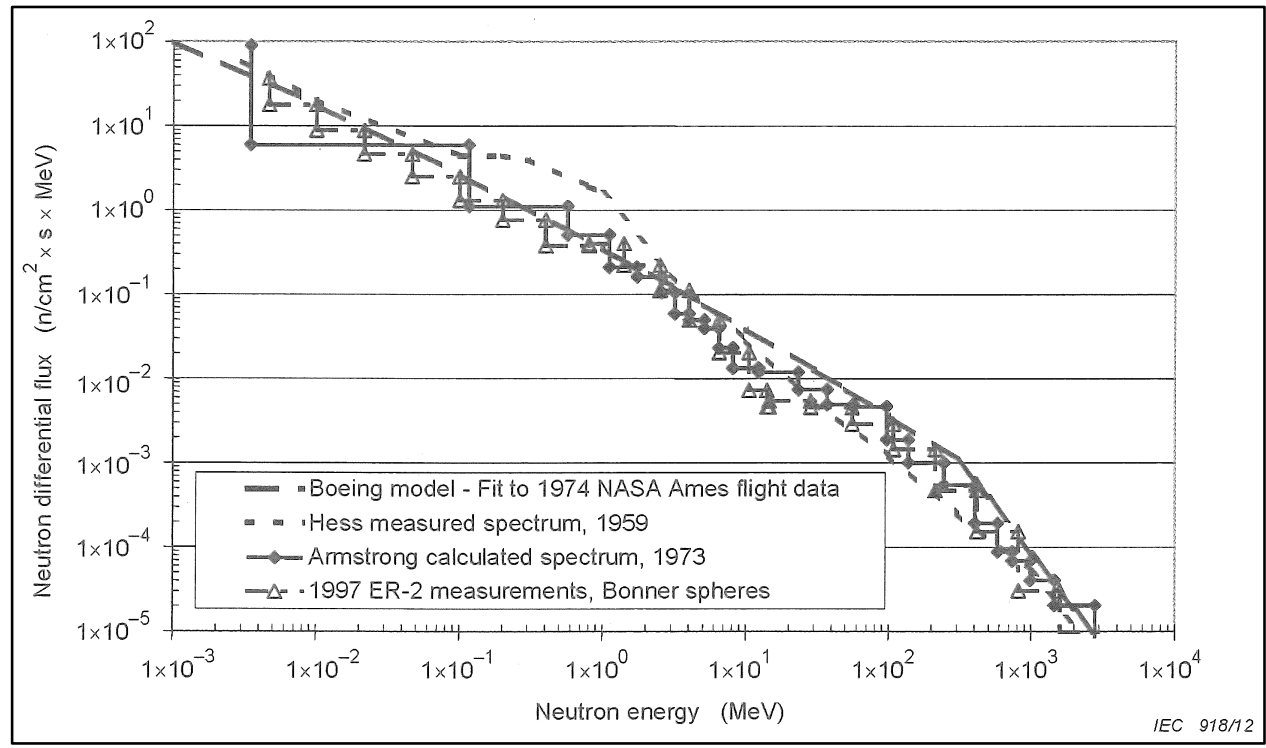

Fig. 3-1. Energy spectrum of atmospheric neutrons at $40,000 \mathrm{ft}(12,160 \mathrm{~m})$, latitude $\mathbf{4 5}^{\circ}$. Source: IEC Standard 62396-1.

Current testing practice is dominated by component testing, with radiation imposed on relatively small areas typical of IC chip sizes. The dominance of component testing is due to current research demands from industry, limited test time at suitable sources, and facility capabilities.

\subsubsection{Facilities}

Identified irradiation source types for SEE testing include:

- mono-energetic proton sources,

- quasi mono-energetic neutron sources,

- heavy-ion sources (space applications),

- laser sources (photoelectric effects),

- neutron generators (deuterium-tritium sources),

- real-time measurements at ground and at mountain-top, and

- spallation neutron sources. 
The spallation neutron sources have several advantageous features that make them particularly desirable. Perhaps most important is that they can produce a neutron spectrum that is prototypic to radiation found in the atmosphere. Figure 3-2 shows the ground elevation differential flux (New York City, scaled) along with those obtained from two HE spallation sources: the ICE House at the WNR Facility at LANSCE and the TRIUMF Neutron Irradiation Facility in Vancouver. The ICE House spectrum matches the ground spectrum particularly well from about 20 to $600 \mathrm{MeV}$. Heavy ions have a minor impact on aircraft at typical commercial vehicle altitudes; they are better suited to spacecraft SEE testing. Ground and mountain-top testing is simply limited in test throughput, as flux levels are less than that of aircraft at altitude.

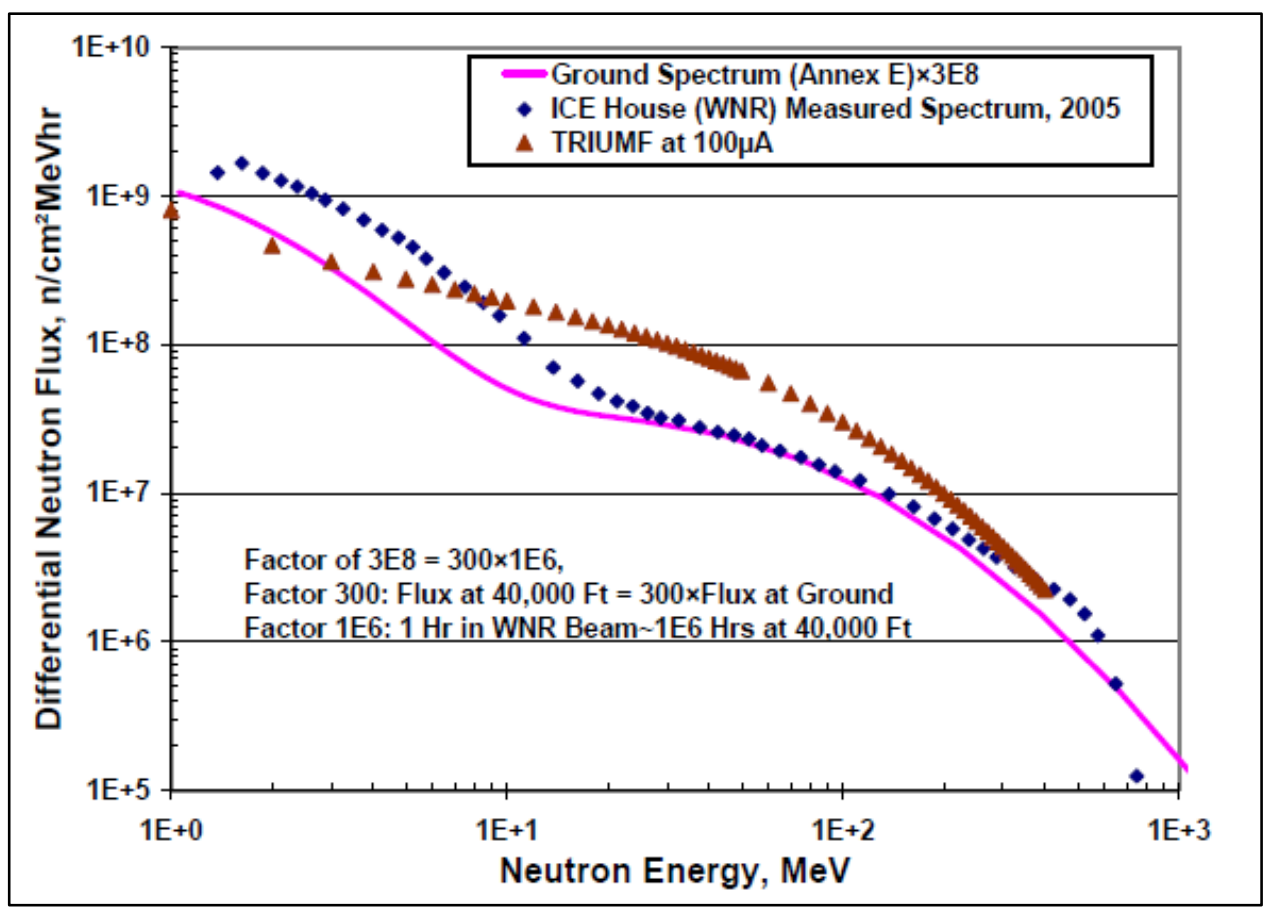

Fig. 3-2. Comparis on of Los Alamos and TRIUMF neutron beam spectra with terrestrial spectrum. Source: JEDEC Standard No. 89A, Measurement and Reporting of Alpha Particle and Terrestrial Cosmic Ray-Induced Soft Errors in Semiconductor Devices, Arlington, Va., 2006.

If moderating material is placed in a HE neutron beam line, flux of thermal energy neutrons can be enhanced to account for lower-energy neutrons encountered inside aircraft from HE interactions with fuel, passengers, and plastics. Thermal neutrons have a higher probability of interacting with certain isotopes, such as boron-10; its use in semiconductors increases their vulnerability to upset events. ${ }^{15}$

It is possible to obtain large-area beams at the ICE House, but according to facility staff, there has been little demand for them. Most users request a 1-3 in. diameter beam (adjustable by collimation) for component testing. It is possible to irradiate larger systems by removing collimation and placing equipment further away from the beam port.

High neutron flux levels are essential for performing accelerated testing. The ICE House neutron flux (integrated neutron flux above $1 \mathrm{MeV}$ is $\sim 10^{6} \mathrm{n} / \mathrm{cm}^{2} / \mathrm{s}$ ) is approximately a million times higher than the flux of neutrons produced by cosmic rays, depending on altitude. ${ }^{16}$ One hour of exposure in the ICE House beam is equivalent to more than 100 years of exposure at aircraft altitudes. Because SEE events are 
somewhat rare, high acceleration is needed for fundamental investigation of components or reliability demonstrations of avionic systems.

Typical ICE House users test with one to a few days of beam time and bring their own DAQ hardware for monitoring equipment under irradiation. The neutron spectrum and fluence on equipment is monitored by LANSCE staff, and the data are provided to the users. A number of tested components can be irradiated simultaneously by stacking and aligning them in the beam line (see Fig. 3-3). Successive neutron attenuation of HE neutrons in such a setup is not large; it is accounted for by "rules of thumb" provided by LANSCE staff. Increasing distance must also be accounted for. Alignment is achieved by use of a double-ended laser that is set on fiducial markings on the fission chamber at the beam outlet (for spectrum characterization) and the beam dump at the far end of the test room. For inch-scale components, this technique has been sufficient.

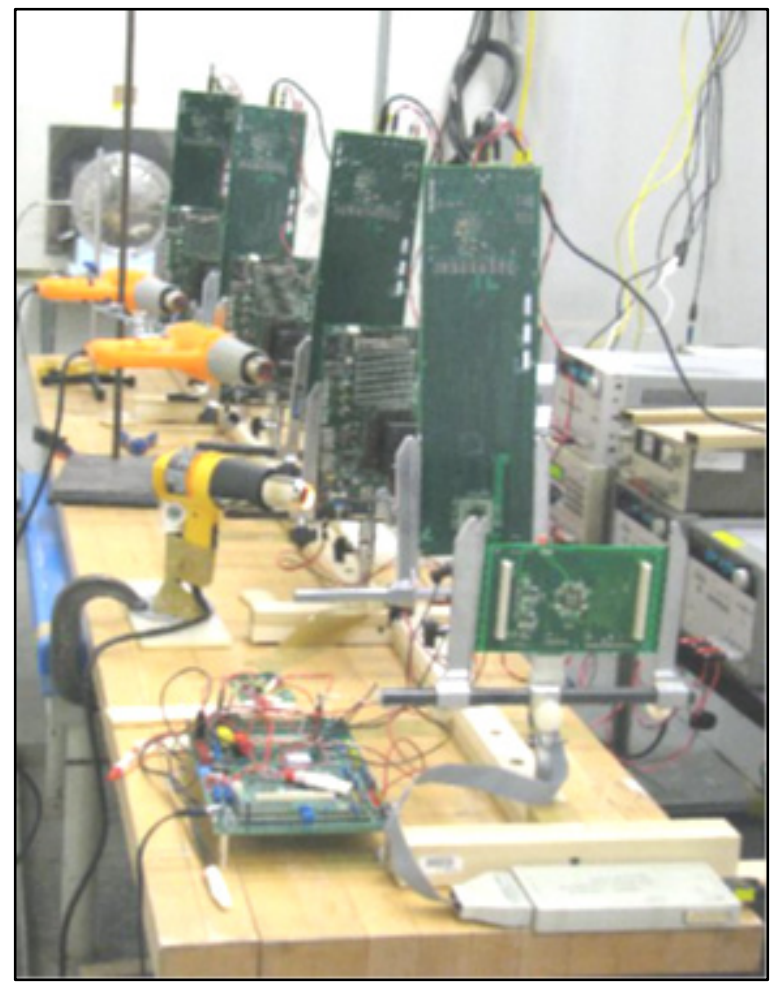

Fig. 3-3. Circuit boards with components aligned for neutron irradiation at the ICE House. Source: L. Dominik, "Atmospheric Radiation Testing," Presentation at 2012 National User Facility Organization meeting, Los Alamos, N.M., June 2012.

The ICE House offers fairly large test rooms, and, once users have taken the proper safety training, they are free to operate the neutron shutter and to access their hardware as needed. Aside from beam size collimation, the beam condition is coupled to other users of the spallation target at the WNR. Any unique operating requirements must be negotiated with LANSCE staff with consideration for other users. Since 2012, a second test area at the WNR has been configured and dedicated for SEE testing. With the two ICE Houses now operating, the annual number of available test hours is reported as approximately 3000 each. ${ }^{17}$

TRIUMF offers both component and system test capabilities in separate areas: 
High energy neutron beams are produced by $450 \mathrm{MeV}$ protons stopping in a water-cooled aluminum beam dump on one of the high intensity proton lines. The neutron beam of dimensions $5 \mathrm{~cm}$ by $12 \mathrm{~cm}$ and fluxes of $3 \times 10^{6} \mathrm{n} / \mathrm{cm}^{2} / \mathrm{s}(>10 \mathrm{MeV})$ is accessed vertically by a long narrow slot in the surrounding steel shielding. The presence of the water moderator means that a significant flux of thermal neutrons $(\sim 25 \%$ of the high energy flux) is also present. While this arrangement is frequently used for small component and device testing the access is limited for larger systems and the flux is too great for high level system testing. ${ }^{18}$

The access for components, noted as being awkward, is by way of a $5 \times 15 \mathrm{~cm}$ vertical channel, requiring that test components be lowered into place by a pulley system. A system test capability has been developed at TRIUMF with a large-area neutron beam generated by protons on a lead absorber in another area. The neutron beam size is $80 \times 80 \mathrm{~cm}^{2}$, with a maximum flux $10^{7}$ higher than the sea level flux for neutrons of $10 \mathrm{MeV}$ or higher. It can be varied from more than $50,000 \mathrm{n} / \mathrm{cm}^{2} / \mathrm{s}$ to less than $1000 \mathrm{n} / \mathrm{cm}^{2} / \mathrm{s}$ by changing the proton current or the distance to the test point. Two proton beam energies are possibleeither 500 or $116 \mathrm{MeV}$. Wender reported that there are $3000 \mathrm{~h}$ per year available for component testing and $800 \mathrm{~h}$ per year available for system testing at TRIUMF. ${ }^{10}$

ChipIR at the ISIS TS-2 spallation neutron source is now in commissioning. ${ }^{6-8}$ Located at the Rutherford Appleton Laboratory in the UK, ChipIR was purpose built for SEE testing of avionics and ground-based electronics systems and components. A typical instrument on a spallation neutron source for scattering science uses thermal and/or cold neutrons, and the TS-2 source was designed for such instruments. Modifications to the ChipIR beam line are designed for maximizing HE neutrons to the sample equipment. Simulations predict that the neutron spectrum will be a good match to atmospheric neutrons from cosmic rays at commercial aircraft altitudes and at ground level. Flux levels with small beams for components are expected to exceed the ICE House level (perhaps reaching $10^{7} \mathrm{n} / \mathrm{cm}^{2} / \mathrm{s}$ ), and large systems will have more modest fluxes. Up to $1 \times 1 \mathrm{~m}^{2}$ systems can be irradiated. Spectrum tailoring is also possible.

The ChipIR facility was toured in August 2013, and a number of features and user accommodations were noted. These include movable equipment stages for components and systems, allowing remote alignment of equipment to beam; remotely controlled beam collimators; remotely controlled neutron beam filters; patch panels and cabling between the test enclosure and the DAQ room; an electromagnetically shielded DAQ room; quiet power supply for the DAQ room and test enclosure; quiet heating, ventilation, and airconditioning for the DAQ room; and a private break room for ChipIR users. If it achieves its performance goals, ChipIR is poised to become the premier neutron SEE test facility in the world. Annual operating hours should be around 3000 .

Two other spallation source SEE test facilities are briefly noted here. There is the ANITA (Atmosphericlike Neutrons from thIck TArget) facility at the Svedberg Laboratory in Sweden, which uses a $180 \mathrm{MeV}$ proton beam incident on a tungsten target. ${ }^{19}$ The Research Center for Nuclear Physics at Osaka University uses a proton beam with incident energies up to $392 \mathrm{MeV} .^{20,21}$

\subsection{TASK 2-DETERMINE THE CAPABILITIES OF WORLD LEADING SEE TEST FACILITIES. DETERMINE THE SHORTCOMINGS OF THESE FACILITIES BY WORKING WITH THE AVSI AFE 72 WORKING GROUP.}

Some Task 2 findings overlap with the Task 1 scope and are reported in Sect. 3.1. Based on discussions with the FAA and with AVSI member L. Dominik, a primary issue is the lack of available test time at suitable facilities to satisfy the anticipated increase in need that will result from new FAA regulations 
mandating testing of avionics systems. Motivation for a new test facility at the SNS is further described by Dominik et al. ${ }^{22}$

The WNR ICE House facility is seen as being oversubscribed and underfunded, and access to it is seen as being sometimes difficult or unreliable:

\section{Existing Limitations at WNR}

Government and customer specifications increasingly require assessments of the single event effects probability in electronics from atmospheric neutrons. The accelerator that best simulates this neutron spectrum is the WNR facility at Los Alamos, but it is underfunded and oversubscribed. ${ }^{15}$ As the demand for this facility in terms of hours of neutron beam time has consistently increased over the past ten years, accessibility to this facility has become a problem for the variety of industries and companies that want to use it for testing their new electronics in a simulated neutron environment.

In 2004, because of security issues at LANL, the entire laboratory was shutdown to visits from outside users for many months. In 2005 there were indications that due to cost cutting pressures, the entire LANSCE operation may be curtailed by about a factor of $50 \%$. Since 2005 , access to LANSCE is available only via a yearly proposal and followon LANSCE time allocation. If an industry need for LANSCE beam time is identified, it conceivably could take an investigator 18 months to get the beam time. Such delays cannot be tolerated in fast paced industries. ${ }^{22}$

Note: The article from which this quotation was taken was published before the opening of the second ICE House at WNR in 2012, which effectively doubled the potential operating hours. In CY 2012, LANSCE reported $2845 \mathrm{~h}$ of beam delivered to $\mathrm{WNR} ;{ }^{17}$ it is unknown how much of that was available to users of the ICE House, which requires beam sent to WNR target 4. By comparison, in CY 2011 LANSCE reported the WNR received $1062 \mathrm{~h}$ of beam. ${ }^{23}$ In CY 2010, 2635 hours were delivered to WNR target $4{ }^{24}$ The longer-term outlook for WNR operating hours is difficult to predict. The accelerator began operations in 1972. The LANSCE-LINAC Risk Mitigation project will replace obsolete and end-of-life equipment at LANSCE and will provide new capabilities. ${ }^{17}$

Regardless, a presentation provided by G. Horan of the FAA to the SNS (included in Appendix B, with permission) further highlights these reasons for the need for additional test facilities:

- increasing demand for SEE testing of components,

- system-level testing for robustness and mitigation verification,

- HE (solar storm) testing, and

- thermal neutron testing.

Boron is again being used in IC manufacturing, increasing vulnerabilities to thermal neutrons. Hence FAA, AVSI, and IEC foresee an increasing need for testing systems and components with thermal neutrons. The demand will depend on the specific test goals of the experimenter. The ability to add thermal neutrons to an HE (atmospheric-like) spectrum can be accommodated by placement of a water or polyethylene volume and thermalizing reflector in the HE beam line at close proximity to the target, at some or small expense to the HE flux. It is conceivable that such a moderator could be moved in and out of use on demand. 


\subsection{TASK 3-WHAT IS REQUIRED FOR A FUTURE SYSTEM TEST FACILITY TO SATISFY ANTICIPATED NEEDS}

HE neutrons of energies $1 \mathrm{MeV}$ and up are largely responsible for SEE because of their abundance in the atmosphere and their penetrability. The neutron flux intensity varies greatly with altitude and latitude, with peak fluxes reached at $60,000 \mathrm{ft}$ and $90^{\circ}$ latitude. The spectral shape of the neutron flux field is fairly constant, exhibiting roughly a $1 / \mathrm{E}$ dependence up to $300 \mathrm{MeV}$ and a $1 / \mathrm{E}^{2}$ dependence above $300 \mathrm{MeV}$, extending to multiple tens of $\mathrm{GeV}$. The conditions at $40,000 \mathrm{ft}$ altitude and $45^{\circ}$ latitude are commonly adopted as a reference cosmic-ray-induced flux field for electronics exposure, as this is the region most often frequented by commercial flights. At this altitude and latitude, approximately half of the peak flux values are achieved with integrated neutron fluxes of $1.55 \mathrm{n} / \mathrm{cm}^{2} / \mathrm{s}$ and $2.44 \mathrm{n} / \mathrm{cm}^{2} / \mathrm{s}$ above $10 \mathrm{MeV}$ and $1 \mathrm{MeV}$, respectively. ${ }^{12}$

Solar flare events can substantially increase the atmospheric particle fields; for example, two orders of magnitude increase in the neutron flux was reported for the solar flare that occurred on February 23, 1956. The spectral differences in the neutron fields are minor (in the $1-1000 \mathrm{MeV}$ range that makes up the bulk of the neutron flux intensity), as shown by data from the QinetiQ Atmospheric Radiation Model (QARM) database, depicted in Fig. 3-4. ${ }^{25,26}$ At energies above $1 \mathrm{GeV}$, the falloff for the solar flare is more pronounced because the incoming solar protons have a considerably softer energy spectrum compared to cosmic particles. ${ }^{16,27}$ The spectral differences between cosmic source atmospheric radiation and solar flare source are inconsequential to SEE; the danger of solar flares lies in the increase of the flux intensity. Providing higher flux at a test facility is more important than closely matching the solar spectrum.

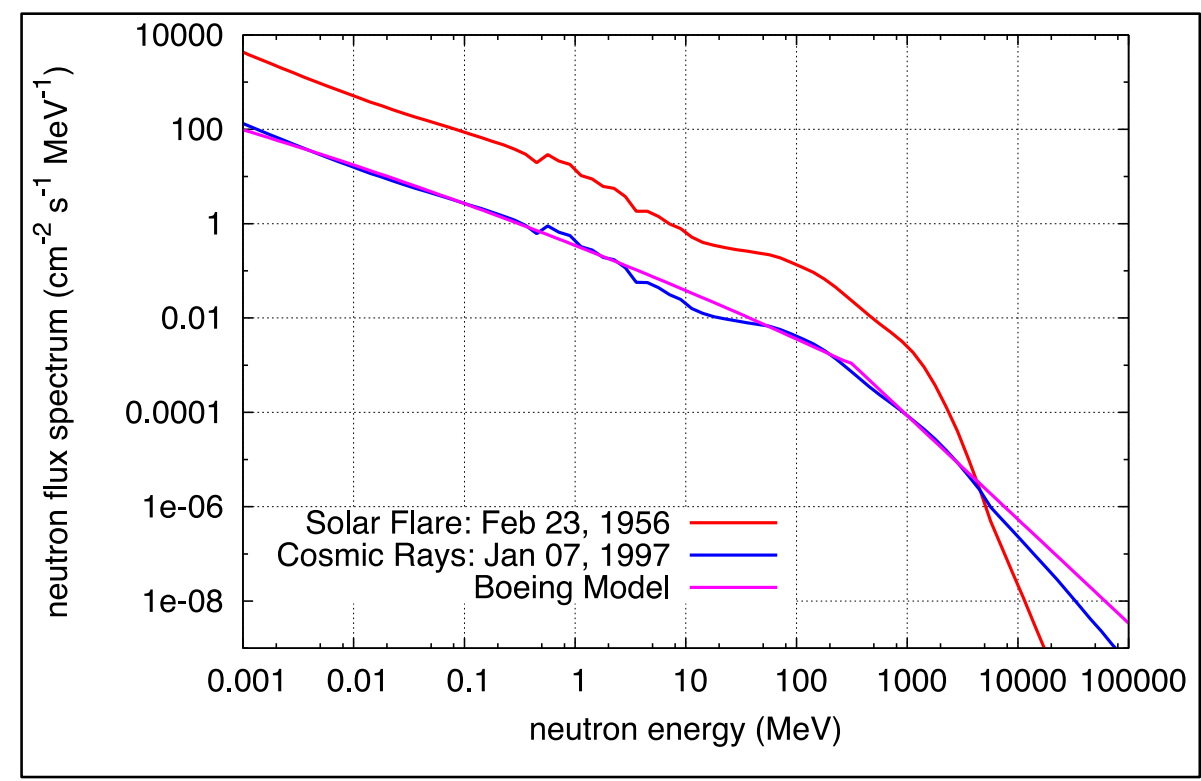

Fig. 3-4. Comparis on of neutron flux spectra for regular cosmic-ray and solar-flare enhanced conditions of January 7, 1997, and February 23, 1956. Sources: F. Lei et al., "Improvement to and Validations of the QinetiQ Atmospheric Radiation Model(QARM)," IEEE Transactions on Nuclear Science 53, No. 4, 1851, August 2006, and C. Dyer et al., "The QinetiQ Atmospheric Radiation Model and Solar Particle Events," presentation at the Third European Space Weather Week, Brussels, November 13-17, 2006. 
To conduct electronics testing within a reasonable experiment time, it is desirable to accelerate the SEE rate by increasing the flux intensity. Acceleration is limited by the fact that, depending on the sensitivity of the particular electronics under investigation at a certain flux level, the frequency of the irradiation effects rise to a point at which undesirable interference effects of two or more events come into play and cloud the experimental results. As present-day SEE irradiation facilities allow acceleration factors of about $10^{6}$, we decided for the study phase of our work to limit the study to a peak of $>10 \mathrm{MeV}$ neutron fluxes of $10^{7} \mathrm{n} / \mathrm{cm}^{2} / \mathrm{s}$. As the acceptable level of acceleration depends on the radiation sensitivity of the components, the irradiation facility must provide means of tuning the flux intensity.

The ICE irradiation facilities at Los Alamos National Laboratory demonstrate that an $800 \mathrm{MeV}$ proton beam incident on a compact tungsten target generates a neutron source with a spectrum closely matching the atmospheric neutron spectrum if viewed at $30^{\circ}$ with regard to the incident proton beam (see Fig. 3-2). Simulations were performed with MCNPX (Monte Carlo N-Particle Transport Code) for the SNS $1.0 \mathrm{GeV}$ proton beam to assess the angular dependence of neutron emission from a tungsten target of $5 \mathrm{~cm}$ diameter. ${ }^{28}$ Figure 3-5 compares the $1.0 \mathrm{GeV}$ results with the Boeing model atmospheric neutron spectrum. ${ }^{12}$ The calculations were done at $1 \mathrm{~kW}$ proton beam power. In the energy range of 10 to 600 $\mathrm{MeV}$, the spallation spectrum at a $30^{\circ}$ emission angle describes the Boeing model spectrum shape very well; for lower energies, the spallation spectrum over-predicts the Boeing model; and for energies above $600 \mathrm{MeV}$, the spallation spectrum under-predicts the model.

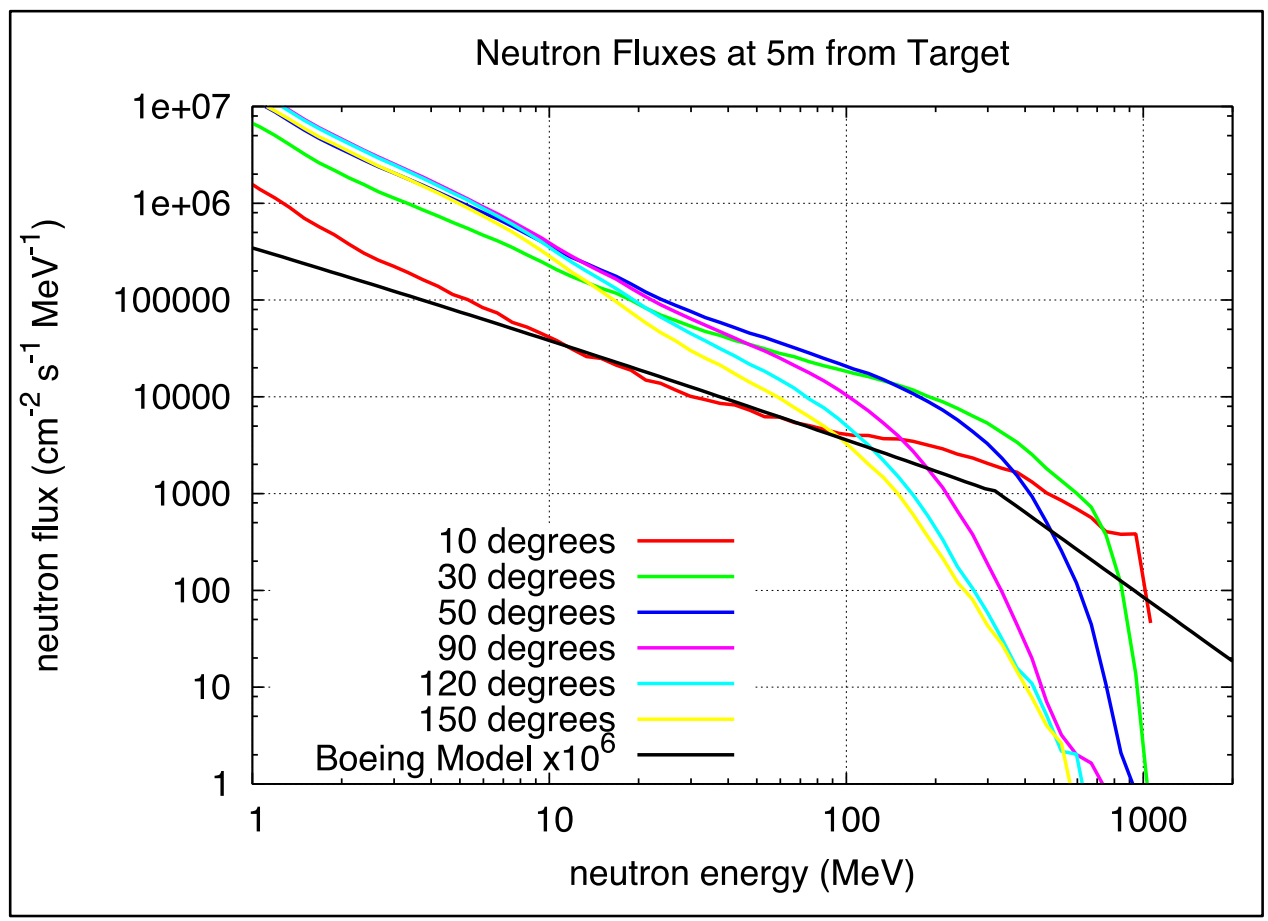

Fig. 3-5. Angular neutron and proton emissions due to a proton beam of $1.0 \mathrm{GeV}$ energy and $1 \mathrm{~kW}$ power incident on a $5 \mathrm{~cm}$ diameter tungsten target compared with the Boeing model atmospheric neutron spectrum.

Particles in the atmosphere other than neutrons can contribute to SEE, as is discussed in IEC International Standard 62396-1. ${ }^{12}$ Proton fluxes are reported to be equal to neutron fluxes above $300 \mathrm{MeV}$ and to drop to the $10 \%$ level below $300 \mathrm{MeV}$. Because SEE caused by HE protons are similar to neutron induced 
SEE, their contribution can be included in neutron irradiation experiments by further scaling up the HE neutron flux by $20-30 \%$.

Other atmospheric particle contributions to SEE, like those from pions and muons, in the past were considered negligible. However, the impact of pions and muons on SEE seems to be an area of continued investigation.

Secondary protons and pions are also produced in proton-induced spallation reactions in tungsten. Figure 3-6 shows the calculated proton, pion, and muon fluxes at $30^{\circ}$ emissions from a $5 \mathrm{~cm}$ diameter tungsten target compared with the neutron emission on a per-proton basis. Muons are produced through pion decay in flight; as a consequence, the pion/muon mix changes with distance from the target. Based on Ziegler and Lanford, the muon fluxes at spallation targets are about an order of magnitude lower than those in the atmosphere. $^{29}$
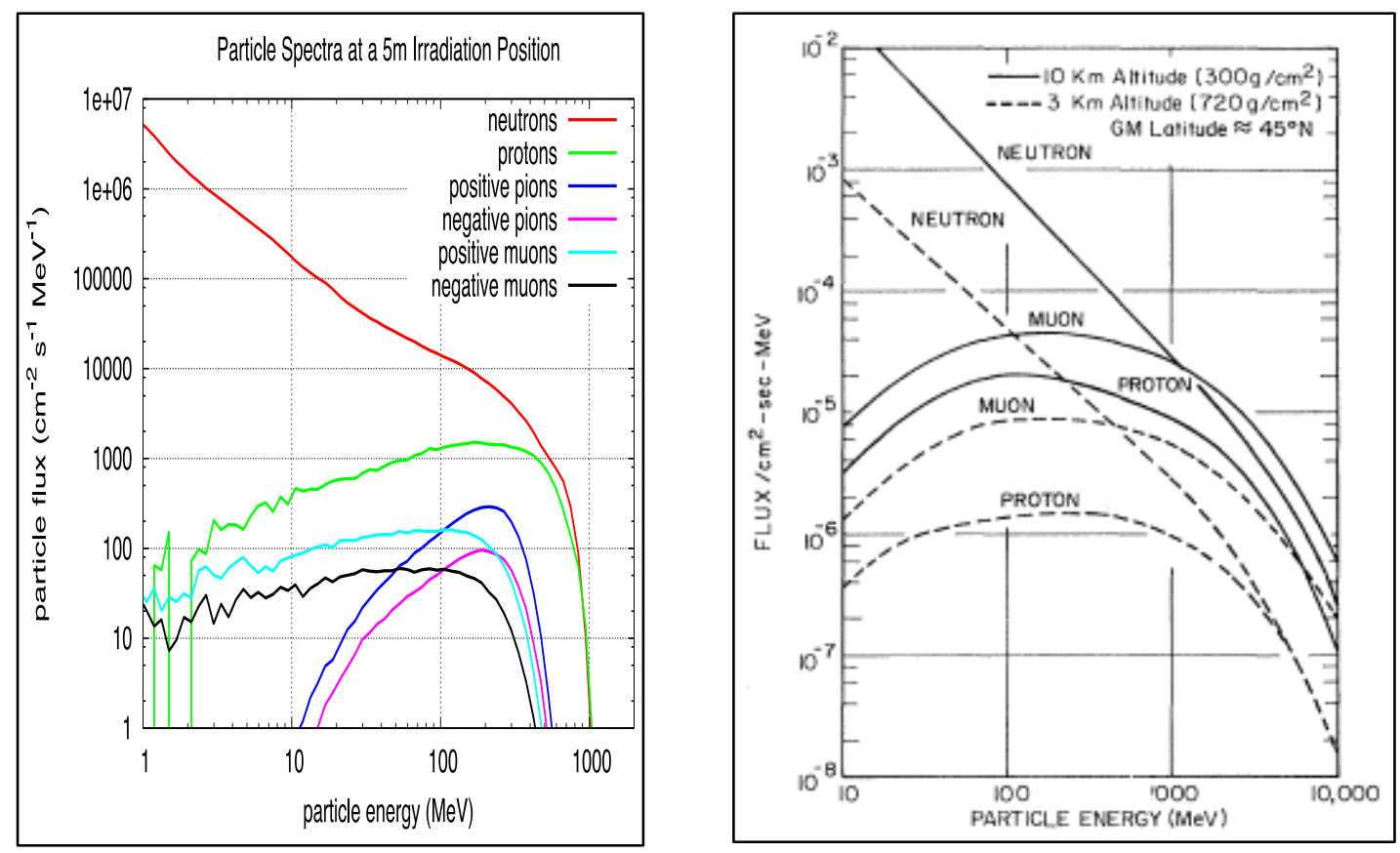

Fig. 3-6. Left: Angular neutron and particle emissions due to a proton beam of $1.0 \mathrm{GeV}$ energy and $1 \mathrm{~kW}$ power incident on a $5 \mathrm{~cm}$ diameter tungsten target. Right: Atmospheric particle spectra [reported by J. F. Ziegler and W. A. Lanford, "Effect of Cosmic Rays on Computer Memories," Science 206, No. 4420, 776 (November 16, 1979)].

When moderating materials containing hydrogen and/or carbon are present, large quantities of moderated and thermalized neutrons can build up in airliners. These can harm electronics as a result of absorption in neutron poisons like B-10 that are occasionally present as trace isotopes in IC insulation. The thermal flux in an airliner may vary greatly based on the presence of hydrogenous moderator materials such as fuel or passengers. IEC Technical Standard 62396-5 summarizes the current research on thermal neutron flux (below $1 \mathrm{eV}$ ) in commercial airliners to be at levels about 0.2-2 times the HE neutron flux (above $10 \mathrm{MeV}) .{ }^{14}$ Considering this range, a reasonable choice for a testing beam is to have equal numbers of thermal neutrons and above $10 \mathrm{MeV}$ neutrons, keeping in mind that locations with double the thermal flux may exist on airplanes. 
The thermal component in the neutron spectrum can be generated with a spallation source by placing hydrogenous materials at the target. Figure 3-7 shows the addition of a thermal beam component for a target surrounded with a $2.5-\mathrm{cm}$ thick water layer compared to a bare target, and also for a configuration that had the target and water layer additionally surrounded by $30 \mathrm{~cm}$ of beryllium. Here, the simulated beams were extracted at $30^{\circ}$ off the incident proton direction. The water layer not only builds up the thermal spectrum, but also reduces the $0.1-10 \mathrm{MeV}$ hump caused by the evaporation stage of the spallation reaction. The water layer plus beryllium reflector configuration exhibits a thermal-to-above-10$\mathrm{MeV}$ ratio of 0.9 .

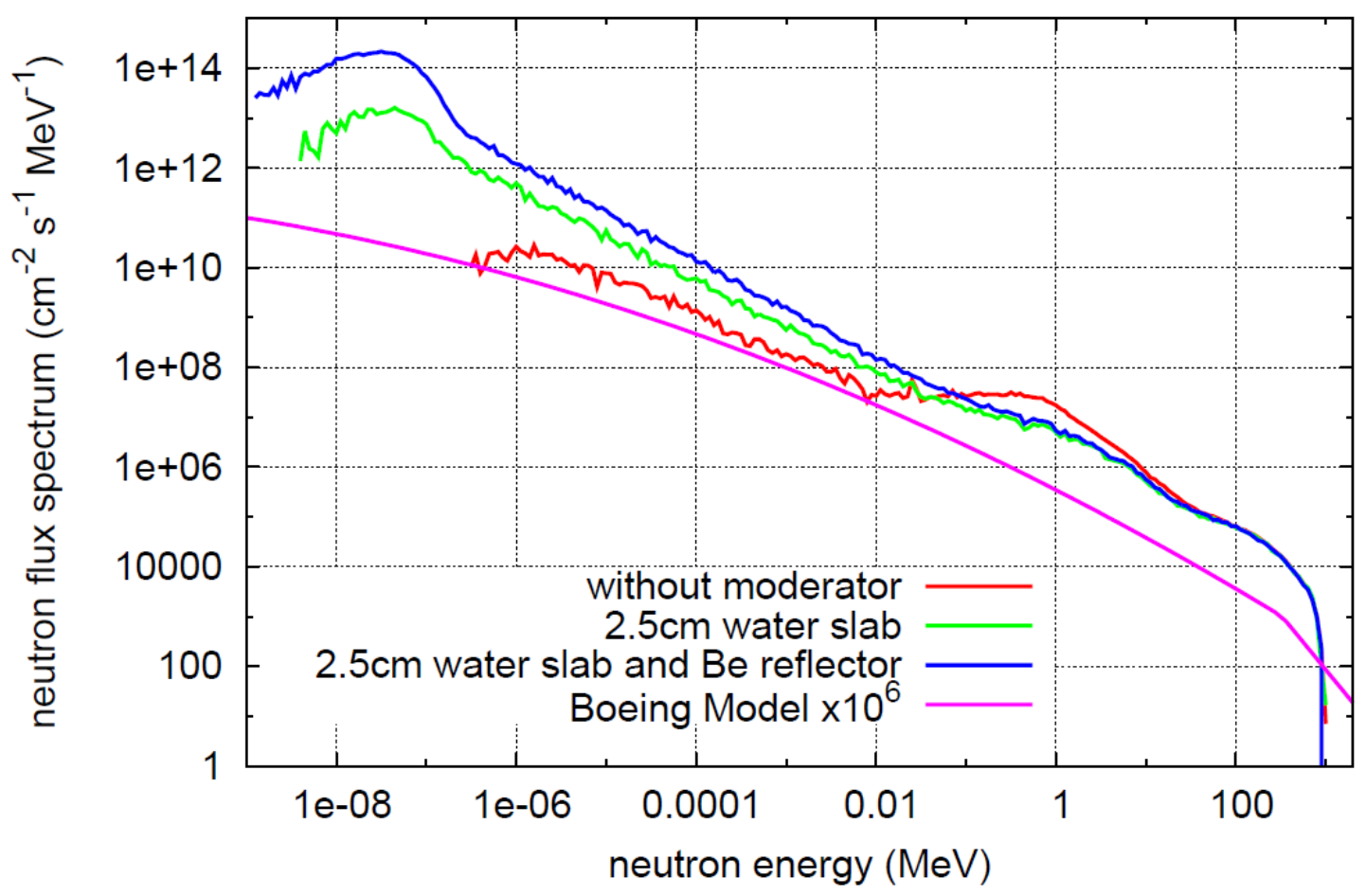

Fig. 3-7. Neutron spectrum at $30^{\circ}$ from a $1 \mathrm{~kW} 1 \mathrm{GeV}$ proton beam incident on a bare tungsten target, from a $2.5 \mathrm{~cm}$ water slab at the tungsten target, and from a $2.5 \mathrm{~cm}$ water slab at a reflector surrounded by beryllium, to a $30 \mathrm{~cm}$ radius, at a tungsten target.

A $30^{\circ}$ takeoff angle from a GeV proton beam incident on a tungsten target seems to be the most economical method of generating an atmospheric neutron spectrum. However, the neutron beam from the SNS water moderator emitted into beam line 8 provides a spectrum and intensities above $10 \mathrm{MeV}$ that come very close to the ideal (assumed irradiation position at $9 \mathrm{~m}$ distance from target), even though beam line 8 is at a $49^{\circ}$ angle. Below $10 \mathrm{MeV}$, though, the differences are pronounced a shown in Fig. 3-8. This beam is generated by viewing the water moderator located below the mercury target, meaning that spallation neutrons from the target must undergo another scattering event to contribute to the neutron beam. By filtering this beam with $2 \mathrm{~cm}$ polyethylene (PE) and $12 \mathrm{~cm}$ of aluminum (Al), the spectral shape for energies below $10 \mathrm{MeV}$ can be significantly improved at a cost to overall intensity. Simulations indicate that integral fluxes (filtered) above $10 \mathrm{MeV}$ of $5.4 \times 10^{6} \mathrm{n} / \mathrm{cm}^{2} / \mathrm{s}$ are achievable with SNS being driven at 2 megawatt (MW), compared with $6 \times 10^{6} \mathrm{n} / \mathrm{cm}^{2} / \mathrm{s}$ obtainable at a $5 \mathrm{~m}$ distance from a tungsten target powere d by a $1 \mathrm{~kW}$ proton beam. The charged particle contribution in an SNS neutron beam line is low because the neutron beam is generated by a secondary scattering source. 


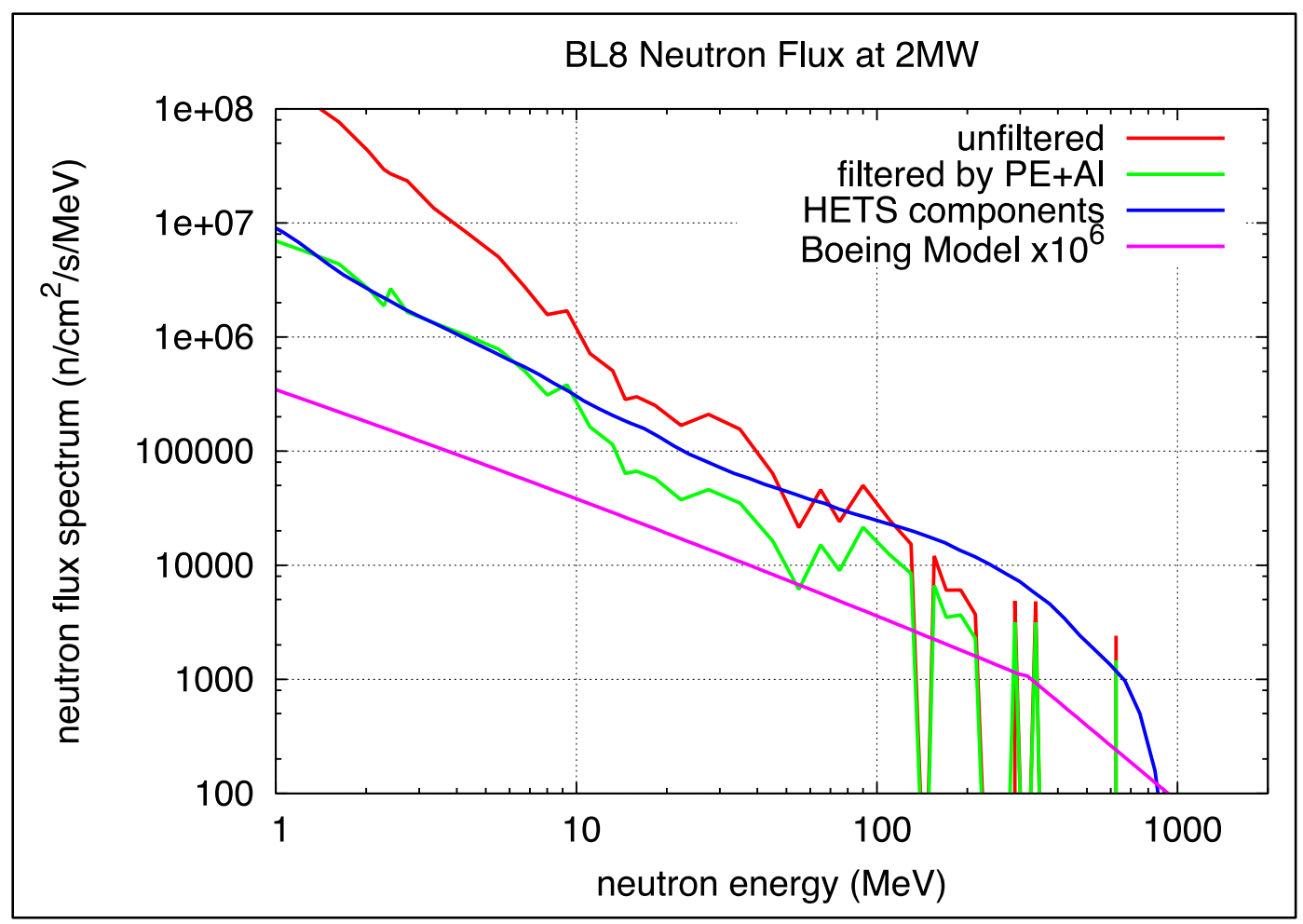

Fig. 3-8. High-energy neutron flux spectra at SNS beam line 8 at $9 \mathrm{~m}$ distance from the moderator compared to the Boeing model and a high-energy test station (HETS).

SEE testing is an area of constant change, driven in part by rapid developments in electronics in terms of new chip innovations and improvements in technologies striving for even smaller chip designs, and in part by changes in testing standards being established to qualify electronics for use in avionics. A facility for SEE testing should be planned with enough flexibility to cope with these ongoing developments.

An irradiation facility testing aviation electronics for SEE should mimic the atmospheric radiation field caused by cosmic ray exposure as closely as possible. It might be possible to test electronics components with sources that are mono-energetic and of different radiation types and then piece together the sensitivity to radiation of all their individual contributions. However, testing of active systems involving multiple components and their interactions, perhaps even including SEE mitigation strategies, implies that the whole system should be simultaneously exposed in its entirety to all types of radiation present in the environment in which it functions. This means that the radiation field must be large enough to expose the complete system, be homogenous over the system, and include all components of radiation in the broad spectralbands to which the exposed system would be sensitive in its working environment. If a system exhibits radiation self-shielding effects because of its mass or composition, it might even require a multidirectional radiation field, which would be expensive to establish.

For diagnostic purposes, it may be desirable to selectively turn features of the radiation field off and on (for example, to eliminate the thermal neutron component, suppress the 1-10 MeV neutron component, or even disregard charged particle contributions). Furthermore, it may be advantageous to be able to flexibly expose only parts of a system to radiation by allowing variable beam collimation and system positioning. 


\subsection{TASK 4-FACILITY OPTIONS AT THE SNS}

At the inception of this study, it was envisioned that a SEE test facility could be situated at or near the SNS RID, which is rated to accept approximately $100 \mathrm{~kW}$ of unstripped $\mathrm{H}^{-}$beam. Actual power delivered to the RID depends on the operating power and injection stripping foil efficiency. Regardless, as the construction of the RID is not suited to reconfiguration, adding an HE neutron irradiation area into the RID would be difficult. The accelerator tunnel region upstream of the RID and downstream of the injection foil equipment is very congested with equipment (such as magnets and beam diagnostics) that is critical to SNS operation (see Fig. 3-9). Redirection of part or all of the RID beam to a new target nearby and locating test space appears to be difficult and to pose some risks to primary accelerator operation. The operation of a SEE testing area using RID beam would be coupled to SNS primary operation so that independent control of power on target and neutron intensity would require beam attenuators and collimation that would generate spurious radiation fields. Overall, using RID beam for this purpose is not an attractive option.

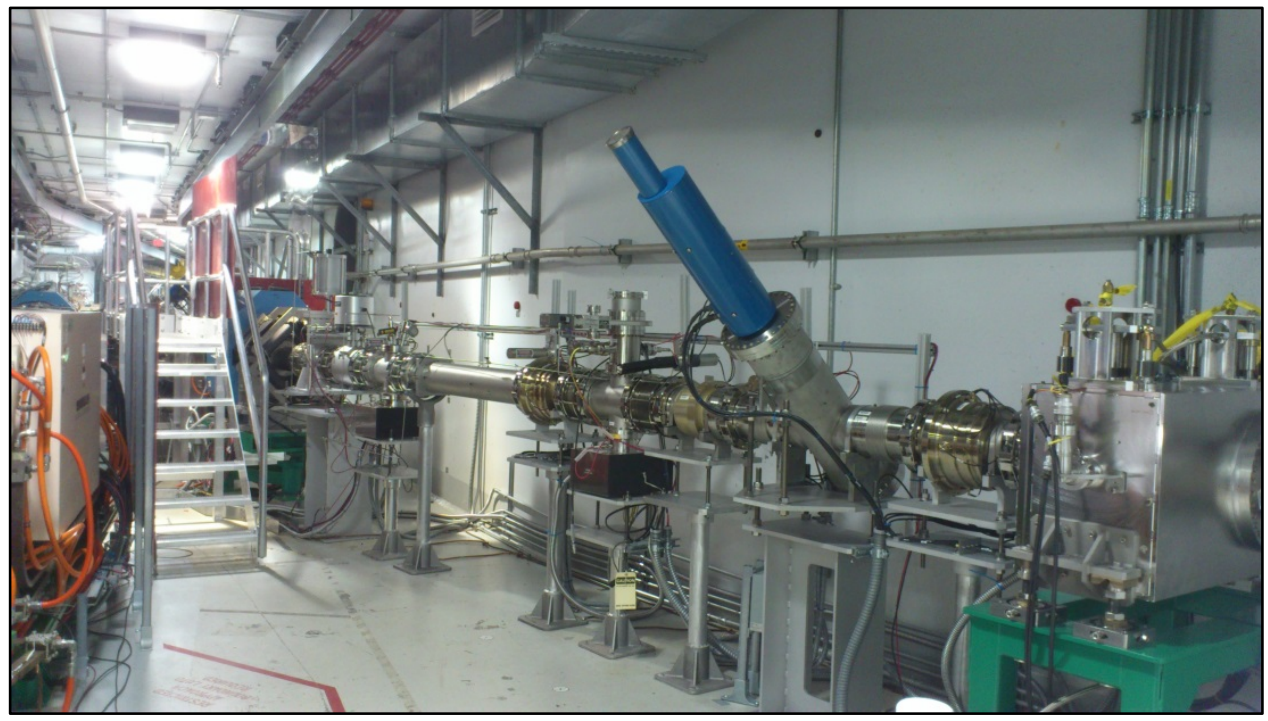

Fig. 3-9. Beam transport to the RID, which is off to the right. The stripping foil equipment is behind the stairs; this is the highest dose rate region of the accelerator.

A broad look at test facility options produced a list of roughly ten prospects. These have been reduced to three, which offer varied degrees of performance and functionality, cost, and estimated time to complete. They are presented briefly here and described in detail in Sects. 4-6.

HETS would provide the maximum test capacity and irradiation flexibility. A dedicated target station would be constructed for HE neutron research and testing. It would use approximately $1 \mathrm{~kW}$ of proton beam power on a gas-cooled tungsten target and would have two irradiation test areas capable of high neutron flux for components, or modest flux over a large spot size (up to $1 \times 2 \mathrm{~m}^{2}$ ) for system testing. The proton beam would be taken from the end of the accelerator HEBT section using laser stripping techniques. This is established technology in this power range and is finely controllable. A new proton beam tunnel and transport line would have to be constructed to the HETS location, which is foreseen as being situated between the RID building and the water tower. The HETS would be fully featured for broad flexibility for users by offering the capability to add thermal neutrons, tailor the neutron spectrum with filters, vary incident beam size, and align test pieces remotely without re-entry to the test enclosure. 
A facility installed on the SNS target station, fashioned after the ChipIR instrument at ISIS TS-2, is envisioned at beam line 8; both $\mathrm{A}$ and $\mathrm{B}$ channels would be required thus occupying space for two neutron scattering instruments. This beam line faces the ambient water moderator and could provide neutron flux at more than $10^{6} \mathrm{n} / \mathrm{cm}^{2} / \mathrm{s}$ at a 9 m distance without modification of the neutron optical path. A higher flux might be achievable with reasonable specialization of that beam line's core vessel insert. It could also provide thermal neutrons and large irradiation spot sizes for system testing although smaller than at the HETS facility. As in the HETS, the test enclosure would require unusually thick enclosure shielding (ca. $1.5 \mathrm{~m}$ high-density concrete), that along with external constraints from neighboring instruments would limit the enclosure's inside dimensions somewhat. These factors are also the reason both $\mathrm{A}$ and $\mathrm{B}$ channels are needed because the available space could not accommodate a second beam line 8 neutron instrument. Nevertheless this is the least expensive option of the three and could be available in about 3.5 years after approval and funding. It has the advantage of using existing utilities and infrastructure that is at hand, and its construction would have virtually no impact on SNS operation. Beam line 10 is also an attractive location from a technical standpoint. These presently open beam lines are highly desirable locations for proposed (but yet unfunded) neutron scattering instruments and obtaining one of them for an SEE test facility will come only with very persuasive and timely arguments to SNS leadership and the DOE BES.

A mid-cost option suitable for system irradiation could be built that would have little neutron spectrum tailoring capability. This option would also use laser-stripped beam extracted from the end of the accelerator HEBT and sent to a new tunnel/cave facility that would house an uncooled tungsten target. Shielding blocks arranged around the target and cave walls would allow for positioning of avionic systems fairly close to the target for HE neutron exposure. Only about a 100 milliwatt would be needed for fluxes suitable for system testing at close target distances $(\mathrm{ca} .1 \mathrm{~m})$. The flux intensity over the system would vary by as much as $30 \%$ over an area of $1 \mathrm{~m}^{2}$ and would not be comparable to what could be achievable with the other two options. The new tunnel/cave could be designed so that it could be reconfigured in the future and built out to an HETS option.

Construction and operation activities for any SEE facility cannot present a risk to SNS operations. 


\section{HIGH-ENERGY NEUTRON TEST STATION}

\subsection{CONCEPT-FACILITY DESCRIPTION}

A complete and flexible SEE irradiation station is proposed around a green-field dedicated target station that would require only a kilowatt-level proton beam incident on a tungsten target. The required beam can be extracted from the SNS beam transport line by laser stripping, a proven technology that was developed at SNS a couple of years ago. ${ }^{5}$ The target station - to be named the High Energy neutron Test Station (HETS) - would house two independent high-energy irradiation test areas and would allow for placing additional beam ports for other applications if required.

A computer aided design (CAD) model of the proposed HETS facility positioned on the SNS site is shown in Fig. 4-1. The building plan area is approximately $100 \times 100 \mathrm{ft}^{2}$ and $50 \mathrm{ft}$ in height. The proton tunnel would be underground and part of the HETS building below grade level. Access would be by North Perimeter Drive, which is presently a gravel-paved road on the edge of the SNS site boundary.

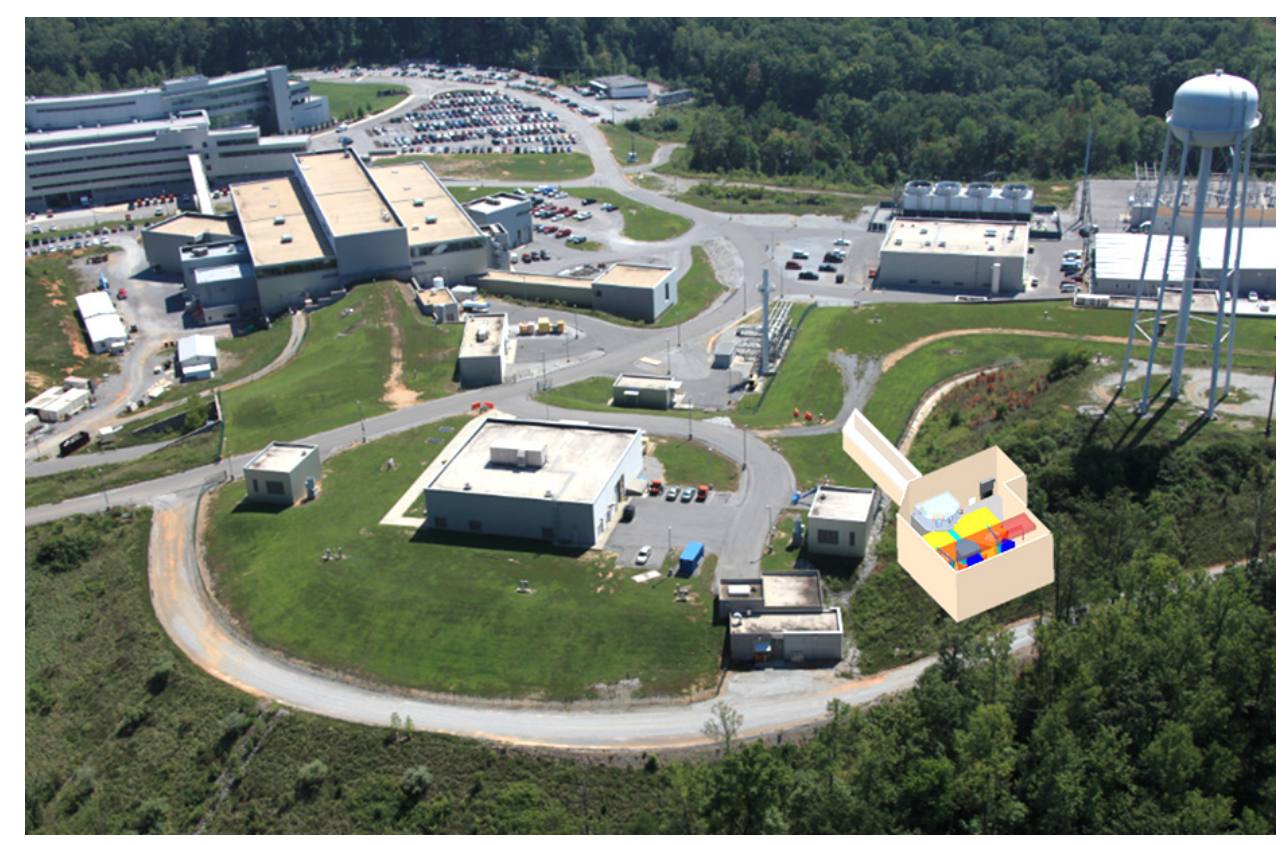

Fig. 4-1. CAD model of the High Energy neutron Test Station superimposed on an aerial photo of the Oak Ridge Spallation Neutron Source site.

Sectional views of the target facility design are shown in Fig. 4-2. Both test enclosures will be capable of either system or component testing, making it possible for two user groups to work simultaneously. Separated DAQ rooms are planned. 


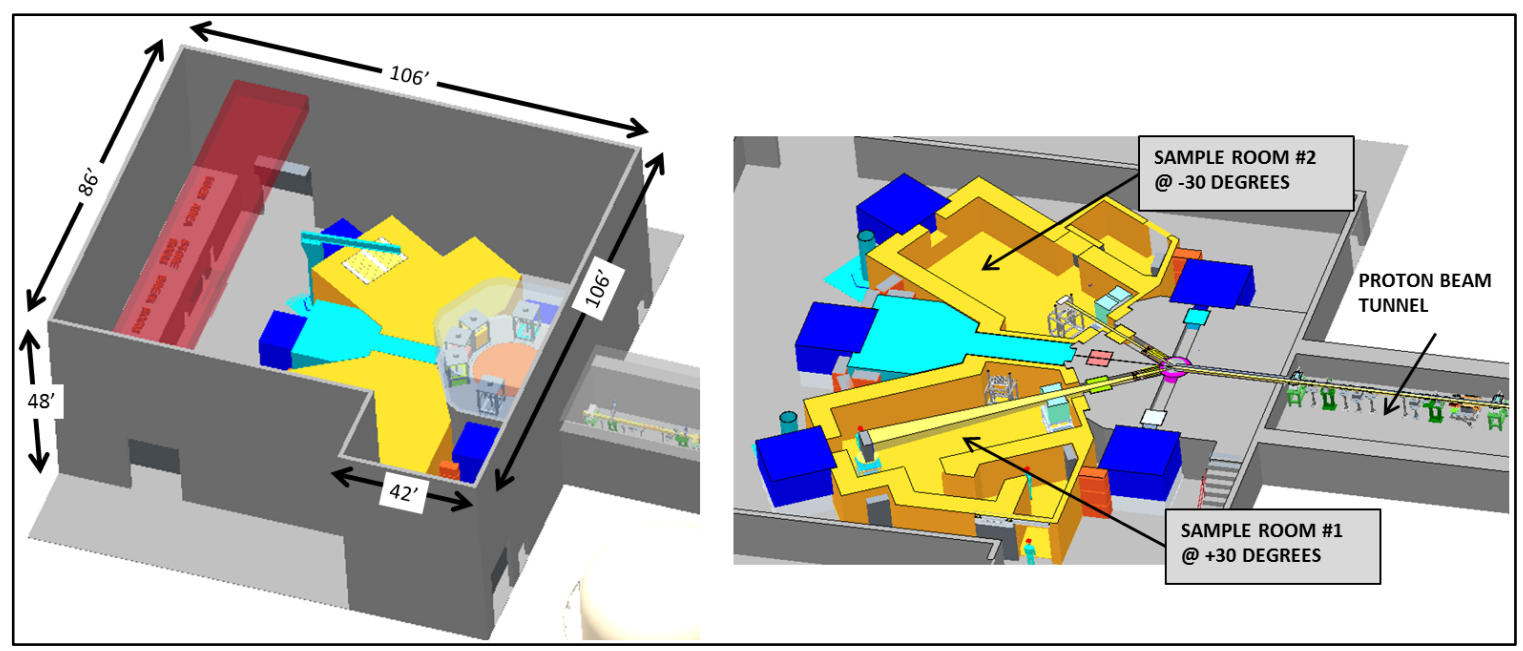

Fig. 4-2. HETS target station layout.

HETS will deliver peak neutrons fluxes above $10 \mathrm{MeV}$ neutron energy of $10^{7} \mathrm{n} / \mathrm{cm}^{2} / \mathrm{s}$ for component irradiation and of $10^{4} \mathrm{n} / \mathrm{cm}^{2} / \mathrm{s}$ for system irradiation. The absolute normalized neutron flux spectra are shown in Fig. 4-3. Assuming that the component irradiation area is positioned at $5 \mathrm{~m}$ distance from the target, a peak proton beam power of $1,350 \mathrm{~W}$ is necessary.

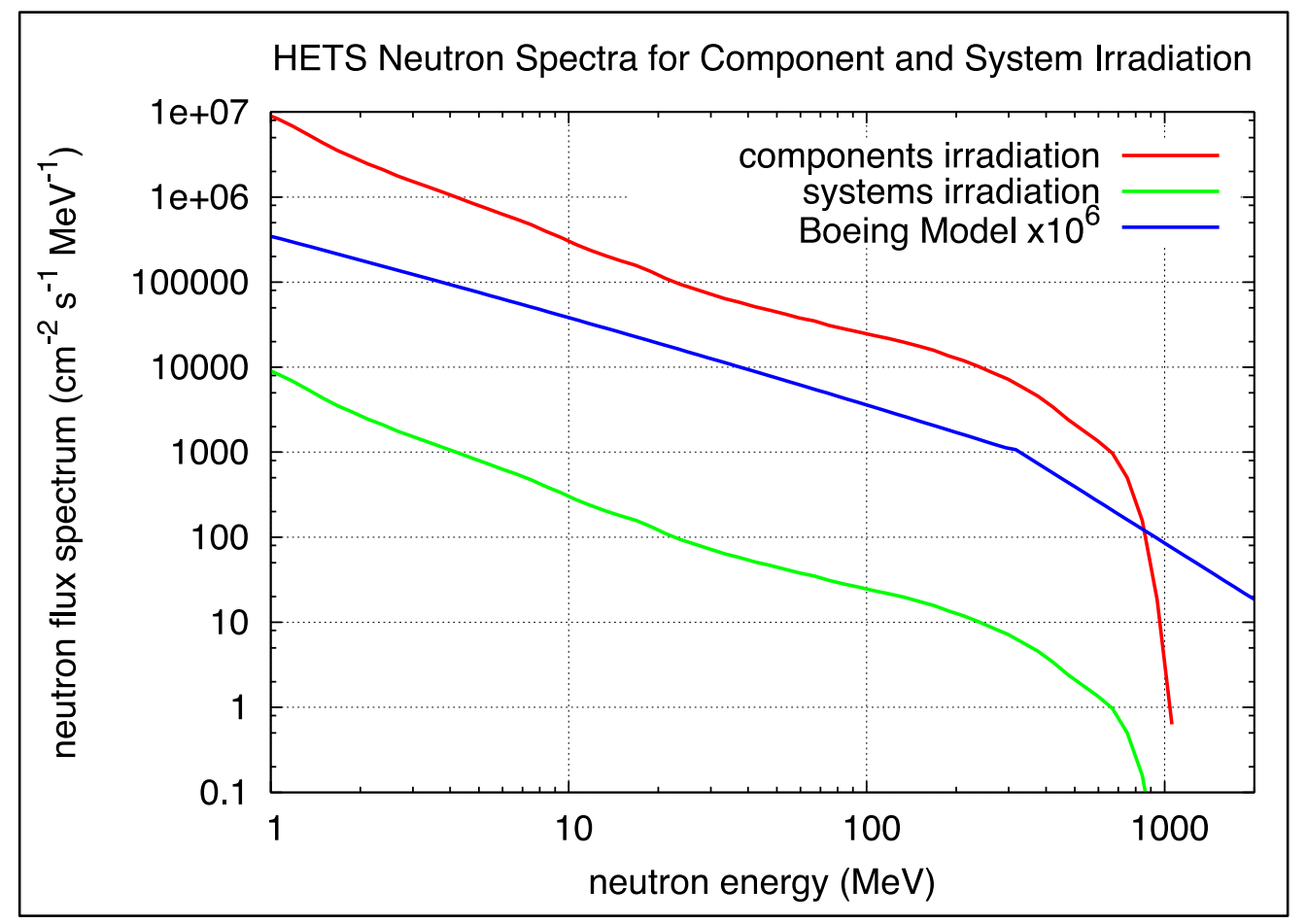

Fig. 4-3. HETS neutron spectra at the component and system test positions.

A work breakdown structure (WBS) was developed to help define project scope and organize cost estimates. The WBS for HETS is shown in Fig. 4-4. Sections 4.1.1-4.1.6 (Accelerator Systems, Target Systems, Neutron Test Systems, Conventional Facilities, Integrated Controls, and R\&D) describe the 
WBS Level 2 elements. Project management is covered in the cost estimate as a percentage of all other costs.

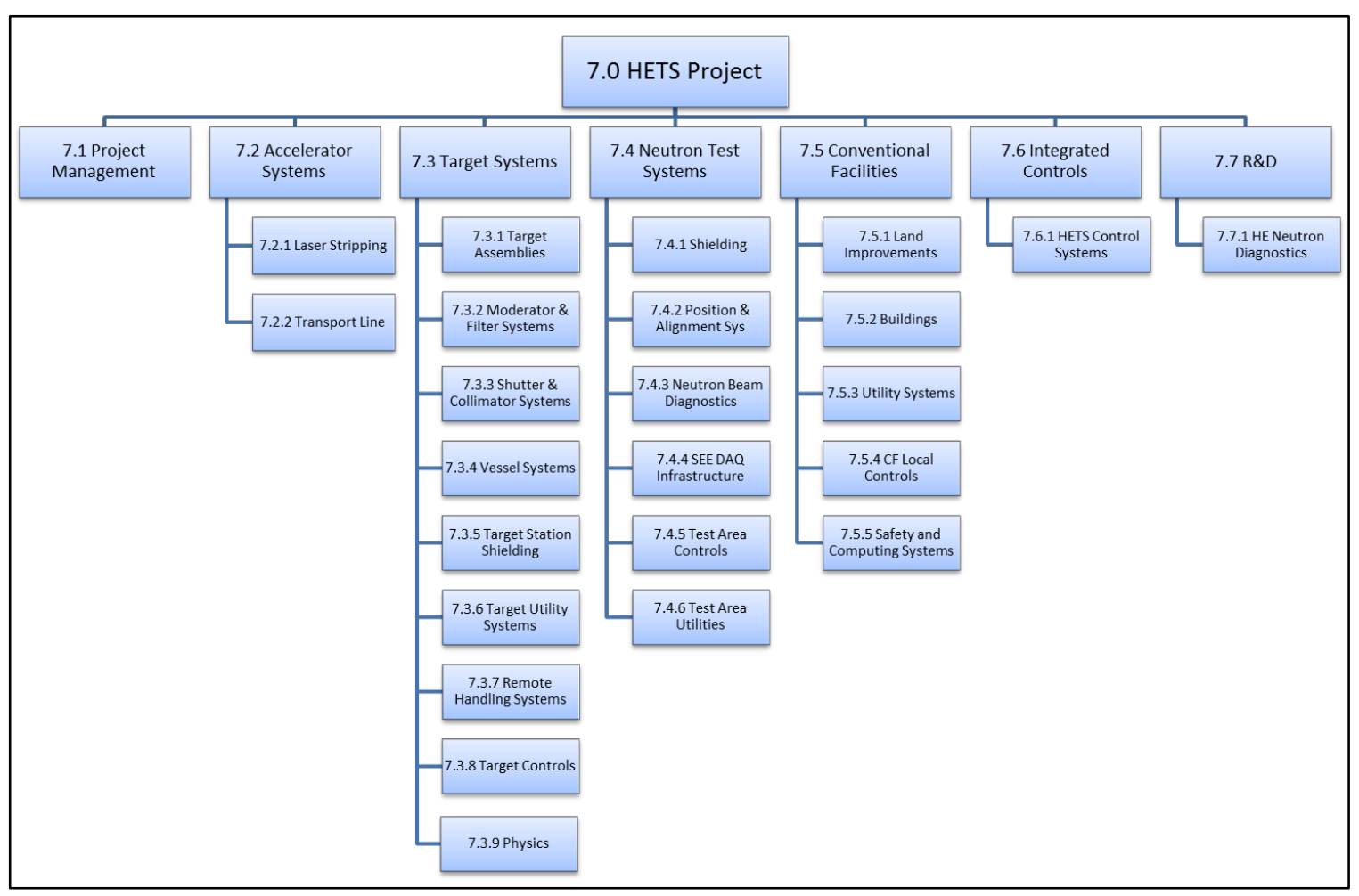

Fig. 4-4. HETS project work breakdown structure.

\subsubsection{Accelerator Sys tems (WBS 7.2)}

It is proposed that the kilowatt-level proton beam be extracted from the main $\mathrm{SNS} \mathrm{H}^{-}$beam between where it is transported from the linac to the beam compression ring (Fig. 4-5). 


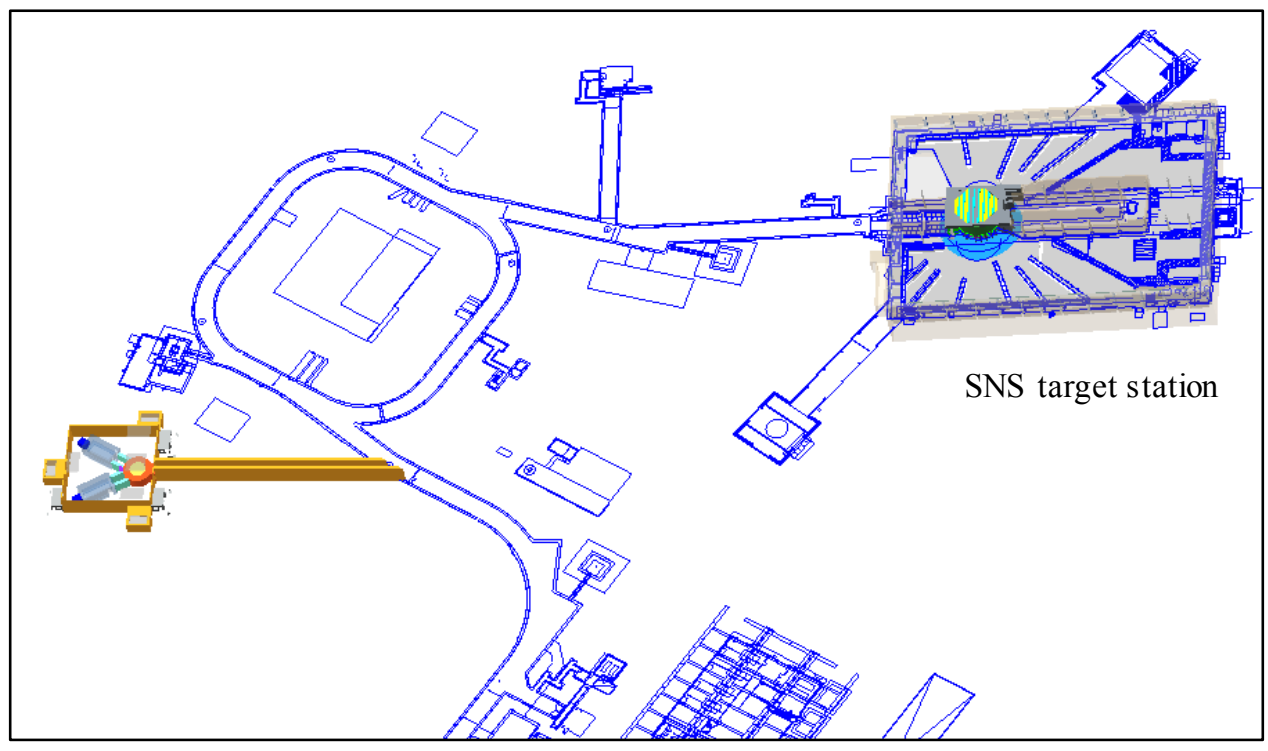

Fig. 4-5. Location of beam extraction from main SNS H beam for HETS.

Figure 4-6 illustrates the setup for beam splitting using the laser stripping technique introduced earlier. Right before entering the last dipole magnet in the HEBT section, the $\mathrm{H}^{-}$beam is exposed to a highintensity laser beam, which causes one electron to strip off from the $\mathrm{H}^{-}$particles. A fraction of beam is stripped from $\mathrm{H}^{-}$to $\mathrm{H}^{0}$, the latter drifting straight through the dipole magnet that separates the neutral and charged beam fractions. The straightly propagating $\mathrm{H}^{0}$ beam is then passed through a thin foil to strip the remaining electron to convert the $\mathrm{H}^{0}$ beam into $\mathrm{H}^{+}$(proton) beam. The once again charged beam is then bent by another dipole magnet to a trajectory towards HETS. Quadrupole magnets in regular spacing along the proton beam line keep the beam focused.

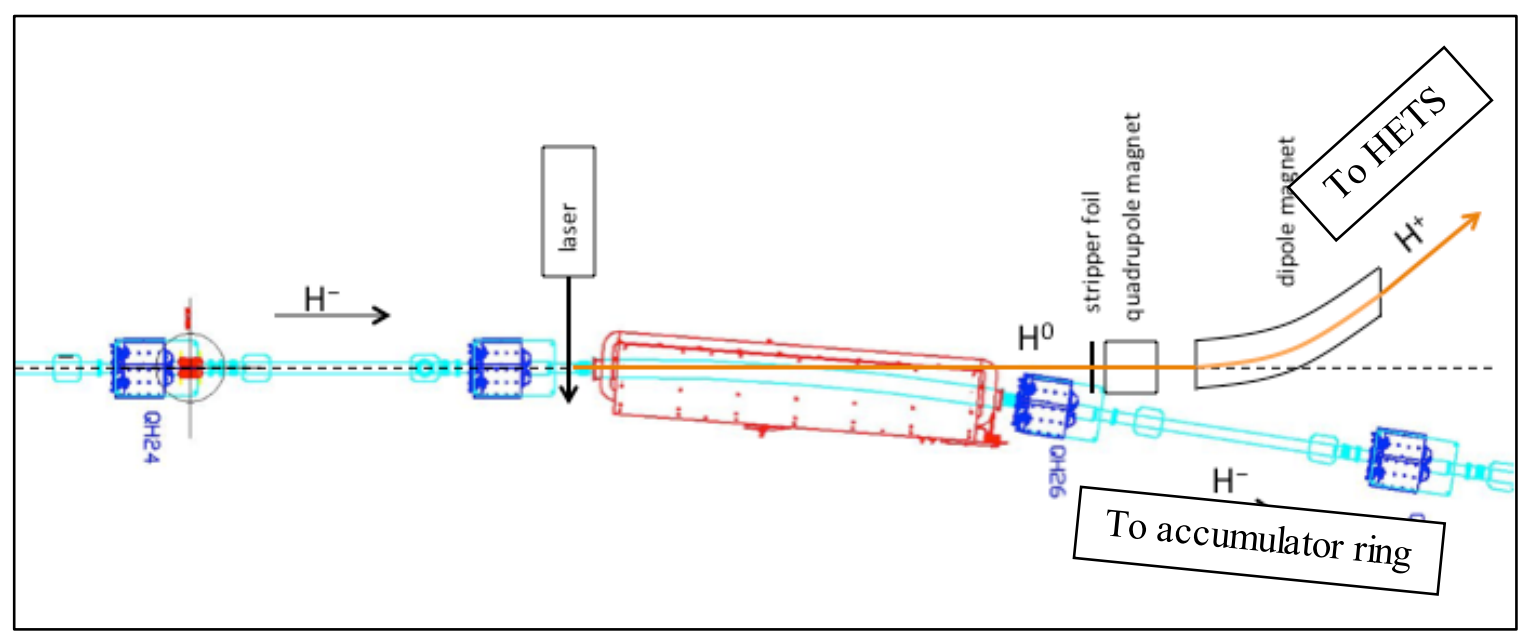

Fig. 4-6. Laser stripping and beam separation of the kilowatt-level beam sent to HETS. 
The laser stripping system will be capable of producing $\mathrm{H}^{+}$beams with as much as $4 \mathrm{~kW}$ power. Beam position monitors and wire scanners will track the $\mathrm{H}^{+}$beam from separation to the target; a beam current monitor will measure the intensity of the proton current delivered to the target.

A new underground tunnel ( $3 \mathrm{~m}$ high, $4 \mathrm{~m}$ wide, and approximately $70 \mathrm{~m}$ long) will house the beam line connecting the SNS tunnel and HETS. Its estimated construction cost is summarized in Sect. 4.1.4, "Conventional Facilities Scope (WBS 7.5)."

All the support equipment and utilities for the HETS proton beam line (water pumps, power supplies, and control racks) will be housed in the HETS building.

\subsubsection{Target Syste ms (WBS 7.3)}

The target station is a shielding monolith with a tungsten target at its center. The target monolith has to attenuate the radiation field generated by the proton beam impact to meet the DOE limits and Oak Ridge National Laboratory (ORNL) policies for radiation protection. Penetrations through the shielding monolith - the so-called beam lines - allow the extraction of neutron beams into again well-shielded experimental areas. The target systems include:

- a proton delivery beam pipe, including a proton beam window;

- a compact, helium-cooled tungsten target;

- a target helium cooling loop;

- insertable moderators for thermal neutron production;

- a core vessel as containment for the high-radiation area;

- two neutron beam lines for high-energy particle extraction with optics components;

- monolith shielding;

- shutters for all beam lines;

- selectable charged particle deflectors and neutron filters for tailoring spectra; and

- target instrumentation, utilities and controls (those not assigned to integrated controls).

WBS 7.3 furthermore covers project efforts on physics (except for accelerator physics), an essential project element for optimizing neutron performance and defining design requirements for the neutron source, test areas and shielding.

The target monolith consists of stacked steel structures interspersed with polyethylene (PE) at a volume ratio of steel to PE of 9/1. In its center, the monolith houses a core vessel of $0.6 \mathrm{~m}$ diameter and $0.5 \mathrm{~m}$ height; the core vessel contains the target and moderators and acts as containment for the high radiation area.

The target, a tungsten rod of $50 \mathrm{~mm}$ diameter and $200 \mathrm{~mm}$ length, is helium cooled within an aluminum vessel.

Two beam lines penetrate the shielding monolith in the horizontal plane, viewing the target at $30^{\circ}$ with regard to the proton beam axis (Fig. 4-2). The best match with an atmospheric neutron and proton spectrum is obtained at this emission angle. The moderators are sized such that in the inserted/filled condition they provide about as much thermal flux intensity as high-energy flux intensity. The neutron beam line openings are tailored to allow the extraction of a $1 \times 2 \mathrm{~m}^{2}$ beam at $14 \mathrm{~m}$ distance from the moderator.

The moderators will either be slabs of PE that can be remotely manipulated or thin aluminum vessels that can be filled with water through a pump and valve system. The moderators will be placed close to the 
target to give maximum exposure to neutrons from the target. A 30-cm thick reflective layer of beryllium will be wrapped around the target and moderator, leaving a direct view of the target and moderator.

The solid cylindrical tungsten target will be cooled by a closed loop of helium gas flow ( 2 bar $2 \mathrm{~mm}$ flow gap, $200 \mathrm{~m} / \mathrm{s}$ gas flow) through an annular flow around the target cylinder (Fig. 4-7). Neutronics and heat removal calculations have been performed to validate this condition. The neutronics evaluation showed that at a proton beam power of $2.3 \mathrm{~kW}$, the heat deposited in the target would be about $1 \mathrm{~kW}$. Peak temperatures in the target of $130{ }^{\circ} \mathrm{C}$ would be easily manageable (Fig. 4-8).

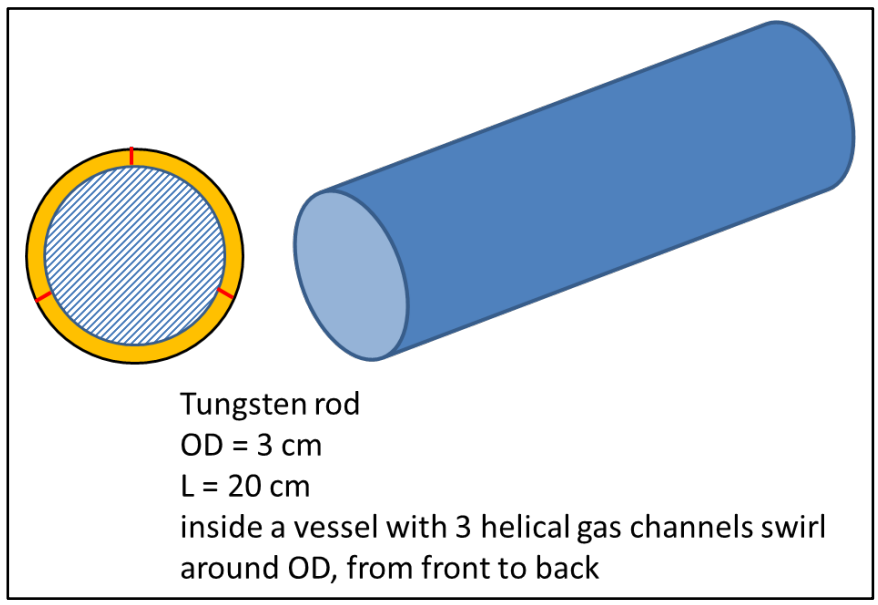

Fig. 4-7. Tungsten target with annular flow gap.
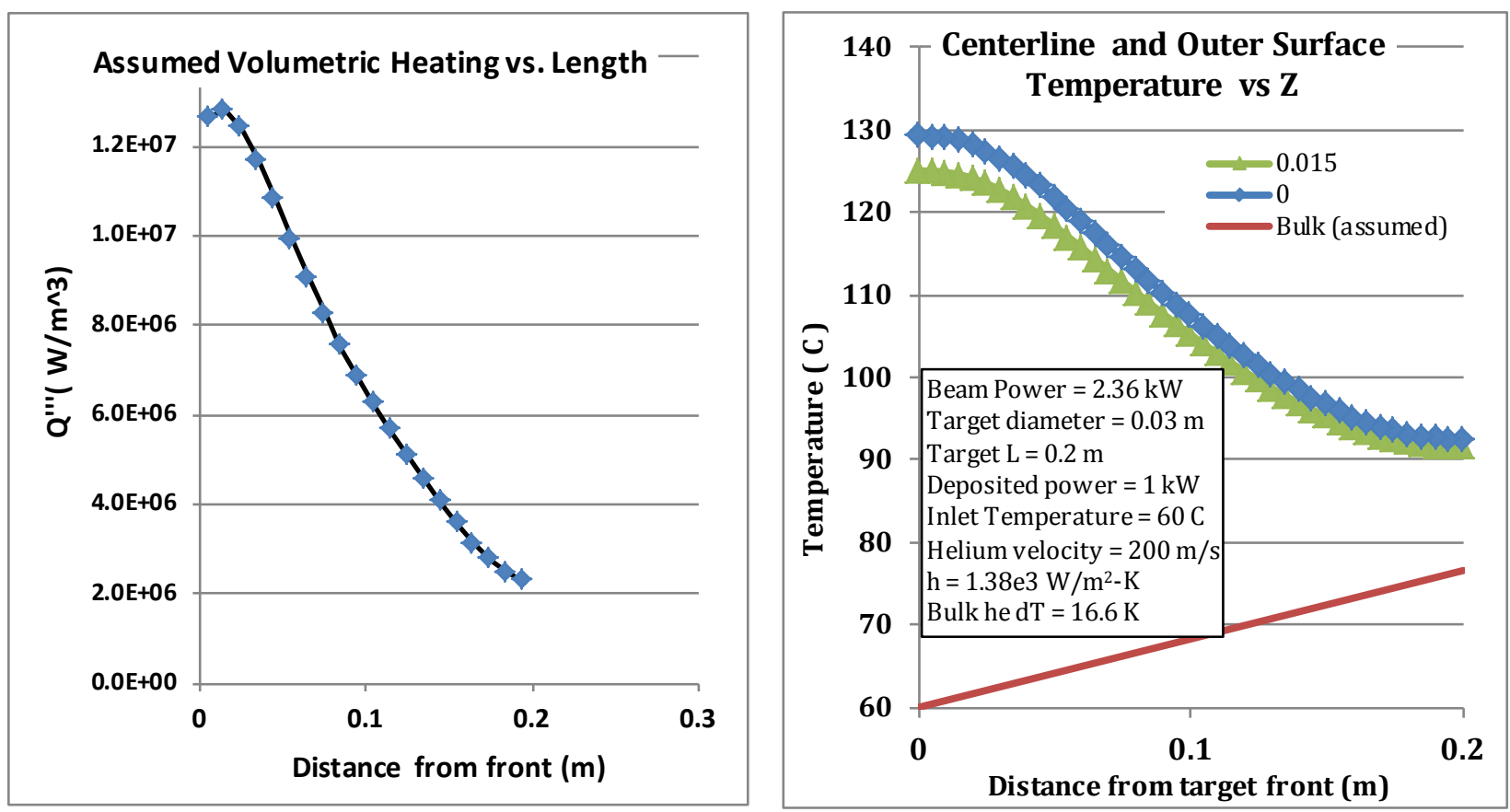

Fig. 4-8. Target axial heat distribution (left) and resulting tungsten centerline and outer surface temperatures (right), assuming $2.3 \mathrm{~kW}$ proton beam power incident on the tungsten target. 
The beam lines contain a number of beam shaping elements housed in the monolith. These components are listed beginning from outside of the target core vessel outward in Table 4-1.

Table 4-1. Beam-shaping components integrated into the high-energy beam line

\begin{tabular}{|c|c|c|}
\hline Component & Function & $\begin{array}{c}\text { Radial } \\
\text { location } \\
\text { (cm) }\end{array}$ \\
\hline Intensity dialer & $\begin{array}{l}\text { Variable collimator to vary the neutron flux at the test location by } \\
\text { restricting the view of the target }\end{array}$ & $30-50$ \\
\hline Charged particle filter & Dipole magnet of 1 Tesla & $60-140$ \\
\hline Spectrum modifier & $\begin{array}{l}\text { Slabs of materials on translation stages acting as transmission filters to } \\
\text { act as spectrum modifiers }\end{array}$ & $150-180$ \\
\hline Shutter/coarse collimator & $\begin{array}{l}\text { Vertically moving shutter with four positions of collimators of varying } \\
\text { sizes }\end{array}$ & $190-290$ \\
\hline Structure/testing area wall & $\begin{array}{l}\text { Shield testing area against particles scattering from the coarse collimator } \\
\text { and target monolith; beam diagnostics placed in wall depth }\end{array}$ & $300-380$ \\
\hline Beam diagnostics & Detectors for reporting delivered beam intensities & $350-380$ \\
\hline Fine collimator & $\begin{array}{l}\text { Sets of vertically and horizontally movable jaws for fine beam size } \\
\text { definition }\end{array}$ & $390-490$ \\
\hline Component test position & Component testing & $500+$ \\
\hline
\end{tabular}

An intensity dialer is an instrument for decoupling the neutron flux level delivered into the testing area from the proton beam intensity delivered to the target. It is required when two (or more) simultaneous tests need different irradiation conditions. The intensity dialer will be a set of 0.20 -m thick tungsten jaws that move horizontally and define the viewed area of the target/moderator system. The maximum beam attenuation of a factor of 100 will be achieved when the tungsten jaws are completely closed, which should be sufficient attenuation to perform component irradiation in one testing area that is receiving full beam intensity and system irradiation in a second testing area with a factor of 400-500 intensity reduction.

The charged particle filter will be used to eliminate the proton, charged pion and muon contributions from the neutron beam when preferred by the users. A homogeneous magnetic field of about 1 Tesla can be applied across the beam line over a length of $0.80 \mathrm{~m}$, which will build sufficient transverse momentum to send the charged particles into the monolith shielding.

The spectrum modifier unit consists of plates of various materials such as polyethylene, boron-carbide, aluminum, copper, and tungsten. These materials have characteristic transmission functions that will be used as generic attenuators, to filter the thermal and epithermal neutrons, and to tune the spectral shape to better fit the atmospheric neutron spectrum.

A massive guillotine steel structure will integrate the functions of the beam line shutter and coarse collimator. This device will make it possible to shut off the beam to one testing area while the second testing area is still served. Additionally, the coarse selection of beam size deep inside the monolith terminates the scattered beam fraction in the established shielding.

The fine collimator will fine tune the beam size delivered to an experiment and allow for beam sizes from $1 \mathrm{~mm}^{2}$ to $0.2 \times 0.2 \mathrm{~m}^{2}$. It will be built from two sets of 0.5 -m-thick steel jaws, providing adjustable slits in the vertical and horizontal directions. It will be possible to move the fine collimator completely out of the beam path for system testing. 


\subsubsection{Neutron Test Systems (WBS 7.4)}

Neutron Test Systems are comprised of the test enclosure shielding, equipment to locate and remotely align user components and systems with the beam, neutron beam diagnostics, DAQ infrastructure (DAQ room, clean power, patch cabling and panels, etc.), test area controls, and utilities. Some controls are covered under integrated controls (e.g., personnel protection systems).

The two testing stations receiving the $30^{\circ}$ neutron beams will be identical. Each testing stations will offer two irradiation positions, one for component testing and one for system testing, in a $9 \times 3 \mathrm{~m}$ interior area. The position for component irradiation will be located at about $5 \mathrm{~m}$ from the target, and the beam line will provide above-10 MeV fluxes up to $10^{7} \mathrm{n} / \mathrm{cm}^{2} / \mathrm{s}$ in areas as large as $20 \times 20 \mathrm{~cm}^{2}$. The position for system irradiation will be located at the far-target position ( $14 \mathrm{~m}$ from the target). Figure 4-9 shows cross sectional views of the proposed facility. At the system position, it will be possible to deliver peak above$10 \mathrm{MeV}$ fluxes up to $1.3 \times 10^{6} \mathrm{n} / \mathrm{cm}^{2} / \mathrm{s}$ over an area of $0.56 \times 0.56 \mathrm{~m}^{2}$ (propagation of component testing beam to the back of enclosure). Alternately, it will be possible to deliver a beam over an area of $1 \times 2 \mathrm{~m}^{2}$ with a peak above-10-MeV fluxes up to $2 \times 10^{5} \mathrm{n} / \mathrm{cm}^{2} / \mathrm{s}$. At these flux levels and beam dimensions, the peak integral in-beam neutron currents are equivalent for all irradiation conditions.

It will be possible to tune the neutron flux intensity in three ways: by the laser intensity in the $\mathrm{H}^{-}$stripping process, by the intensity dialer (target-near collimator), and by the spectrum modifier unit. With this combination of features, the system should be capable of producing a very broad range of flux intensity. Altering the laser intensity directly changes proton power on target; hence, both test areas will be affected.

As a neutron beam enters a test area, real-time diagnostic equipment determines its flux intensity in order to have a means to tailor the beam to user requirements and to quantify the delivered fluence. The neutron beam monitoring and diagnostics are envisioned using a three-part approach. Neutron energy spectra and absolute intensity will be measured by activation foils and proton recoil telescopes during dedicated calibration periods, during which real-time detectors will be calibrated to provide scaling estimates for the established spectral distributions. Active calibration will be provided by a proton-recoil telescope of $1 \mathrm{~cm}^{2}$ rastered across the active area. ${ }^{30}$ For passive calibration and monitoring, activation foil packets will be employed that will be assayed following irradiation. ${ }^{31}$ For real-time monitoring, transistor arrays ${ }^{32}$ and fission chambers ${ }^{33}$ will be deployed. 

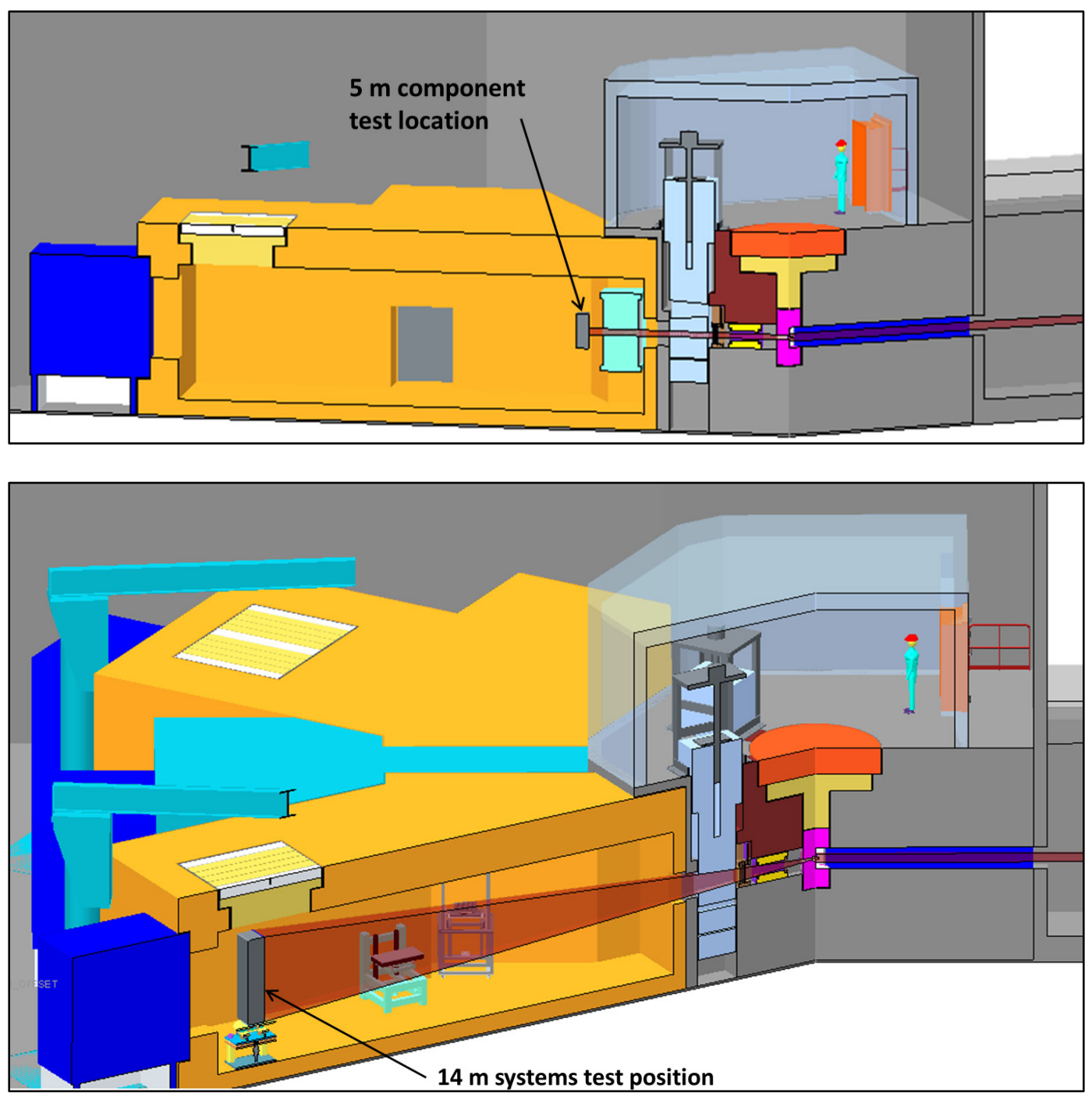

Fig. 4-9. Sectional views of HETS target monolith and test enclosures.

The test enclosure shielding will be designed to accept a high-energy neutron current of $4 \times 10^{8} \mathrm{n} / \mathrm{s}$ and neutron fluxes of $2 \times 10^{6} \mathrm{n} / \mathrm{cm}^{2} / \mathrm{s}$ to the back of the enclosure. Assuming that the beam is scattered by interaction with the testing equipment, shielding walls and ceiling of 2-m thick high-density concrete will be required to attenuate the dose rate to the limit of uncontrolled access of $0.25 \mathrm{mrem} / \mathrm{h}$. The beamstop consists of $0.8 \mathrm{~m}$ steel with a cross sectional area of $1.2 \times 2.2 \mathrm{~m}^{2}$ encased in a $1.5 \mathrm{~m}$ thick layer of highdensity concrete on the side and a $1.8 \mathrm{~m}$ layer of high-density concrete on the downstream side to achieve the same design goal as for the enclosure walls.

The testing stations will be equipped with severalamenities for convenient and flexible experimental setup:

- a controlled temperature and humidity environment;

- electromagnetically shielded testing areas;

- low-noise power through independent grounding grids for each of the testing areas;

- translation stages at the component testing areas, including laser trackers and camera surveillance from different viewpoints for remote and flexible and positioning of the electronics boards; 
- remote control over beam optics components (collimators, filters, and shutters);

- DAQ patch panels for flexible and short electronic connections between the control room and testing areas without discriminating the shielding;

- cable feed-through options for direct electric connections between testing areas and the control room; and

- crane access to the systems irradiation area through a hatch in the testing area enclosure and the HETS building crane.

The testing areas will be accessed through the DAQ/control room area and labyrinths. Access control will be implemented through a personnel protection system (PPS) that senses the status of the main shutter and shuts the access door at beam permit. Prior to allowing beam permit, a protocol of enclosure search will be followed to make sure that the enclosure is emptied by all personnel. The PPS will force an automatic beam termination (either by shutter, by laser trip, or by main SNS beam trip) in case anybody breaks open the access doors or the radiation conditions exceed established limits.

All controls of the experimental areas will be brought together in the test area DAQ and control rooms. These rooms will also house the PPS panel, monitors for SNS and HETS beam status and surveillance cameras in the test areas, and monitors for the environmental conditions in the testing area. The test control room will provide computer access to all the neutron beam optics (collimators, filters, and shutter) and thus control the beam delivery to the experiment. The beam delivery system will record the online beam diagnostic data and provide running fluence tallies for experiment steering. The test area DAQ and control rooms will also provide space for user-provided DAQ equipment that can be hooked up with the electronics in the testing area through the feed-through and or patch panels.

\subsubsection{Conve ntional Facilities (WBS 7.5)}

The conventional facilities section of the WBS covers site land improvements, buildings (including the accelerator tunnel), cooling systems, electric power and other site utilities, facility-wide control systems, waste handling systems, maintenance systems, fire protection, business computing and all other needed support services to accelerator, and target and experimental systems. The HETS facility will be integrated into and benefit from many established on-site SNS and ORNL systems.

The HETS building will be accessible by vehicle or by foot via the SNS North Perimeter Road. It will be an industrial building of about $1000 \mathrm{ft}^{2}$ footprint and $50 \mathrm{ft}$ height that will house the proton beam receiving line, the target monolith, and the test enclosures under one roof. In addition, it will provide space for the proton beam line equipment (power supplies, cooling pumps, and control racks); a HETS systems control room; experiment staging and cooling-down areas; restrooms; and break rooms. A work laydown area for maintenance activities will be available.

Truck access bays for efficient transfer of testing equipment will be provided at both enclosure sides. Building cranes will cover the truck access bays, the enclosures, and the target monolith so that equipment and shielding blocks can be moved efficiently when needed. Secure storage space for equipment will be provided.

Because of its weight, the target monolith has to be secured by piles extending to the Chestnut Ridge bedrock. Excavating for the new tunnel segment and interfacing it with the existing SNS tunnel will be delicate because it will require digging into the HEBT earth berm, which is considered safety relevant shielding during SNS operations. 
Practically all of the utilities (electrical power, water, cooling water, sewage, communications lines) will be available through the nearby RID. Depending on requirements established in future project phases, conventional facilities could provide the utility systems:

- tower cooling water,

- deionized cooling water,

- chilled water,

- building heating water,

- process water,
- $\quad$ sanitary waste,

- potable water,

- demineralized water,

- fire suppression,

- compressed air,
- vacuum,

- process gas distribution, and

- natural gas.

Buildings and systems will comply with industry standards and with federal and local regulations. Besides the above utilities, the building and beam transport tunnel will be equipped with communications lines (phone, internal and external networks) and provide the hookup to all relevant control systems, which are addressed later.

\subsubsection{Integrated Controls (WBS 7.6)}

The HETS facility instrumentation and controls will be integrated into the site-wide SNS control system known as EPICS ${ }^{34}$ that monitors and controls nearly all accelerator, neutron source, and instrument systems. Machine parameters such as delivered proton beam current and shutter positions will be continuously logged. The SNS control system is centrally managed through the SNS control room, but control rooms that are close to subsystems are also used. Such will be the case with many HETS controls.

The neutron beam-relevant systems like collimators, filters, and shutters will be bundled into the respective test area control systems.

From the point of view of radiation protection, the HETS site will be integrated into PPS. The network of active real-time radiation monitors (so-called Chipmunks) will be extended to cover the HETS portion of the transport line, the target station, and the testing enclosure to mitigate off-normal and accidental excessive beam losses by terminating the beam within $2 \mathrm{~s}$ of triggering.

Radiological controls that will be implemented for the testing area include radiological area classifications and postings, radiological surveys, beam fault studies, and radiological work control and ALARA (as low as reasonably achievable) practices similar to those used for neutron beam lines at SNS. The neutron beam line shutters and access doors of the testing enclosures will be controlled by independent control sensors that will be integrated into the PPS system to be able to respond to abnormal conditions such as forced open access doors or elevated readings of radiation monitors.

\subsubsection{R\&D (WBS 7.7)}

HETS as presented here is based almost exclusively on proven technologies. One area requiring development is high-energy neutron beam diagnostics. Because the diagnostic suite must provide vital information to experimenters, development work will be required to prove, qualify, and tune the systems for the needed accuracy.

\subsection{COST}

The cost of the HETS facility in FY 2015 dollars was assessed using the described WBS structure; Table 4-2 summarizes costs at level three (L-3) WBS resolution. Over all, the cost sums up to almost 
$\$ 100$ million. The L-3 costs were burdened with 30\% contingency to cover uncertainties. No contingency was applied to R\&D (research and development). Project Management (WBS 7.1) is estimated at 5\% of project subtotal cost.

Table 4-2. HETS facility cost estimate

\begin{tabular}{|c|c|c|c|c|c|c|}
\hline WBS & 7.0 & HIGH & ENERGY TEST STATION & & & $\$ 99,187,207$ \\
\hline WBS & 7.1 & Project & t Management & & $\$ 4,755,394$ & \\
\hline \multirow[t]{3}{*}{ WBS } & 7.2 & \multicolumn{3}{|c|}{ Accelerator Systems } & $\$ 8,682,960$ & \\
\hline & & 7.2 .2 & Laser Stripping & $\$ 734,084$ & & \\
\hline & & 7.2 .3 & Transport Line & $\$ 7,948,876$ & & \\
\hline \multirow[t]{10}{*}{ WBS } & 7.3 & \multicolumn{3}{|c|}{ Target Systems } & $\$ 22,672,239$ & \\
\hline & & 7.3.2 & Target assemblies & $\$ 173,498$ & & \\
\hline & & 7.3.3 & Moderator and Filter Systems & $\$ 72,519$ & & \\
\hline & & 7.3.4 & Shutter and Collimator Systems & $\$ 2,392,615$ & & \\
\hline & & 7.3.5 & Vessel Systems & $\$ 173,165$ & & \\
\hline & & 7.3.6 & Target Station Shielding & $\$ 17,932,212$ & & \\
\hline & & 7.3.7 & Target Utility Systems & $\$ 36,632$ & & \\
\hline & & 7.3.8 & Remote Handling Systems & $\$ 171,288$ & & \\
\hline & & 7.3.9 & Target Controls & $\$ 320,821$ & & \\
\hline & & 7.3.10 & Physics & $\$ 1,399,489$ & & \\
\hline \multirow[t]{7}{*}{ WBS } & 7.4 & \multicolumn{3}{|c|}{ Neutron Test Systems } & $\$ 25,435,194$ & \\
\hline & & 7.4 .2 & Shielding & $\$ 23,696,365$ & & \\
\hline & & 7.4 .3 & Position and Alignment Systems & $\$ 329,004$ & & \\
\hline & & 7.4.4 & Neutron Beam Diagnostics & $\$ 673,244$ & & \\
\hline & & 7.4.5 & SEE DAQ Infrastructure & $\$ 336,596$ & & \\
\hline & & 7.4.6 & Test Area Controls & $\$ 112,548$ & & \\
\hline & & 7.4.7 & Test Area Utilities & $\$ 287,437$ & & \\
\hline \multirow[t]{4}{*}{ WBS } & 7.5 & \multicolumn{3}{|c|}{ Conventional Systems } & $\$ 36,118,700$ & \\
\hline & & 7.5.2 & Land Improvements & $\$ 6,700,000$ & & \\
\hline & & 7.5.3 & Buildings & $\$ 22,620,100$ & & \\
\hline & & 7.5.4 & Utilities/Communications & $\$ 6,798,600$ & & \\
\hline \multirow[t]{2}{*}{ WBS } & 7.6 & \multicolumn{3}{|c|}{ Integrated Controls } & $\$ 267,583$ & \\
\hline & & 7.6 .2 & HETS Control Systems & $\$ 267,583$ & & \\
\hline \multirow[t]{2}{*}{ WBS } & 7.7 & $R \& D$ & & & $\$ 1,287,470$ & \\
\hline & & 7.7 .1 & HE Neutron Diagnostics & $\$ 1,287,470$ & & \\
\hline
\end{tabular}

The big cost items are shielding (making up $40 \%$ of the cost), followed by buildings $(22 \%$ ), and the proton transport line equipment $(8 \%)$. 


\subsection{TIME TO COMPLETE}

It is estimated that it will take 5 years to complete HETS after award of contract, including engineering design and construction. Commissioning would take at least another 6 months. Interference with SNS principal operations has not been considered in the construction time estimate; connection of the proton transport line and tunnel from the accelerator HEBT and construction around existing site utilities will require careful planning and coordination.

\subsection{LICENSING AND SAFETY}

Prior to operating HETS, safety and environmental evaluations must take place and be formally reviewed and approved. The SNS Final Safety Assessment Document (FSAD) will have to be modified to include HETS. HETS will be a kilowatt power beam facility with a small footprint, and it is expected to fit into the environmental impact envelope of SNS. No unusual waste streams (beyond current SNS wastes) are anticipated during operations of HETS.

The tungsten target will accumulate an inventory of radionuclides which must be reviewed. The expectation is that it can last the life of the facility. Using helium to cool it instead of water avoids loss of coolant accident scenarios where moisture might lead to tungsten vaporization and dispersal from the site. 


\section{SNS BEAM LINE INSTRUMENT / TEST FACILITY}

\subsection{THE ChipIR SEE TEST INSTRUMENT AT THE ISIS TS-2 SPALLATION NEUTRON SOURCE}

We visited the ChipIR instrument at ISIS late in its construction stage (August 2013). The instrument is now being commissioned. Our assessment was that it is poised to become the world's leading site for SEE testing in terms of capabilities for electronic components and systems, neutron spectrum flexibility, DAQ infrastructure, and user accommodations. Using a beam line on the TS-2 spallation source originally designed for cold and thermal neutrons, clever design modifications to the source's beryllium reflector, and use of a special scattering neutron shutter should enable integral flux levels (above $10 \mathrm{MeV}$ ) on components approaching $10^{7} \mathrm{n} / \mathrm{cm}^{2} / \mathrm{s}$ and system irradiations up to $1 \times 1 \mathrm{~m}^{2}$ in size with high energy flux up to $10^{4} \mathrm{n} / \mathrm{cm}^{2} / \mathrm{s}$. Fig. $5-1$ shows a drawing and a photograph of ChipIR.
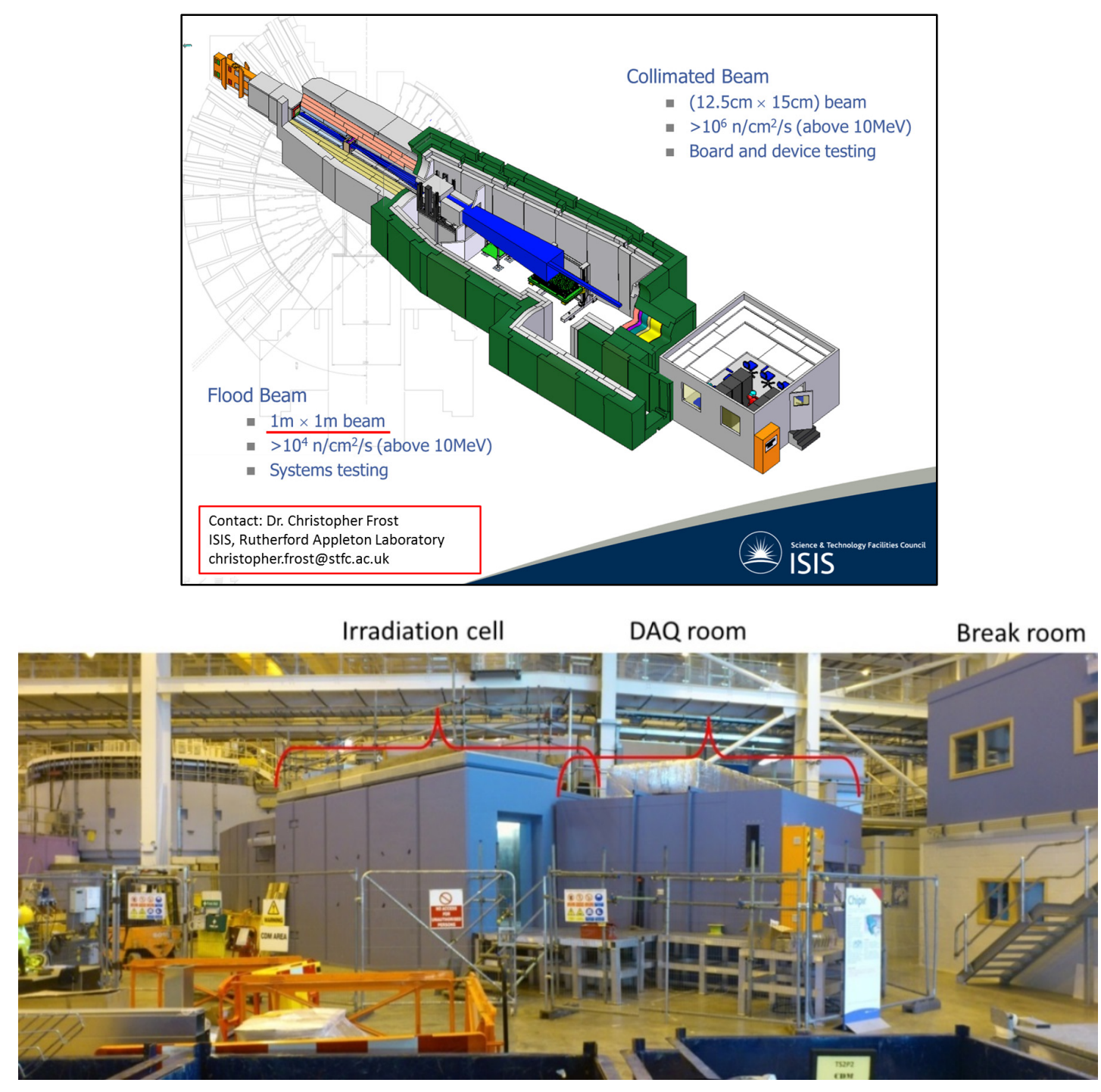

Fig. 5-1. ChipIR at ISIS. Source: Drawing of ChipIR provided by Dr. Christopher Frost, Rutherford Appleton Laboratory. 


\subsection{A ChipIR AT THE SNS IN OAK RIDGE?}

Could a similar SEE test facility be built using an SNS beam line? Technically, the answer is yes. A more modest effort than for the HETS concept was put into developing a concept for a high energy neutron instrument / test station to be located at SNS beam line 8 (BL-8) and describing its potential performance capabilities. BL-8 is a dual channel beam line; it is currently unoccupied. It sits at $49^{\circ}$ off the incident proton direction, which is not ideal but near enough to the optimum $30^{\circ}$ angle to produce a high energy spectrum comparable to a standard atmospheric spectrum. The adjacent beam lines have been built, but the remaining space seems adequate if both channels are combined for a single instrument (Fig. 5-2).
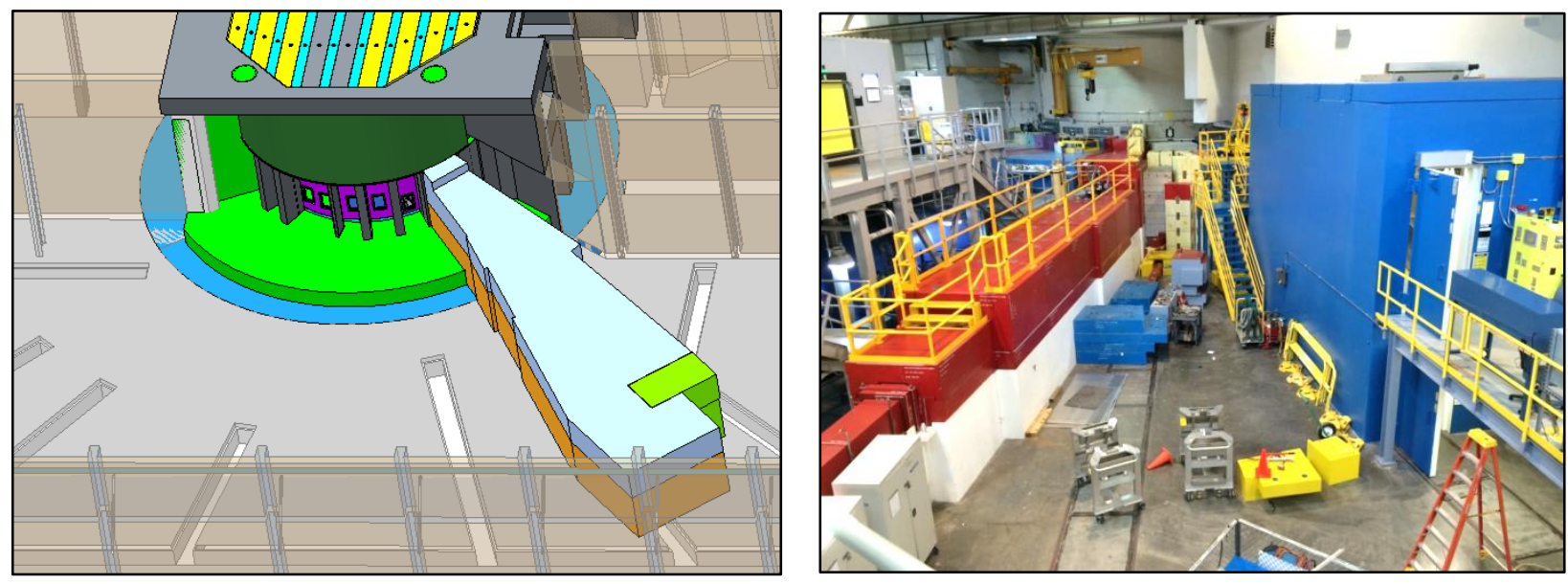

Fig. 5-2. SNS beam line 8 high energy neutron instrument concept (L); space between BL-7 and BL-9 as of July 2014 (R).

BL-10 could also support an instrument for this mission. It has the advantage of having only one neighboring instrument, thus affording some additional lateral space. Another instrument has been proposed for this location, but it is not yet funded. Capabilities and costs would be similar to those for an instrument located at BL-8.

However, these presently open beam lines are highly desirable locations for future neutron scattering instruments and obtaining one of them for an SEE test facility will come only with persuasive and timely arguments to SNS leadership and the DOE BES.

Prospects for beam line assignment aside, an initial characterization of the neutron beam at BL- 8 is shown in Fig. 3-8. As the nominal beam line optics point directly to the water moderator (bottom upstream moderator), the proportion of thermal to high energy neutrons in the spectrum is about 50 and hence large with respect to atmospheric conditions. Some thermal neutrons could be filtered, albeit at expense to the integrated high energy flux. Nevertheless, initial results indicate that very high flux levels for SEE testing are achievable.

For component irradiations at $9 \mathrm{~m}$ from the moderator, $1.8 \times 10^{7} \mathrm{n} / \mathrm{cm}^{2} / \mathrm{s}$ neutrons above $10 \mathrm{MeV}$ would be available without filtering $\left(2 . \times 10^{8} \mathrm{n} / \mathrm{cm}^{2} / \mathrm{s}\right.$ above $\left.1 \mathrm{MeV}\right)$; with filtering $(2 \mathrm{~cm}$ polyethylene and $12 \mathrm{~cm}$ aluminum), this falls to $5.4 \times 10^{6}$ and $2.1 \times 10^{7} \mathrm{n} / \mathrm{cm}^{2} / \mathrm{s}$, respectively. These values are based on 2 MW SNS operation, which is foreseen with accelerator upgrades associated with the proposed Second Target Station Project. ${ }^{35}$ 
It would be necessary to benchmark measurements of the high energy spectrum on the SNS beam line to validate estimated flux values before beginning in-depth development of this design concept. While neutronics simulations have been validated for thermal and cold neutrons at the SNS, and simulations are used with confidence for shielding of high energy neutrons, fidelity for predicting performance of a HE source for an application such as a SEE test facility has not been verified. Nonstandard techniques must be applied to characterize the HE spectrum.

Preliminary design layouts of the instrument / test facility were prepared and are shown in Fig. 5-2(L) and Fig. 5-3. A BL-8 facility would require especially thick shielding, similar to HETS test enclosures.

Large area system irradiations would be done at greater distances (ca. $24 \mathrm{~m}$ ) from the source than at HETS, but some attenuation components would still be necessary to reduce flux to useful levels for testing systems (roughly between $10^{2}$ and $10^{4} \mathrm{n} / \mathrm{cm}^{2} / \mathrm{s}$ ). Unlike HETS, power on target cannot be reduced to serve this instrument's user requirements without affecting all scattering instruments. The BL-8 concept assumes a neutron shutter unique to SNS with two open positions - one for systems and one for components. In addition to having different openings, the systems position would include attenuating material. Further collimation equipment that is adjustable to the user's test needs is also envisioned downstream of the shutter.
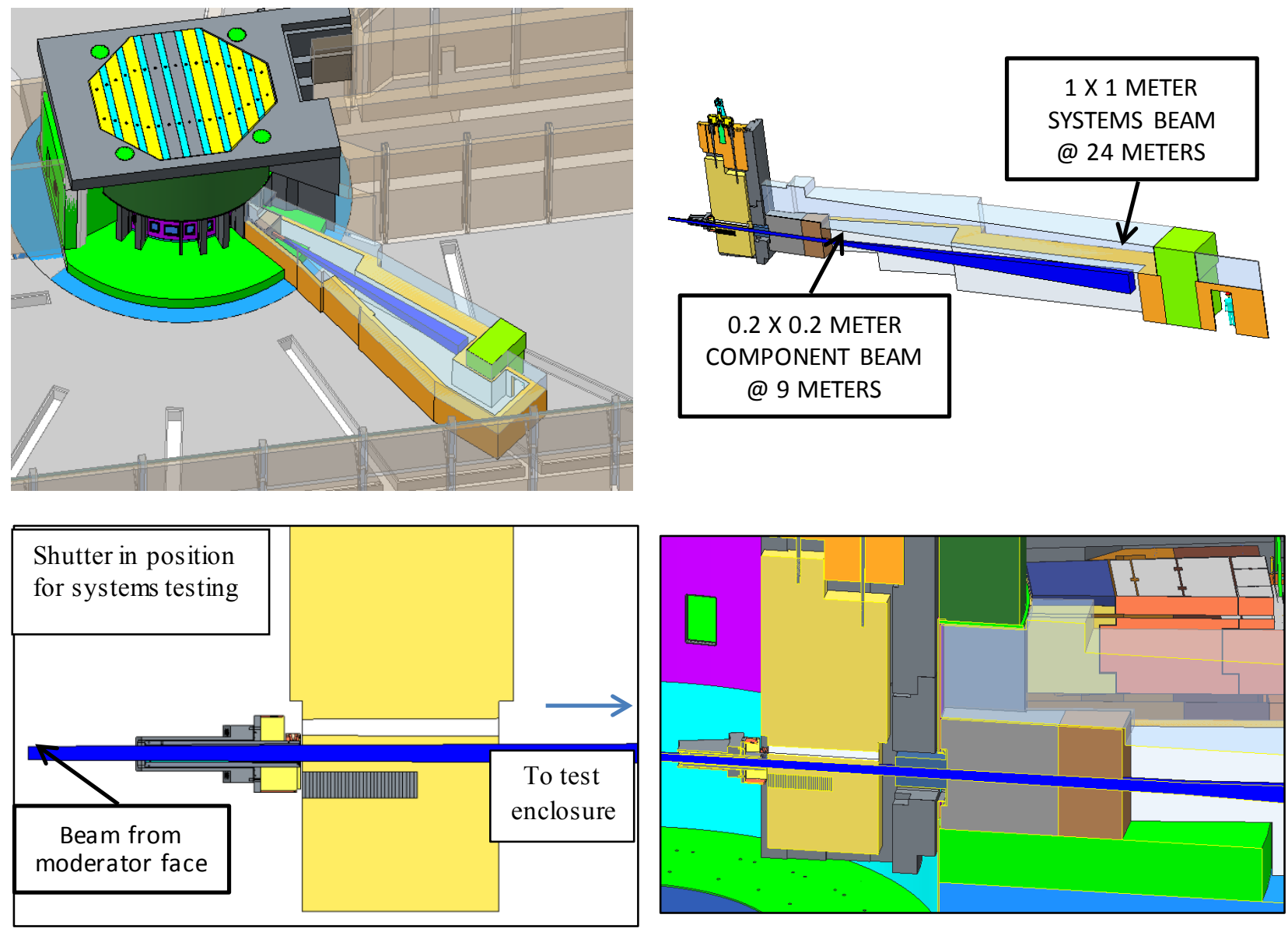

Fig. 5-3. Views of a proposed BL-8 SEE test instrument.

A suite of sample handling equipment, selectable beam filtering, beam diagnostic, and DAQ infrastructure similar to HETS is envisioned for the BL-8 option. However, it is recognized that limited 
space will constrain deployment of all features. For example, the limited space height and width available around the component test area (at the so-called "chopper shelf") would provide less freedom for fine collimation equipment than would be available at a HETS. It is unlikely that a charged particle / pion deflector would be included, but a deflector would not be needed since the beam would be transmitted from scattering through the moderator rather than directly from the target. The substantial required shielding thickness would limit the overall interior height of the test enclosure as external height is limited in the instrument bay to allow for unrestricted crane operations.

Both -A and -B neutron channels would be necessary for a SEE test facility on BL-8. Illuminating a useful system beam spot size will require a special shutter with an opening larger than one of the dual channel openings. The thick shielding required for the enclosure limits the available interior floor space because of restrictions on the extent of external walls. A facility designed around single channel could not provide sufficient interior floor space to serve SEE activities.

\subsection{COST}

The estimated cost to complete a SEE test facility on BL-8 was prepared based on WBS structure and data prepared for the full-featured HETS option. The total estimated cost is \$14.7 million in FY 2015 dollars. There is no accelerator or conventional facilities cost in this estimate. The dominant contribution comes from test enclosure shielding; there is only one test enclosure. Estimated neutron shielding requirements and initial CAD modeling provided volumes for scaling shielding cost. A 50\% contingency factor was applied to all WBS systems (except management) because the concept has not been as well developed as HETS.

Table 5-1.SNS beam line SEE instrument / test facility cost estimate

\begin{tabular}{|c|c|c|c|c|c|}
\hline WBS & 8.0 & & I LINE HIGH ENERGY NEUTRON & TEST INSTRUMENT & $\$ 14,705,216$ \\
\hline WBS & 8.1 & \multicolumn{2}{|c|}{ Project Management } & $5 \%$ & $\$ 732,435$ \\
\hline \multirow[t]{7}{*}{ WBS } & 8.3 & \multicolumn{3}{|c|}{ Neutron Source Systems } & $\$ 3,041,936$ \\
\hline & & 8.3 .3 & Moderator and Filter Systems & $\$ 52,200$ & \\
\hline & & 8.3 .4 & Shutter and Collimator Systems & $\$ 1,102,431$ & \\
\hline & & 8.3 .5 & Vessel Systems & $\$ 27,131$ & \\
\hline & & 8.3 .6 & Target Station Shielding & $\$ 364,269$ & \\
\hline & & 8.3 .8 & Remote Handling Systems & $\$ 91,320$ & \\
\hline & & 8.3 .10 & Physics & $\$ 1,404,585$ & \\
\hline \multirow[t]{7}{*}{ WBS } & \multirow[t]{7}{*}{8.4} & \multicolumn{3}{|c|}{ Neutron Test Systems } & $\$ 9,460,498$ \\
\hline & & 8.4 .2 & Shielding & $\$ 7,918,786$ & \\
\hline & & 8.4 .3 & Position and Alignment Systems & $\$ 222,120$ & \\
\hline & & 8.4 .4 & Neutron Beam Diagnostics & $\$ 776,820$ & \\
\hline & & 8.4 .5 & SEE DAQ Infrastructure & $\$ 216,480$ & \\
\hline & & 8.4 .6 & Test Area Controls & $\$ 129,863$ & \\
\hline & & 8.4 .7 & Test Area Utilities & $\$ 196,429$ & \\
\hline \multirow[t]{2}{*}{ WBS } & 8.6 & \multicolumn{3}{|c|}{ Integrated Controls } & $\$ 215,064$ \\
\hline & & 8.6 .2 & HETS Control Systems & $\$ 215,065$ & \\
\hline \multirow[t]{2}{*}{ WBS } & 8.7 & $R \& D$ & & & $\$ 1,287,470$ \\
\hline & & 8.7 .1 & HE Neutron Diagnostics & $\$ 1,287,470$ & \\
\hline
\end{tabular}




\subsection{TIME TO COMPLETE}

If approved and funded, it is estimated that it would take 3 years for engineering design and construction. An additional 6 months is anticipated for commissioning, after which the first users could begin to work. The potential for construction activities to interfere with primary SNS operations is minimal.

\subsection{LICENSING AND SAFETY}

A beam line instrument / test facility should have no impact on existing SNS licensing or environment impact. 


\section{HIGH-ENERGY NEUTRON CAVE}

\subsection{FACILITY CONCEPT DESCRIPTION}

The title of the work for others statement of work (SOW) is "Definition of Capabilities Needed for a System Test Facility," and its content is clearly focused on avionic systems. The concepts presented in Sects. 4 and 5 (HETS and a SEE test instrument on an SNS beam line) offer not only systems test capability but also comprehensive tools for component testing (i.e., individual ICs or similarly sized components). Component testing is broadly understood to be vital to industrial and institutional research for the foreseeable future, a perspective reinforced in the project review meeting in November 2013 at the FAA William J. Hughes Technical Center. ${ }^{11}$ High flux, flexibility to adjust the spectrum, and the ability to add ions are necessary component test capabilities. Flexibility in testing parameters will make it possible to investigate specific SEE vulnerabilities from particular types of radiation. Indeed, this report's title differs from the SOW in light of these facts to reflect the broader facility requirements.

For the limited scope of system testing, particularly for performing validation / verification tests, the bare need is to simultaneously expose all of the system components to all of the beam components, with above $10-\mathrm{MeV}$ neutron fluxes up to ca. $10^{4} \mathrm{n} / \mathrm{cm}^{2} / \mathrm{s}$, plus a $10-20 \%$ proton component, and - when desired by users - thermal neutrons at similar flux levels. These more limited and rigid requirements could be delivered by a neutron source setup that is simpler and costs less than HETS.

This third, more basic concept would be located off the end of the HEBT part of the SNS accelerator; it would consist of a shielded cave with a bare tungsten target fed by a GeV-energy proton beam. The systems to be tested would be exposed at close distance to the broad radiation field produced by the target in forward direction with respect to the incident proton beam. A thermal beam component would be included by placing a polyethylene and beryllium reflector around the target. The physical setup would be similar to performing SEE testing with a (mono-energetic) neutron generator. It would require proton beam power of only some hundreds of milliwatts. For the moment, this proposed test instrument has been named the High-energy Neutron Cave (HENC) facility. Figure 6-1 shows the proposed location on the SNS site and a concept configuration.
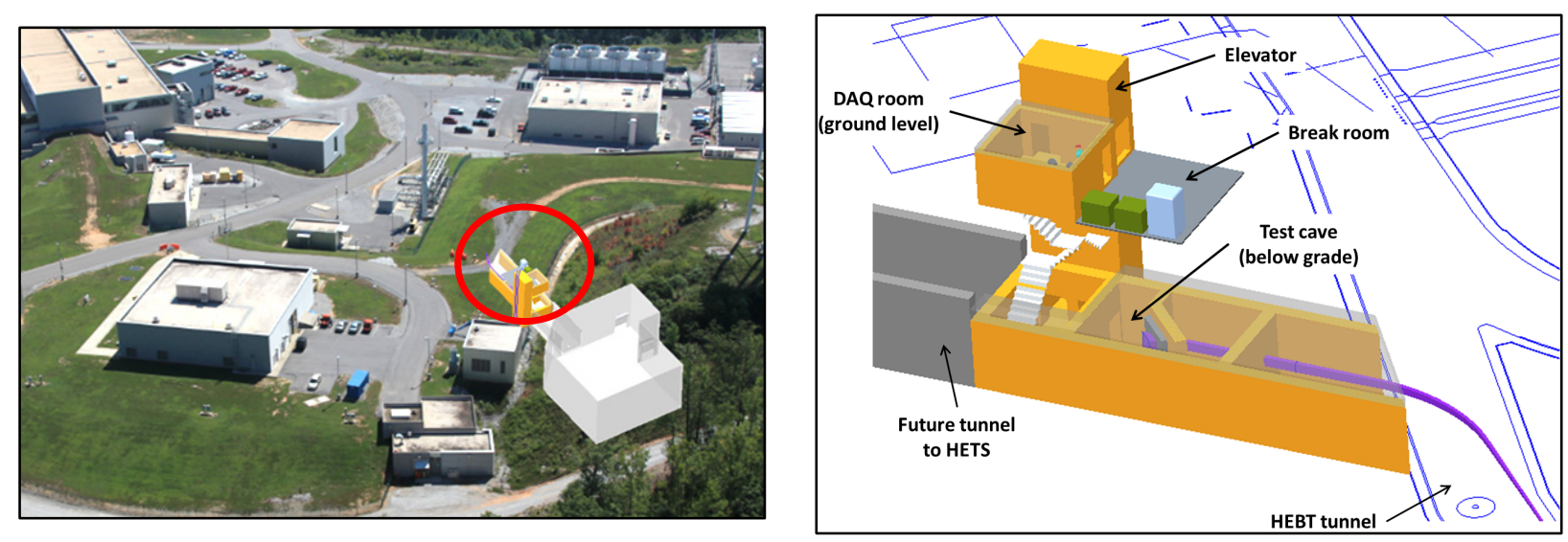

Fig. 6-1. HENC location on SNS site (L) and concept configuration (R).

The cave would be situated in an accelerator tunnel spur with the same configuration as the initial tunnel section conceived for HETS. Indeed, the intention is that this facility could be upgraded to the fully featured HETS at a later time if programmatic needs warrant it and funding becomes available. The tunnel is below ground, as is the entire SNS accelerator. The user DAQ and control room and supporting 
areas would on ground level above the irradiation cave. Access to the cave would be by elevator or stairway.

There are some detriments to this concept. HENC would not be suitable for component testing. Although fairly large systems could be irradiated, the flux uniformity would not be as good as with the other options. No capability to deflect charged particles away from the tested system would be possible. There would be limited ability to adjust the spectrum; the only mechanism would be moving a thermal moderator in and out of position.

\subsubsection{Proton Transport}

The below-watt-level proton beam would be produced in precisely the same way that the beam for the HETS would be produced except that the stripping laser would require much less power. Instead of the $70 \mathrm{~m}$ long proton transport tunnel that would be needed for the HETS, the HENC would require only a $21 \mathrm{~m}$ long dead-end tunnel segment to house the irradiation cave.

Beam position monitors and wire scanners would track the $\mathrm{H}^{+}$beam from HEBT separation to the target, and a beam current monitor would measure the delivered proton current to target. The laser stripping system would be capable of producing $\mathrm{H}^{+}$beams of no more than 300 milliwatt $(\mathrm{mW})$ power.

All the support systems for $\mathrm{H}^{-}$beam stripping and proton beam transport will probably have to be located in a new service building because available room in the ring service building is limited. If the support systems can be made to fit into the ring service building, then some cost savings may be possible, although cable lengths will be longer than if a new building is constructed.

\subsubsection{Target and Irradiation Area}

A tungsten target similar to the HETS target is suitable, but would at most it would be exposed to $50 \mathrm{~mW}$ heating at $300 \mathrm{~mW}$ proton beam power. No active cooling system is required for this level of heating. The target would be placed at the end of the proton beam pipe window. The system irradiation area receives a neutron beam centered at $45^{\circ}$ off the incident proton beam. The above $10 \mathrm{MeV}$ flux level can be tuned by the stripping laser intensity for up to $10^{4} \mathrm{n} / \mathrm{cm}^{2} / \mathrm{s}$.

In a $30^{\circ}$ wide sector between $30^{\circ}$ and $60^{\circ}$, the spectral variation and intensity variation of the neutron flux field may be tolerably small and limited to the high-energy tail as shown in simulation results presented in Fig. 6-2. System irradiation over an area $1 \mathrm{~m}$ wide and $1 \mathrm{~m}$ high at a $2 \mathrm{~m}$ distance is foreseen. The variation in the proton flux is larger; however, protons contribute to the SEE at most $30 \%$ overall. 

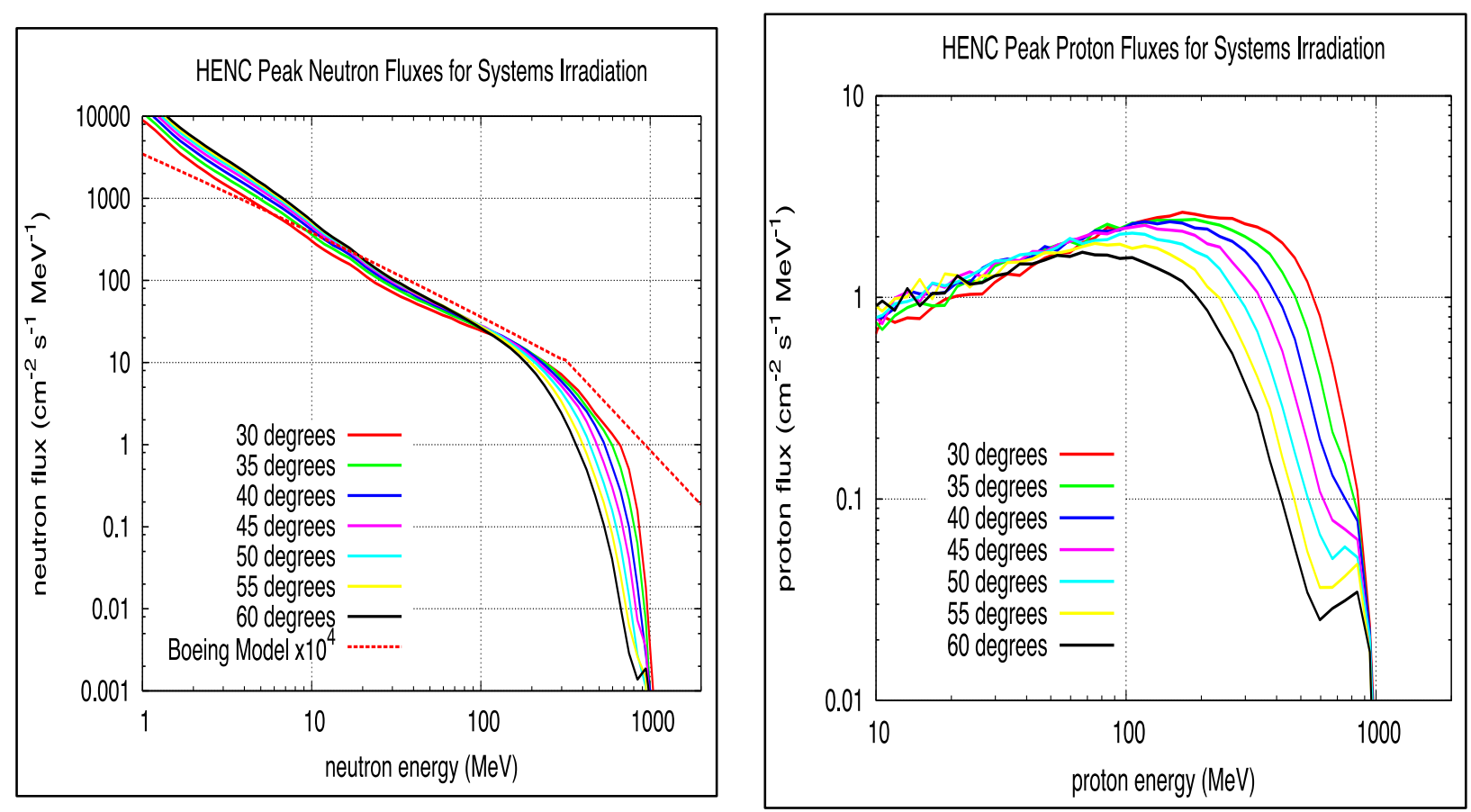

Fig. 6-2. Angular variation of neutron and proton emission spectra from a tungsten target powered by a $0.1 \mathrm{~W}$ proton beam.

The target and testing area would be staged in the tunnel (the cave) as illustrated in Fig. 6-3. Background radiation and area activation would be reduced by separating the target and testing area by a 60 -cm-thick high-density concrete shield wall. In addition, $30 \mathrm{~cm}$ thick vertical and horizontal jaw collimators at the upstream and downstream side of the wall are proposed. This shielding configuration will allow some tailoring of the beam size to the needs of the experimenter and reduce radiation background. Neutron beam monitoring and diagnostics would be located at the downstream side of the shielding/collimator wall. The area upstream of the target to the HEBT tunnel will be filled in with shielding after transport magnets and supporting equipment are installed. 

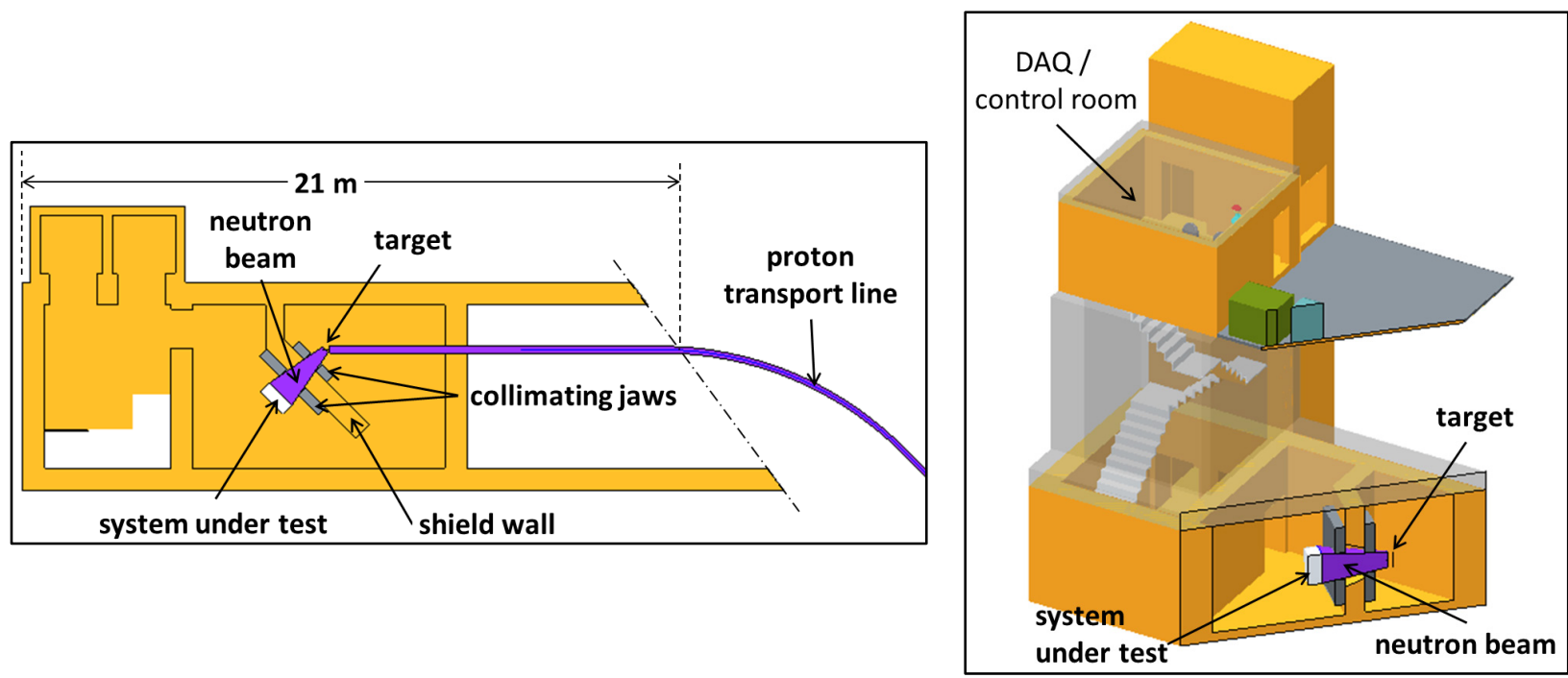

Fig. 6-3. HENC tunnel-cave facility plan (L) and isometric (R) sections.

The facility shielding design must plan for an accident case where the full SNS beam is delivered into the target. Having the DAQ and control room on the surface above a $5 \mathrm{~m}$ thick earth berm and using labyrinth-type access to the testing area will satisfy shielding requirements for this scenario. This shielding arrangement results in more distance between the DAQ equipment and the testing area than the HETS option, whose target is shielded by a complete monolith. Shorter distances would be better for data transmission fidelity, but would incur greater cost.

\subsubsection{Data Acquisition and Control Room}

The DAQ and control room would be located in a new building at ground level; it would be accessible from the ring utility building access road. It would be equipped in a manner similar to the proposed arrangement for HETS. Access to the system irradiation area would be by elevator and/or stairway, both of which would be interlocked by SNS PPS. Local secure storage would be provided, and a truck bay for loading and unloading user equipment will be included. Break and rest rooms can be provided, but access to the SNS Experimental Hall and Central Lab and Office building is better than for HETS.

\subsection{COST}

The cost of the HENC facility in FY 2015 dollars was assessed by utilizing HETS cost spreadsheets and downscaling the WBS elements appropriately. The total project cost estimate comes to $\$ 30.2$ million, as summarized in Table 6-1. Contingency was increased to $50 \%$ on all L-2 WBS elements except Conventional Facilities (7.5) and R\&D (7.7) to cover uncertainties with this less developed design concept. Contingency on Conventional Facilities is $40 \%$; there is no contingency on R\&D. 
Table 6-1. HENC Facility Cost Estimate

\begin{tabular}{|c|c|c|c|c|c|}
\hline WBS & 7.0 & & HIGH ENERGY NEUTRON C & CAVE & $\$ 30,278,669$ \\
\hline WBS & 7.1 & \multicolumn{2}{|c|}{ Project Management } & $5 \%$ & $\$ 1,441,841$ \\
\hline \multirow[t]{3}{*}{ WBS } & 7.2 & \multicolumn{3}{|c|}{ Accelerator Systems } & $\$ 5,411,700$ \\
\hline & & 7.2 .2 & Laser Stripping & $\$ 847,020$ & \\
\hline & & 7.2 .3 & Transport Line & $\$ 4,564,680$ & \\
\hline \multirow[t]{10}{*}{ WBS } & 7.3 & \multicolumn{3}{|c|}{ Target Systems } & $\$ 2,764,978$ \\
\hline & & 7.3.2 & Target as semblies & $\$ 110,880$ & \\
\hline & & 7.3 .3 & Moderator and Filter Systems & $\$ 46,476$ & \\
\hline & & 7.3.4 & Shutter and Collimator Systems & $\$-$ & \\
\hline & & 7.3.5 & Vessel Systems & $\$ 52,230$ & \\
\hline & & 7.3.6 & Target Station Shielding & $\$ 742,957$ & \\
\hline & & 7.3.7 & Target Utility Systems & $\$-$ & \\
\hline & & 7.3.8 & Remote Handling Systems & $\$ 197,640$ & \\
\hline & & 7.3.9 & Target Controls & $\$-$ & \\
\hline & & 7.3.10 & Physics & $\$ 1,614,795$ & \\
\hline \multirow[t]{7}{*}{ WBS } & 7.4 & \multicolumn{3}{|c|}{ Neutron Test Systems } & $\$ 2,279,541$ \\
\hline & & 7.4 .2 & Shielding & $\$ 911,960$ & \\
\hline & & 7.4.3 & Position and Alignment Systems & $\$ 111,120$ & \\
\hline & & 7.4.4 & Neutron Beam Diagnostics & $\$ 747,900$ & \\
\hline & & 7.4 .5 & SEE DAQ Infrastructure & $\$ 216,480$ & \\
\hline & & 7.4 .6 & Test Area Controls & $\$ 95,651$ & \\
\hline & & 7.4 .7 & Test Area Utilities & $\$ 196,429$ & \\
\hline \multirow[t]{4}{*}{ WBS } & 7.5 & \multicolumn{3}{|c|}{ Conventional Systems } & $\$ 16,897,000$ \\
\hline & & 7.5 .2 & Land Improvements & $\$ 5,000,000$ & \\
\hline & & 7.5.3 & Buildings & $\$ 6,595,100$ & \\
\hline & & 7.5.4 & Utilities/Communications & $\$ 5,301,900$ & \\
\hline \multirow[t]{2}{*}{ WBS } & 7.6 & \multicolumn{3}{|c|}{ Integrated Controls } & \$ 196,139 \\
\hline & & 7.6 .2 & HENC Control Systems & $\$ 196,139$ & \\
\hline \multirow[t]{2}{*}{ WBS } & 7.7 & $R \& D$ & & & $\$ 1,287,470$ \\
\hline & & 7.7.1 & HE Neutron Diagnostics & $\$ 1,287,470$ & \\
\hline
\end{tabular}

\subsection{TIME TO COMPLETE}

The time to complete the HENC is expected be more than 3 years, with an additional 6 months for commissioning. Here again, construction interference with SNS operations has not been accounted for and could have significant impact on how long it might take for operations to begin.

\subsection{LICENSING AND SAFETY}

Prior to operating HENC, safety and environmental evaluations must take place and be formally reviewed and approved. Modification to the SNS FSAD is needed. 
HENC is a $\sim$ watt beam power facility with a small footprint, and it is expected to fit into the environmental impact envelope of SNS. No unusual waste streams (beyond current SNS wastes) are anticipated during operations of HENC. 


\section{SUMMARY}

Authors and contributors of this study investigated SEE testing practices around the world and developed an understanding of future testing requirements through communication with the project sponsor, industry, literature searches, and facility tours. The SNS - with its $1.0 \mathrm{GeV}$ protons $(1.3 \mathrm{GeV}$ with the Second Target Station upgrade), typical operation of $5000 \mathrm{~h}$ per year, expertise in spallation neutron sources, user program infrastructure, and decades of useful life ahead-is ideally suited for hosting a world-class SEE test facility. A number of options at the SNS were considered, but ultimately the choices were reduced to three. The three proposed facilities offer different levels of functionality, performance, cost, and programmatic viability; all can address system testing needs.

Delivery and acceptance of this report serve as the final deliverable for the WFO study project. Advancing a SEE test facility at the SNS will require a strategic and sustained effort involving all stakeholders. The SNS staff stands ready to contribute. 


\section{REFERENCES}

1. Oak Ridge National Laboratory Neutron Sciences, Spallation Neutron Source, http://neutrons.ornl.gov/facilities/SNS/, accessed September 2014.

2. L. Dominik, "Atmospheric Radiation Testing," presentation at 2012 National User Facility Organization meeting, Los Alamos, N.M., June 2012, https://www.nufo.org/meetings/files/2012 Laura Dominik.pdf, accessed September 2014.

3. R. Edwards, C. Dyer, and E. Normand, Technical Standard for Atmospheric Radiation Single Event Effects, (SEE) on Avionics Electronics, Standard 0-7803-8697-3/04, IEEE, 2004.

4. R. Heald, "How Cosmic Rays Cause Computer Downtime," presentation at IEEE Reliability Society, Santa Clara Valley Meeting, March 23, 2005, http://www.ewh.ieee.org/r6/scv/rl/articles/ser-050323talk-ref.pdf, accessed September 2014.

5. V. Danilov et al., "Proof-of-principle Demonstration of High Efficiency Laser-assisted $\mathrm{H}^{-}$Beam Conversion to Protons," Phys. Rev. ST Accel. Beams 10, 053501 , May 2007.

6. C. Frost, "A New Dedicated Neutron Facility for Accelerated SEE Testing at the ISIS Facility," in Reliability Physics Symposium, 2009 IEEE International, Proceedings of the IEEE $47^{\text {th }}$ Annual Reliability Physics Symposium, Montreal, April 2009, ISBN 978-1-4244-2889-2/09, 2009.

7. ChipIR website: http://www.isis.stfc.ac.uk/instruments/chipir/chipir8471.html, accessed September 2014.

8. ISIS web site, http://www.isis.stfc.ac.uk/, accessed September 2014.

9. B. Takala, "The ICE House: Neutron Testing Leads to More-Reliable Electronics," Los Alamos Science 30, 2006, http://library.lanl.gov/cgi-bin/getfile?30-12.pdf, accessed September 2014.

10. S. Wender, "Neutron-Induced Failures in Semiconductor Devices," Presentation at Workshop on Fast Neutron Applications at Spallation Sources, Abingdon, UK, 2013, http://plone.esss.lu.se/fastneutrons-workshop, accessed September 2014.

11. FAA William J. Hughes Technical Center, http:/www.faa.gov/about/office org/headquarters offices/ang/offices/tc/, accessed September 2014

12. IEC International Standard 62396-1, "Process Management for Avionics-Atmospheric Radiation Effects-Part 1: Accommodation of Atmospheric Radiation Effects via Single Event Effects within Avionics Electronic Equipment," March 2006.

13. IEC International Standard 62396-2, "Process Management for Avionics-Atmospheric Radiation Effects-Part 2: Guidelines for Single Event Effects Testing for Avionics Systems," August 2008.

14. IEC Technical Specification 62396-5, "Process Management for Avionics-Atmospheric Radiation Effects - Part 5: Guidelines for Assessing Thermal Neutron Fluxes and Effects in Avionics Systems," August 2008.

15. C. Dyer and F. Lei, "Monte Carlo Calculations of the Influence on Aircraft Radiation Environments of Structures and Solar Particle Events," IEEE Transactions on Nuclear Science 48, No. 6, 1987, December 2001.

16. JEDEC Standard No. 89A, "Measurement and Reporting of Alpha Particle and Terrestrial Cosmic Ray-Induced Soft Errors in Semiconductor Devices," Arlington, Va., 2006.

17. LANSCE Activity Report 2012: Building the Foundation for New Capabilities, LA-UR-13-28295, Los Alamos National Laboratory, Los Alamos, N.M., October 2013. 
18. E. W. Blackmore, "Development of a Large Area Neutron Beam for System Testing at TRIUMF," Proceedings of the 2009 IEEE Radiation Effects Data Workshop, Quebec City, IEEE Nuclear and Plasma Sciences Society, pp. 157-60, July 2009.

19. A. V. Prokofiev et al., "Characterization of the ANITA Neutron Source for Accelerated SEE Testing at the Svedberg Laboratory," Proceedings of the 2009 IEEE Radiation Effects Data Workshop, Quebec City, IEEE Nuclear and Plasma Sciences Society, pp. 166-73, July 2009.

20. Y. Iwamoto et al., "Evaluation of the White Neutron Beam Spectrum for Single-event Effects Testing at the RCNP Cyclotron Facility," Nuclear Technology 173,210, February 2011.

21. Research Center for Nuclear Physics, Osaka University, https://www.rcnp.osaka-u.ac.jp/index.html, accessed September 2014.

22. L. Dominik et al., "Proposal for a New Integrated Circuit and Electronics Neutron Experiment Source at Oak Ridge National Laboratory," in Reliability Physics Symposium, 2009 IEEE International, Proceedings of the IEEE $47^{\text {th }}$ Annual Reliability Physics Symposium, Montreal, pp. 940-947, April 2009.

23. Los Alamos Neutron Science Center Activity Report 201 1, LA-UR-12-24471, Los Alamos National Laboratory, Los Alamos, N.M., September 2012.

24. LANSCE (Los Alamos Neutron Science Center) Activity Report 2010, LA-UR-11-05580, Los Alamos National Laboratory, Los Alamos, N.M., September 2011.

25. F. Lei et al., "Improvement to and Validations of the QinetiQ Atmospheric Radiation Model (QARM)," IEEE Transactions on Nuclear Science 53, No. 4, 1851, August 2006.

26. C. Dyer et al., "The QinetiQ Atmospheric Radiation Model and Solar Particle Events," presentation at the Third European Space Weather Week, Brussels, November 13-17, 2006, http://sidc.oma.be/esww3/, accessed September 2014.

27. S. Roesler, W. Heinrich, and H. Schraube, "Calculation of Radiation Fields in the Atmosphere and Comparison to Experimental Data," Radiation Research 149, 87 (1998).

28. D. B. Pelowitz, ed., MCNPX User's Manual, Version 2.7.0, Los Alamos National Laboratory report LA-CP-11-00438 (April 2011).

29. J. F. Ziegler and W. A. Lanford, "Effect of Cosmic Rays on Computer Memories," Science 206, No. 4420, 776 (November 16, 1979).

30. G. Ban et al., "A telescope for monitoring fast neutron sources", Nuclear Instruments \& Methods In Physics Research Section A- Accelerators Spectrometers Detectors And Associated Equipment 577(3), pp. 696-701, 2007.

31. E, Kim et al., "Measurements of neutron spallation cross sections of C-12 and Bi-209 in the 20- to 150-MeV energy range", Nuclear Science and Engineering 129(3), pp. 209-223, 1998.

32. J. Mekki et al., "Prediction of the response of the commercial BPW34FS silicon p-i-n diode used as radiation monitoring sensors up to very high fluences", IEEE Trans.Nucl.Sci.,57, pp. 2066-2073, 2010

33. S. A. Wender et al., "A Fission Ionization Detector for Neutron Flux Measurements at a Spallation Source", Nuclear Instruments \& Methods in Physics Research A, 336, pp. 226-231, 1993.

34. EPICS (Experimental Physics and Industrial Control System), http://www.aps.anl.gov/epics/index.php, accessed September 2014.

35. J. K. Zhao et al., "Optimizing moderator dimensions for neutron scattering at the spallation neutron source”, Rev. Sci. Instrum. 84, 125104 (2013). 
APPENDIX A. NOTES FROM REVIEW MEETING AT FAA WILLIAM J. HUGHES TECHNICAL CENTER, ATLANTIC CITY, NJ, NOVEMBER 7, 2013 (B. RIEMER) 



\section{APPENDIX A. NOTES FROM REVIEW MEETING AT FAA WILLIAM J. HUGHES TECHNICAL CENTER, ATLANTIC CITY, NJ, NOVEMBER 7, 2013 (B. RIEMER)}

Attending:

1. SNS: Bernie Riemer, Franz Gallmeier

2. FAA: John Zvanya (project technical contact), Charles (Chuck) Kilgore II (project manager)

3. Honeywell: Laura Dominik

4. By telecom: Gary Horn (FAA), Srini Mandalapu (FAA)

The meeting took place in John Zvanya's building, which was apart from the central office. We proceeded through the agenda beginning at 9 AM. The review was informally conducted, i.e., we had lots of discussion as topics were presented. By noon, we'd only gotten through Bernie's first talk.

- Chuck Kilgore had expressed concerns regarding Laura Dominik's participation in the project, from the perspective that Honeywell could be perceived as having preferential influence. It had to be explained about her lead AVSI and IEC committee roles as an industry representative.

- There was concurrence on the requirement that any facility should be capable for both system and component testing. However, it is difficult to pin down the specific maximum system size, and the range of fluxes required for systems and components testing.

- Laura strongly expressed the view that high-energy flux needs to get down to $1 \mathrm{MeV}$, even though contemporary standards work to $10 \mathrm{MeV}$ and above.

- Considerable discussion took place on the role of thermal neutrons and capabilities of a new facility. Clear consensus was that thermal neutrons are needed at times, depending on what's being tested.

- There are JEDEC standards beyond what we have (62396-1). There are -2, -3, -4 and -5 . We need to look at -5 in particular as it addresses thermalneutrons.

- Wider flexibility in facility performance (flux, thermal neutrons) is desired. Cost trade-offs are needed to understand what you get for how much.

- Time for facility completion is also important to the FAA. There was a sense of urgency in their discussion.

- Upgradeability. If possible, design / build in a way that allows increasing testing capacity or performance.

- Gary Horn was thinking on system size: "bread box". I'm thinking $1 \mathrm{~m} x 2 \mathrm{~m}$ minimum. The former may be from his aircraft avionics perspective, but we should not forget about ground based systems testing, e.g., a standard electronics rack.

- John Zvanya and Gary: why do the same as another facility? I agree: we should meet or exceed Chipir capabilities. How much to exceed depends on cost.

- Laura Dominik: cable length from test component to DAQ equipment can be an issue. Minimize length, or provide "repeater" capability.

- Laura: beam characterization. One issue is characterizing the true effect of stacking boards or chips in series. They want to know better what each board really gets. A better way than attenuation estimators provided by LANSCE.

- Yes, some interest in sample environment: temperature, pressure.

- Studies are now in progress on the role / need for protons, pions and muons in SEE testing. For now, should plan on capability to eliminate charged particles on test components. But it could be that they are needed. Not clear that - if present - they are harmful to testing. 
- There was no resistance to designing for uses other that aircraft avionics. Rather there was encouragement. Generally, designing the facility for performance flexibility was deemed as wise, in particular with respect to unclear future testing needs. Flux intensity, energy range, spectrum shape, system size, other particles.

- On the other hand, cost and time to get a facility up and running are also important to the FAA and industry. The "Chipir" approach therefore had strong appeal. We made clear the sensitivities on this option with our BES sponsor, which they understood. We asked for time to work this issue, but I said I expect to have feedback by next spring, if not earlier.

-BWR November 11, 2013 
APPENDIX B. PRESENTATION "NEUTRON TEST FACILITY INDUSTRY AND FAA VIEW" (G. HORAN, FAA) 

APPENDIX B. PRESENTATION "NEUTRON TEST FACILITY - INDUSTRY AND FAA VIEW" (G. HORAN, FAA)

\section{Neutron Test}

Facility

Industry and FAA View

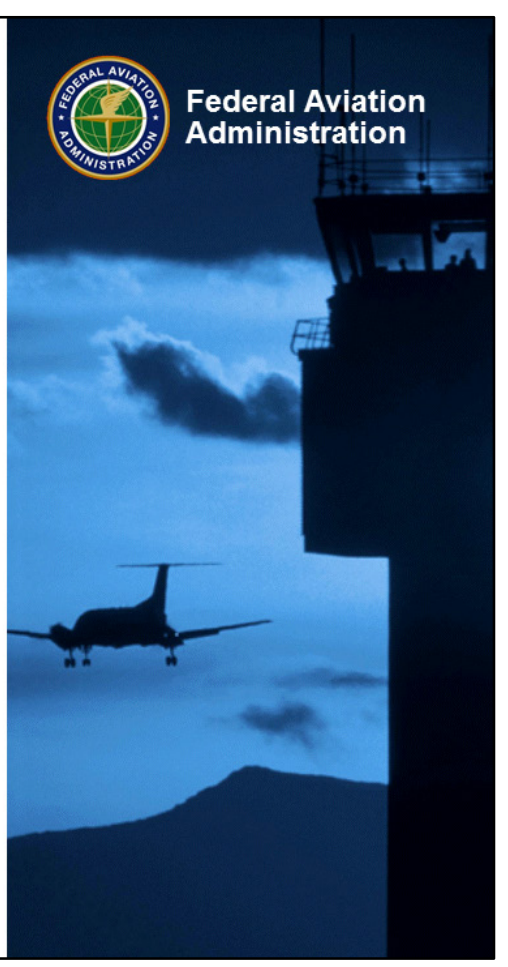

Presented to: SNS Managers

By: Gary Horan, ANE-111/AIR-120

Date: November 2013

\section{Overview}

- Atmospheric Radiation and Single Event Effects

- Standards and Regulatory Requirements

- Need for New Cosmic Ray Neutron Simulation Facility 


\section{Atmospheric Radiation and Single}

Event Effects

- Radiation effects recognized in recent years as safety concern for current and future silicon-based technologies

- Neutrons are mainly responsible for causing single event effects

- Altitude and latitude are factors in the varying neutron flux

- Single Event Effects (SEE)

- Disturbance of an active electronic device caused by energy deposited from the interaction with a single energetic particle

- An event occurs when an ionization charge from the energy deposition exceeds the device critical charge

- Resulting in:

- Corrupted data; including Hazardous Misleading Information

- CPU halts and interrupts

- Unplanned events; including system failure

\section{Technology Trends means}

\section{Increased Risk}

- Increased soft error risk due to

- Smaller circuit dimensions and lower voltage

- Typical charge found at storage nodes decreases

- Takes less energy to disturb stored information

- Stored bit values are more easily corrupted

- Cannot extrapolate behavior of future IC technologies from older devices

- Dramatic increase in multiple cell upset for $90 \mathrm{~nm}$ parts

- Thermal radiation becoming more of an issue 


\section{AVSI}

- Aerospace Vehicle Systems Institute (AVSI)

- Cooperative of aerospace companies, FAA and DoD

- Task Group 72 Charter - Mitigating Radiation Effects on Current and Future Avionics Systems

- Long Term Objective

- Develop approach for cost effective test method/simulation/analysis for device level failure rates

- Key step

- Ensure availability of atmospheric radiation test facilities

\section{Reasons for Atmospheric Radiation Testing}

Regulatory Authorities working in conjunction with Industry Groups

Regulatory Requirements

- EASA CM No.: EASA CM SWCEH - 001 Issue: 01. Requires SEU analysis and its inclusion into the safety process

- EASA CRI

- FAA Issue Papers - Safety Impact of the FADEC's Susceptibility to Atmospheric Neutrons

- EASA and FAA plan to issue additional guidance in 2014
Industry Standards Development

- SAE S-18 \& Eurocae WG-63

- ARP4761A / ED-135 - due in 2013 will address SEE - Supported by AVSI AFE72

- AIR6219 / ER-008 - SEE Safety Analysis - being drafted by S18/WG-63/AVSI AFE72 


\section{Current Industry Standards}

- IEC62396-1 Process Management for Avionics - Atmospheric Radiation Effects - Part 1: Accommodation of atmospheric radiation effects via single event effects within avionics electronic equipment (2012)

- IEC62396-2 - Guidelines for single event effects testing for avionics systems (2012)

- IEC/TS62396-3 - Guidelines to optimize avionics system design to reduce single event effects rates (2008)

- IEC/TS62396-4 - Guidelines for designing with high voltage aircraft electronics and potential single event effects (2008)

- IEC/TS62396-5 - Guidelines for assessing thermal neutron fluxes and effects in avionics systems (2008)

- JEDEC Standard, JESD89A, "Measurement and Reporting of Alpha Particle and Terrestrial Cosmic Ray-Induced Soft Errors in Semiconductor Devices", 2006.

- JEDEC Standard, JESD89-3, Test Method for Beam Accelerated Soft Error Rate

\section{Proposed Additional Standards}

- Addition of SEE topic to ARP4761A - Guidelines and Methods for Conducting the Safety Assessment Process on Civil Airborne Systems and Equipment

- AIR 6219 Development of Atmospheric Neutron Single Event Effects Analysis for use in Safety Assessments

- IEC62396-6 Extreme Space Weather

- IEC62396-7 Process for Incorporating Radiation Analysis into System Design Process

- Update to JEDEC Standard, JESD89-3, Test Method for Beam Accelerated Soft Error Rate 


\section{Need for Cosmic Ray Neutron}

Simulation Facility

- Additional facilities needed to meet

- Increasing demand for SEE testing on components

- System level testing for robustness and mitigation verification

- High energy (solar storm) testing

- Thermal neutron testing

- Oak Ridge National Laboratory (ORNL)

- Incorporates neutron beam for testing microelectronics within Spallation Neutron Source facility

- World's most intense pulsed accelerator-based neutron source

- Flux level >50 times higher than that at Weapons Neutron Research (WNR)

- Proton testing for polar routes

\section{NextGen, Solar Storms and Cosmic Ray Simulation Testing}

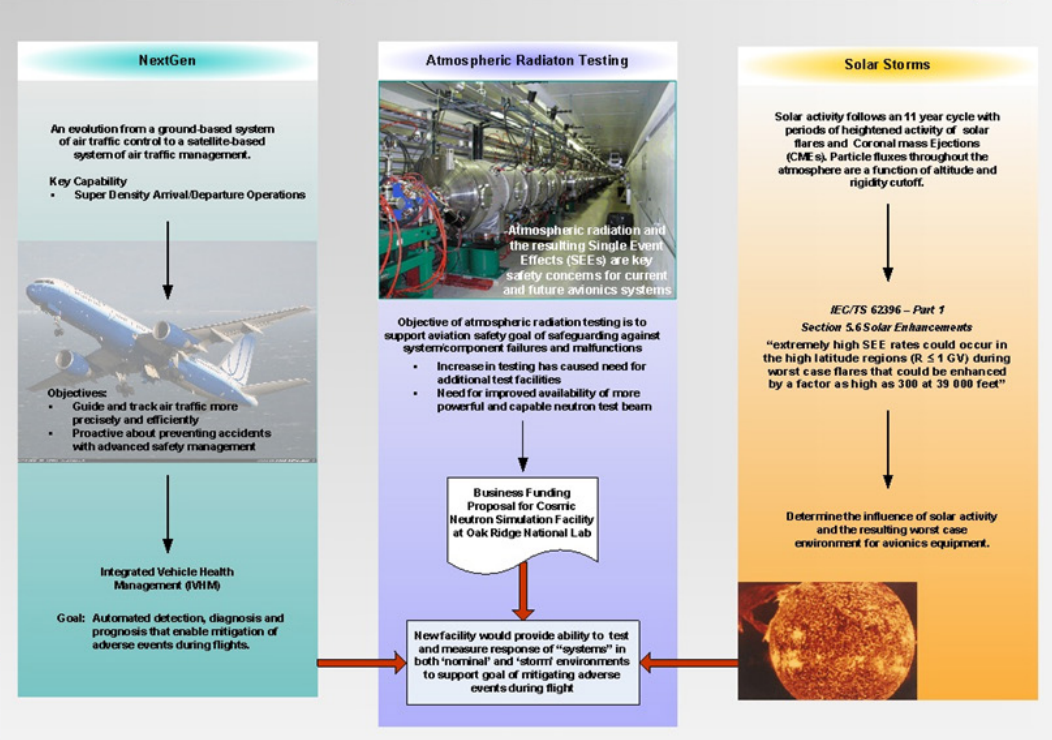




\section{Current Status of SEE Testing}

- Demand for test facilities continues to increase

- Los Alamos National Laboratory is recognized as providing most accurate accelerated neutron test beam; new beam has been added in 2012

- More companies and industries are testing their components and systems

- Technology trends show parts becoming more susceptible to SEE

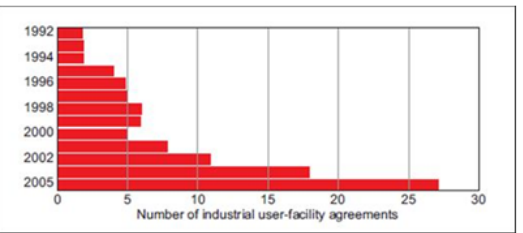

-Use of the ICE House at Los Alamos

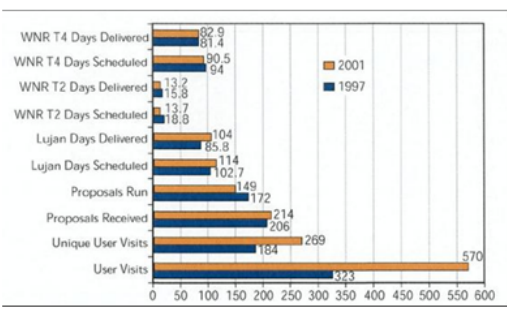

Comparison 1997 versus 2001 run cycle for WNR and Lujan Center at Los Alamos

\section{Los Alamos becoming oversubscribed}

\section{Benefits}

\section{- Cosmic Ray Neutron Simulation Facility will provide}

- Additional capacity to meet current and future test needs for avionics and other safety/reliability critical industries

- More timely access

- Current beam time availability impacting program development schedules

- Overcomes Over subscription at Los Alamos

- Improved availability of more powerful and capable test beams

- Device and system level testing

- System level testing allows for robustness and mitigation verification

- High energy and thermal testing 
ORNL/TM-2014/553

\section{INTERNAL DISTRIBUTION}

1. D. H. Abercrombie

2. R. A. Crone

3. P. D. Ferguson

4. J. D. Galambos

5. F. X. Gallmeier

6. K.W. Herwig

7. E. B. Iverson

8. L. C. Jones

9. W. $\mathrm{Lu}$
10. T. J. McManamy

11. R. J. McQueeney

13. M. E. Phillips

14. M. A. Plum

15. I. Popova

16-18. B. W. Riemer

19. D. A. Tennant

20. ORNL Office of Technical Information and Classification

\section{EXTERNAL DISTRIBUTION}

21-25. J. R. Zvanya, Federal Aviation Administration, William J. Hughes Technical Center, Atlantic City International Airport, NJ 08405

26. H. Kung, U.S. Department of Energy, SC-22, 19901 Germantown Road, Germantown, Maryland 20874-1290

27. J. B. Murphy, U.S. Department of Energy, SC-22.3, 19901 Germantown Road, Germantown, Maryland 20874-1290

28. J. J. Rhyne, U.S. Department of Energy, SC-22.3, 19901 Germantown Road, Germantown, Maryland 20874-1290 